\title{
Confronting Racist Prosecutorial Rhetoric at Trial
}

Mary Nicol Bowman

Follow this and additional works at: https://scholarlycommons.law.case.edu/caselrev

Part of the Law Commons

\section{Recommended Citation}

Mary Nicol Bowman, Confronting Racist Prosecutorial Rhetoric at Trial, 71 Case W. Rsrv. L. Rev. 39 (2020) Available at: https://scholarlycommons.law.case.edu/caselrev/vol71/iss1/5

This Article is brought to you for free and open access by the Student Journals at Case Western Reserve University School of Law Scholarly Commons. It has been accepted for inclusion in Case Western Reserve Law Review by an authorized administrator of Case Western Reserve University School of Law Scholarly Commons. 


\title{
Confronting Racist Prosecutorial Rhetoric at Trial
}

\author{
Mary Nicol Bowman
}

Contents

INTRODUCTION 40

I. How and Why is Racist Prosecutorial Rhetoric So

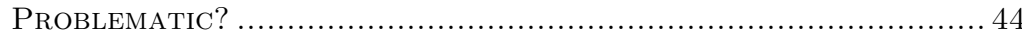

A. Overview of Foundational Concepts for Understanding Racist

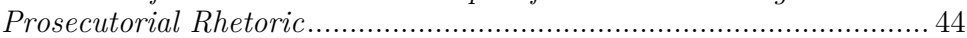

B. How Race Affects Juror Decision-Making ......................................... 50

1. Ingroup versus Outgroup Bias.................................................... 51

2. The Power of Stereotypes ……………………........................ 53

3. Priming for Prejudice....................................................................... 57

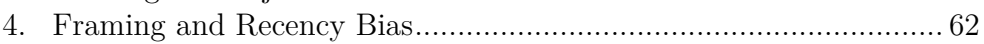

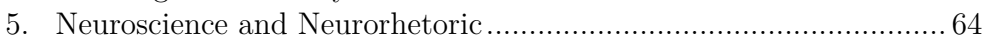

6. Group Decision-Making Can Help But Does Not Cure Individual Biases.

II. Courts' Current Approaches Are Ineffective at Dealing with Racist Prosecutorial Rhetoric at Trial ......................... 69

A. Prosecutors Use Racist Prosecutorial Rhetoric ...................................... 69

B. Appellate Courts Often Refuse to Recognize Improper Language.......... 72

C. Appellate Procedural Doctrines Prevent Meaningful Remedies ............. 77

iII. Focus on Trial Courts for Solutions About Controlling

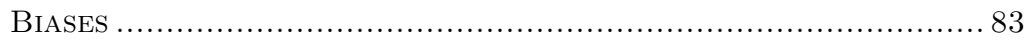

A. Trial Courts are Better Positioned than Appellate Courts to Spur

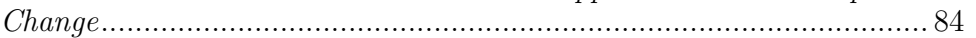

B. Trial Courts Should Focus on Prosecutors......................................... 87

C. Overview of Debiasing Strategies from Social Science Research........... 89

IV. Specific Proposed Solutions................................................... 94

A. Create an Effective Foundation ....................................................... 95

1. Use Voir Dire to Make Race Salient ........................................... 95

2. Give Jury Instruction(s), including a Debiasing Instruction,

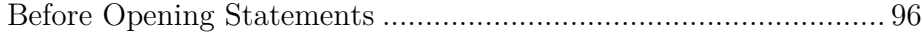

B. Prevent Racist Prosecutorial Rhetoric................................................. 99

1. Use a Checklist to Clarify What Language is Potentially Racist.... 99 a. Prohibit Use of Racial Slurs and Explicit References to Stereotypes. 101

$\dagger$ Clinical Professor of Law, Sandra Day O'Connor College of Law at Arizona State University. Thanks to the College of Law for supporting this project; to Kathryn Stanchi and my colleague Judy Stinson for their detailed feedback; and to my colleagues Sue Chesler, Amy Langenfeld, Rachel Stabler, Tamara Herrera, and Ann Ching for their encouragement and suggestions. I am grateful for the outstanding research assistance provided by Lauren Pauls and Sharon Foster. Any errors are my own. 
b. Coded Language to Invoke Race or Stereotypes 103

c. Balancing the Probative Value Against the Prejudicial Effect of Racial Language

2. Require a Motion in Limine by Prosecutors for Proposed

References to Race on a Case-by-Case Basis .............................. 108

C. Responses When Problems Arise at Trial....................................... 111

1. Act Sua Sponte When a Problem Occurs Rather Than Requiring an Objection .............................................................................. 112

2. Admonish the Prosecutor in Front of the Jury for Appealing to

Bias and Give a Specific Curative Instruction ........................... 112

3. Grant a Mistrial for Particularly Serious or Repeated Violations

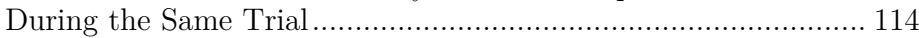

D. Track Repeat Violators Across Trials ....................................... 116

CONCLUSION. 118

Appendix A: Possible Checklist for Courts to Use in Prohibiting

Racist Prosecutorial Rhetoric: 119

\section{INTRODUCTION}

"Discrimination on the basis of race, odious in all aspects, is especially pernicious in the administration of justice."

"Theories and arguments based upon racial, ethnic and most other stereotypes are antithetical to and impermissible in a fair and impartial trial." ${ }^{2}$

We are in a moment of reckoning about the influence of racial bias on the criminal justice system. ${ }^{3}$ To give only a few examples, increased scrutiny is being placed on racially-motivated police brutality and other

1. Rose v. Mitchell, 443 U.S. 545, 555 (1979).

2. State v. Monday, 257 P.3d 551, 557 (Wash. 2011) (alteration in original) (quoting State v. Dhaliwal, 79 P.3d 432, 444 (Wash. 2003) (Chambers, J., concurring))

3. While this reckoning seems to be gaining traction and speed now, it is not entirely new; many voices have been calling for this reckoning for a long time. See, e.g., Anthony V. Alfieri, Race Prosecutors, Race Defenders, 89 GEO. L.J. 2227, 2235 (2001) (noting that "[r]acial contamination of the criminal law in the sway of bias and discrimination is well documented" and citing sources documenting that history). 
misconduct, ${ }^{4}$ and on the racial dimensions of mass incarceration. ${ }^{5}$ The United States Supreme Court recently described racial bias as "a familiar and recurring evil that, if left unaddressed, would risk systemic injury to the administration of justice. ${ }^{16}$ In the last few years, the Court has frankly acknowledged ways that individual actors' racial biases can affect the criminal justice system, including through jury selection ${ }^{7}$ and race-based arguments during jury deliberation. ${ }^{8}$ And earlier this year, the Court acknowledged the "clear" racist origins of a structural issue, the use by two states of nonunanimous jury verdicts in criminal cases. ${ }^{9}$ An overlooked piece of this reckoning, however, is the racist rhetoric ${ }^{10}$ that prosecutors sometimes use in arguing cases.

The United States Supreme Court has stated that "the Constitution prohibits racially biased prosecutorial arguments." 11

4. See, e.g., Isabel Bilotta, Abby Corrington, Saaid A. Mendoza, Ivy Watson \& Eden King, How Subtle Bias Infects the Law, 15 Ann. Rev. L. \& Soc. ScI. 227, 229 (2019) (discussing bias in policing generally and statistics showing disproportionate police killings of unarmed Black and Latino individuals). Beyond police brutality, there is increased scrutiny on the role of police in the disproportionate outcomes for people of color within the criminal justice system. See, e.g., Jonathan M. Warren, Hidden in Plain View: Juries and the Implicit Credibility Given to Police Testimony, 11 DePaul J. Soc. Just. 1 (2018) (arguing that jurors often make unfounded assumptions regarding police credibility).

5. See generally Michelle Alexander, The New Jim Crow: Mass InCARCERATION IN THE AGE OF COLORBLindness (2020) (discussing racial imbalances and the mass incarcerations of Black men).

6. Pena-Rodriguez v. Colorado, 137 S. Ct. 855, 868 (2017).

7. See Flowers v. Mississippi, 139 S. Ct. 2228, 2235 (2019) (holding that the trial court clearly erred in concluding that the state's peremptory challenge of a Black juror "was not "motivated in substantial part by discriminatory intent"" (quoting Foster v. Chatman, 136 S. Ct. 1737, 1754 (2016))). Although the court articulated its holding very narrowly, the court explicitly relied on four "critical facts" that each showed racial bias in the prosecutor's actions. See $i d$.

8. See Pena-Rodriguez, 137 S. Ct. at 868 (holding that an exception to the non-impeachment rule about jury verdicts is needed to allow trial courts to consider juror reports about racially biased comments or actions).

9. Ramos v. Louisiana, 140 S. Ct. 1390, 1394 (2020) (noting the "clear" racist origins of laws in Oregon and Louisiana allowing for criminal convictions without jury unanimity). However, the Supreme Court has only rarely used the terms "racist" or "racism," and there is reason to be cautious about the extent to which the Court is ready to fully engage in this reckoning. See generally Kathryn Stanchi, The Rhetoric of Racism in the United States Supreme Court (unpublished manuscript) (on file with author).

10. See infra notes 41-42 and accompanying text for the explanation of why this article uses the term "racist prosecutorial rhetoric."

11. McCleskey v. Kemp, 481 U.S. 279, 309 n.30 (1987). 
However, that statement was made in a footnote of a case that did not specifically address prosecutorial misconduct. ${ }^{12}$ The Court has never squarely focused on racially biased prosecutorial arguments, so it has not clarified how courts should analyze this issue. ${ }^{13}$ While Justice Sotomayor in 2013 rebuked a prosecutor for "tapp[ing] a deep and sorry vein of racial prejudice that has run through the history of criminal justice in our Nation," she did so in an order denying certiorari. ${ }^{14}$ The Court's failure to take a case that squarely presents this issue has left lower federal courts, state courts, and commentators struggling to provide a useful framework for analyzing these issues, or even to identify what part of the Constitution they violate..$^{15}$

My earlier article on prosecutorial misconduct, Mitigating Foul Blows, offered a framework to try to combat the "helpless piety" displayed by courts when they are quick both to condemn prosecutorial arguments as improper and to affirm resulting convictions based on procedural doctrines such as harmless error. ${ }^{16}$ However, that article did

12. Id. at 283-85 (McCleskey was about statistical evidence of racial bias in death penalty cases; the court noted the prosecutor's racially biased language in passing but did not directly analyze that issue).

13. McCleskey cited Donnelly v. DeChristoforo, 416 U.S. 637, 643 (1974), for the proposition that the Constitution prohibits racially biased prosecutorial arguments. McCleskey, 481 U.S. at 309 n.30. But the dissent in a later case noted that there were only two allegedly improper comments in the closing in Donnelly, and one of those was ambiguous. Darden v. Wainwright, 477 U.S. 168, 193 (1986) (Blackmun, J., dissenting). Darden involved more racist comments, but those comments were interwoven with other improper appeals. See id. at 189-92 n.2. Neither Darden nor Donnelly directly confronted the racial components of the comments, and both held that the trials were not so infected with unfairness as to justify reversal of the convictions. Darden, 477 U.S. at 181-82; Donnelly, 416 U.S. at 645.

14. Calhoun v. United States, 568 U.S. 1206, 1206-08 (2017) (statement of Sotomayor, J., respecting the denial of the petition for writ of certiorari) (justifying the denial of certiorari given "the unusual way in which this case has been litigated" and the defendant's failure to raise the relevant arguments before the circuit court, but clarifying that "I write to dispel any doubt whether the Court's denial of certiorari should be understood to signal our tolerance of a federal prosecutor's racially charged remark. It should not.").

15. For example, Justice Sotomayor's statement in the order denying certiorari mentions three theories (equal protection, right to an impartial jury under the Sixth Amendment, and the ABA Standards on Prosecution and Defense Function), but only gives a single sentence about each one. $I d$. at 1207-08. Commentators generally focus on equal protection, right to an impartial jury, and the due process clause's guarantee of a fair trial. See, e.g., Andrea D. Lyon, Setting the Record Straight: A Proposal for Handling Prosecutorial Appeals to Racial, Ethnic or Gender Prejudice During Trial, 6 Mich. J. RACE \& L. 319, 320 (2001).

16. Mary Nicol Bowman, Mitigating Foul Blows, 49 GA. L. Rev. 309, 352 (2015) (quoting United States v. Antonelli Fireworks Co., 155 F.2d 631, 
not address whether racist prosecutorial rhetoric should be treated differently than other types of prosecutorial misconduct. This article concludes that it should. ${ }^{17}$

More specifically, this article relies on social science research to argue that courts should reevaluate their analysis of prosecutorial appeals to race, and this article focuses on trial courts for solutions. Specifically, Part I provides foundational information needed to understand racist prosecutorial rhetoric and summarizes social science research on how race affects decision-making. ${ }^{18}$ Part II explains the inadequate state of current law. It describes modern case law demonstrating that prosecutors are using racist rhetoric, ${ }^{19}$ explores the disconnect between the social science research and courts' treatment of that rhetoric, and describes the courts' procedural barriers to relief that actually incentivize rather than discourage racist prosecutorial rhetoric. ${ }^{20}$

661 (2d Cir. 1946) (Frank, J., dissenting)); see generally id. at 362-73 (arguing for changes to appellate court review of prosecutorial misconduct claims, such as using an error-focused rather than a guilt-focused approach to harmless error analysis, looking at what effect the improper argument was likely to have had on the trial rather than on the strength of the other evidence against the defendant).

17. Although the Court's decision about racial bias in jury deliberations is not directly applicable, the reasoning is relevant: "This Court's decisions demonstrate that racial bias implicates unique historical, constitutional, and institutional concerns." Pena-Rodriguez v. Colorado, 137 S. Ct. 855, 868 (2017). The Court also stated that "there is a sound basis to treat racial bias with added precautions. A constitutional rule that racial bias in the justice system must be addressed . . . is necessary to prevent a systemic loss of confidence in jury verdicts . . . ." Id. at 869.

18. See generally Jennifer S. Hunt, Race, Ethnicity, and Culture in Jury Decision Making, 11 AnN. REv. L. \& Soc. SCI. 269, 271 (2015) (summarizing dozens of studies showing how race affects jury decision-making); Lucy Jewel, Neurorhetoric, Race, and the Law: Toxic Neural Pathways and Healing Alternatives, 76 MD. L. REV. 663 (2017) (explaining how racist rhetoric physically changes our brains through creation of toxic neural pathways, and arguing that counternarratives can help create healing pathways, both individually and collectively).

19. Perhaps the most appalling example of racist prosecutorial rhetoric involves analogizing Black defendants to animals, a practice that has been repeatedly and recently upheld by the California state courts. See generally Shana Heller, Dehumanization and Implicit Bias: Why Courts Should Preclude References to Animal Imagery in Criminal Trials, 51 Crim. L. Bull. 870 (2015) (exploring the effects of prosecutors referring to Black defendants with animal imagery).

20. Bowman, supra note 16, at 315-16 (explaining that when prosecutors have a strong case, then any misconduct is likely to be harmless; when prosecutors have a weak case, the risk of acquittal is higher than the risk of an appellate court ordering a new trial). 
Part III argues that trial courts, not appellate courts, should be the focus for solutions to racist prosecutorial rhetoric. It also explains why trial courts should focus specifically on prosecutors and provides an overview of debiasing strategies. Part IV builds on this foundation by offering specific solutions that trial courts should implement. That section recommends using voir dire and early jury instructions to prime jurors for egalitarianism rather than susceptibility to prejudice. Most significantly, it argues that trial courts should aim to prevent racist prosecutorial rhetoric through use of a checklist that would clarify what rhetoric is absolutely prohibited and what rhetoric requires a case-bycase determination of appropriateness. Prosecutors would then need to bring a motion in limine to facilitate those case-specific determinations. Part IV also contains strategies for trial courts responding to problems during trial and a method for tracking violators across multiple trials. The combination of these solutions would help prevent racist prosecutorial rhetoric and minimize harm when it occurs.

\section{How and Why is Racist Prosecutorial Rhetoric So Problematic?}

Racial bias "in the jury process can change the course of individual lives, diminish confidence in the justice system, and have profound effects on society." ${ }^{21}$ This section presents foundational information needed to understand how racial bias can infect the jury process through racist prosecutorial rhetoric. This section first provides an overview of foundational concepts necessary for understanding racist prosecutorial rhetoric. It then describes various ways in which racist rhetoric affects decision-making.

\section{A. Overview of Foundational Concepts for Understanding Racist Prosecutorial Rhetoric}

There can be no doubt at this point that racially-charged language affects decision-making in a variety of contexts, including criminal trials, although scholars debate how to conceptualize the way these effects occur. ${ }^{22}$ Much of the legal scholarship over the last twenty or

21. Hunt, supra note 18 , at 283.

22. Compare L. Song Richardson, Systemic Triage: Implicit Racial Bias in the Criminal Courtroom, 126 YALE L.J. 862, 865 (2017) ("[R] esearch from the past several decades reveals that implicit racial biases can influence the behaviors and judgments of even the most consciously egalitarian individuals in ways of which they are unaware and thus unable to control."), with Jonathan Kahn, RaCE on the Brain: What Implicit Bias Gets Wrong About the Struggle for Racial Justice 67-68 (2018) ("[T]he normalizing of implicit bias as common and pervasive . . carries with it the implication that explicit bias is abnormal, uncommon, and even scientifically uninteresting" and that suggesting that explicit racism is a thing of the past "allows us to ignore subtler or more nuanced forms of 
more years has focused on "implicit bias," sometimes called "unconscious racism." ${ }^{23}$ Implicit biases "are composed of well-learned associations that reside below conscious awareness and can automatically drive behavior in a manner that is inconsistent with one's personal attitudes[,]" while "[e]xplicit biases are the beliefs that people consciously possess and intentionally express . . ." O" Other scholars, however, argue that the current focus on implicit bias minimizes the importance of overt or explicit bias and suggest that focusing too heavily on implicit bias is part of the problematic but widespread view that America is now "postracial." 25 Still other scholars reject a "rigid dichotomy" between explicit and implicit biases, noting instead that "implicit bias measures might be revealing concealed [but conscious] beliefs rather than unconscious ones." 26

racism - or frankly any form of racist practice that does not look the same as what came before.").

23. See, e.g., Cynthia Lee, Making Race Salient: Trayvon Martin and Implicit Bias in a Not Yet Post-Racial Society, 91 N.C. L. REv. 1555 (2013); see also Thomas Ross, Innocence and Affirmative Action, 43 VAND. L. REV. 297, 311 (1990) ("This paradox of irrationality and normalcy is part of the reason for the unconscious nature of the racism. When our culture teaches us to be racist and our ideology teaches us that racism is evil, we respond by excluding the forbidden lesson from our consciousness.").

24. Bilotta et al., supra note 4, at 228-29; see also Jerry Kang, Judge Mark Bennett, Devon Carbado, Pam Casey, Nilanjana Dasgupta, David Faigman, Rachel Godsil, Anthony G. Greenwald, Justin Levinson \& Jennifer Mnookin, Implicit Bias in the Courtroom, 59 UCLA L. REV. 1124, 1132 (2012) (distinguishing explicit bias from implicit bias based on whether the attitudes and beliefs involved are "consciously accessible through introspection").

25. See KAHN, supra note 22, at 66 ; see also id. at 67 (noting that this minimization of explicit bias occurs in a variety of fields, including in neuroscientific studies of implicit bias). Kahn also notes that this view of overt expressions of prejudice being extreme and abnormal "hearkens oddly back to the first wave of psychological research on prejudice from the 1920s to the 1950s, which presented explicit prejudice as a pathological aberration from normal thinking." Id.; see also Justin D. Levinson, Robert J. Smith \& Danielle M. Young, Devaluing Death: An Empirical Study of Implicit Racial Bias on Jury-Eligible Citizens in Six Death Penalty States, 89 N.Y.U. L. REv. 513, 564 (2014) ("One mild surprise in our results, however, was that explicit bias matters too. Even though the days of rampant and overt racism are mostly gone, our study shows that it is still valuable to monitor explicit racial bias, at least in capital cases.").

26. Michael Selmi, The Paradox of Implicit Bias and a Plea for a New Narrative, 50 ArIz. St. L.J. 193, 198, 211 (2018); see also id. at 214-15 ("[W]hen [an] individual denies a racial motive we cannot know if she is being honest or whether she is simply and consciously concealing her own discrimination. It also might be the case that although the person was truly unaware of the operational bias, with a little effort she may have been able to access that bias, in other words, it need not be an all or nothing proposition."); Jessica A. Clarke, Explicit Bias, 113 Nw. U. L. REv. 505, 521-22 (2018) (discussing 
This article does not seek to resolve these broader debates. Instead, it takes the position that each of these approaches, as well as others discussed below, provide meaningful lenses through which to understand how and why racist prosecutorial rhetoric affects criminal trials. Despite the common tendency to rely on sweeping characterizations, "attitudes and beliefs about race have long been internally complex and have only become more so . . .." 27 This article therefore discusses both the cognitive states of individual actors and the larger structural racism issues. ${ }^{28}$

This article also focuses on strategies for controlling and minimizing the effects of bias, regardless of whether that bias is implicit or explicit. Some scholars critique implicit bias scholarship as wrongly suggesting that implicit bias is uncontrollable, when in fact social psychology research provides several effective strategies for controlling implicit bias. ${ }^{29}$ Furthermore, research indicates that treating bias as unconscious makes it easier for people to avoid taking responsibility for controlling their biases. ${ }^{30}$ Thus, this article uses the term "implicit bias" rather than "unconscious bias" to help create the foundation for concrete actions to mitigate these biases, and it draws on the extensive social science research that provides tools for doing so.

Furthermore, in exploring these issues, the focus must be on racist rhetoric, not racist prosecutors - i.e., on the language used rather than on the moral culpability of the person using those words. Beyond sidestepping the broader debate about explicit bias versus concealedbut-conscious bias versus implicit bias, this approach reflects the idea

evidence that people are aware of but underreport their explicit biases); Gregory Mitchell, An Implicit Bias Primer, 25 VA. J. Soc. POL'y \& L. 27, 42-45 (2018) (noting that "presently the empirical data do not allow researchers to declare whether implicit bias and explicit bias are truly distinct" and then describing the ambiguities in the empirical research).

27. KAHN, supra note 22, at 70 (quoting Lawrence D. Bobo \& Camille Z. Charles, Race in the American Mind: From the Moynihan Report to the Obama Candidacy, 621 Annals Am. AcAD. Pol. \& Soc. ScI. 243, 244 (2009)).

28. See, e.g., Gary Blasi, Advocacy Against the Stereotype: Lessons from Cognitive Social Psychology, 49 UCLA L. REv. 1241, 1280 (2002) ("[D]iscrimination is a product not only of stereotyping and psychological prejudice, but also of institutional structures and practices through which individual attitudes and behavior play out."). A July 2020 survey of judges through the National Judicial College reveals that most judges (65\% of those who responded) "believe that systemic racism exists in the criminal justice system." Anna-Leigh Firth, Most Judges Believe the Criminal Justice System Suffers from Racism, The National Judicial College (July 14, 2020), https://www.judges.org/ (search title in search bar; then follow hyperlink of title) [https://perma.cc/SVW9-WM6U].

29. Selmi, supra note 26 , at 197-98.

30. Id. at 218 . 
that people more easily recognize speech as racist, even when they would not use that label for the speaker. ${ }^{31}$ Additionally, focusing on the speaker rather than the words used would echo the problems with the application of Batson v. Kentucky ${ }^{32}$ regarding jury selection; scholars have rightly argued that Batson has been ineffective in part because the court has to essentially conclude that the prosecutor was being racist, rather than focus on the prosecutor's actions. ${ }^{33}$ Here, focusing on the person would necessarily require a focus on the prosecutor's intent, which generally only allows courts to address overt rather than subtle references to race. ${ }^{34}$ Moreover, remedying structural racism requires a focus on the harm caused rather than on whether someone intended that harm. ${ }^{35}$ And as explained in more detail below, significant harm can come from the prosecutor's rhetoric, regardless of the prosecutor's intent. ${ }^{36}$

31. See KAHN, supra note 22, at 70 (describing several examples where people were willing to call remarks but not speakers racist and noting that "even bigots can be conflicted about their racist attitudes").

32. 476 U.S. 79 (1986).

33. See, e.g., Jonathan Abel, Batson's Appellate Appeal and Trial Tribulations, 118 Colum. L. Rev. 713, 720-21 (2018) ("According to this critique, the awkwardness of branding the prosecutor racist raises the stakes for all involved and is another impediment to finding a Batson violation."); Nancy S. Marder, Foster v. Chatman: A Missed Opportunity for Batson and the Peremptory Challenge, 49 ConN. L. REv. 1137, 1184 (2017) (noting that the court "would essentially be calling them liars or racists"). Another related problem with Batson is that prosecutors may not realize the effect that stereotypes may have shaped their perception of the reasons for the strike: "When asked to provide a race-neutral reason for the strike, the attorney may sincerely believe that she struck the prospective juror for reasons not related to the juror's race, even though implicit racial bias may have in fact influenced the attorney's perceptions of the individual." Cynthia Lee, A New Approach to Voir Dire on Racial Bias, 5 U.C. IRvine L. Rev. 843, 851 (2015).

34. See, e.g., Elizabeth L. Earle, Note: Banishing the Thirteenth Juror: An Approach to the Identification of Prosecutorial Racism, 92 Colum. L. REV. 1212, 1227-29 (1992).

35. See, e.g., Gilbert C. Gee \& Chandra L. Ford, Structural Racism and Health Inequities: Old Issues, New Directions, 8 Du BoIs Rev. 115 (2011) (defining structural racism as "as the macrolevel systems, social forces, institutions, ideologies, and processes that interact with one another to generate and reinforce inequities among racial and ethnic groups.").

36. See, e.g., Jewel, supra note 18, at 664 ("The harmful rhetoric used to describe racial minorities and other subordinated groups produces toxic thought patterns that can become entrenched in the public mind."); Bilotta et al., supra note 4, at 229 ("It is important to note that the subtle discrimination that emerges as a result of implicit biases is just as harmful as overt discrimination, if not more so, because the target is more likely to internalize the experience than to discount it as discrimination."); State v. Kirk, 339 P.3d 1213, 1216 (Idaho Ct. App. 2014) ("[A] prosecutor's mental state, however 
Rhetoric can be defined narrowly as the art of persuasion or a process for discovering the truth by argumentation, but also can more broadly include "language, conversation, words, and even images" involved in persuasive communication. ${ }^{37}$ "Modern rhetoric is also interdisciplinary, engaging with social and scientific theories to understand how people are persuaded." 38 Theories of rhetoric explain the effectiveness of appeals to stereotypes ${ }^{39}$ and courts have often allowed prosecutors to use these appeals without consequence. ${ }^{40}$ This article uses the terms "racist rhetoric" or "racist prosecutorial rhetoric" to mean these appeals to racial stereotypes, whether deployed consciously or unconsciously. ${ }^{41}$ This rhetoric is racist, regardless of the individual prosecutor's intent in using it, because of the likelihood of triggering racial stereotypes in those who hear it. ${ }^{42}$

innocent, does not determine the message received by the jurors or their individual responses to it.").

37. Jewel, supra note 18, at 665.

38. Id. at 666 .

39. Ryan Patrick Alford, Appellate Review of Racist Summations: Redeeming the Promise of Searching Analysis, 11 Mich. J. RACE \& L. 325, 327 (2006).

40. See generally id. (discussing methods counsel can use in an appeal when the trial was tarnished by the use of racial stereotypes).

41. See Earle, supra note 34, at 1214 n.11 (using the term "prosecutorial racism" "as a shorthand for arguments, unconscious or intentional, that pose the danger of evoking impermissible and irrelevant racial considerations in the minds of jurors."). Earle's use of "prosecutorial racism" is similar to my preferred "racist prosecutorial rhetoric" in that it does not focus on intent, although I think it is also important to include the idea of rhetoric in framing the problem. Cf. Alford, supra note 39, at 326-27 (discussing "racist summations" as including "indirect ... [rather than explicitly biased] yet highly inflammatory" language while arguing that the "indirect" racism displayed can be argued to be intentional given its similarities to classical rhetoric techniques). I agree with Alford about the similarity of modern racist prosecutorial rhetoric to classical rhetorical techniques, but I recommend avoiding focusing on whether the use of that rhetoric is intentional. See also Stanchi, supra note 9, at Part II (discussing the rhetorical power of the words "racist" and "racism" that are lacking in "softer" alternatives).

42. See Richard Delgado \& Jean Stefancic, Critical Race Theory: An INTRODUCTION 183 (3rd ed. 2017) (defining racism-without an intent requirement - as "any program or practice of discrimination, segregation, persecution, or mistreatment based on membership in a race or ethnic group"); see also Anna Spain Bradley, Human Rights Racism, 32 Harv. Hum. RTs. J. 1, 28 (2019) ("The common feature that connects racism across countries and spaces is its role in advancing a social hierarchy that places some people at the bottom and others at the top based on constructed racial categories. This hierarchy of racial ideology perpetuates a power structure that becomes embedded in law, politics, economic activity, and culture."); see also infra Section I(B) regarding the effect of race on juror decision-making, including how racist rhetoric exacerbates underlying biases. 
Racist rhetoric is problematic when used by anyone in a criminal trial, but it is particularly problematic given prosecutors' special role in the criminal justice system. Prosecutors are supposed to serve as representatives of the people, not as the representative of crime victims, and "the prosecutor's primary responsibility is to the administration of justice, not just winning cases." 43 This special role undergirds the Supreme Court's famous exhortation that while prosecutors "may strike hard blows, [they are] not at liberty to strike foul ones. It is as much [their] duty to refrain from improper methods calculated to produce a wrongful conviction as it is to use every legitimate means to bring about a just one. ${ }^{\prime 4}$ Courts need to make this exhortation meaningful given modern research showing that jurors' explicit and implicit biases tend to favor the prosecution in criminal trials. ${ }^{45}$ One step toward ridding the criminal justice system of racial bias involves understanding how racist prosecutorial rhetoric activates juror biases.

Racist prosecutorial rhetoric also harms communities of color. Professor Anthony Alfieri notes that when racialized narratives are brought into criminal trials, "they apply a juridical gloss to such images and tropes, restyling popular meaning by force of law. . . . Not only do they translate social meaning into law, but they also construct social meaning out of law." ${ }^{46}$ Furthermore, he discusses the harms to communities of color that can occur from problematic racial narratives, such as the denigration of individuals' experiences and communities, as well as a loss of faith in the system. ${ }^{47}$ Alfieri therefore urges a "new ethic of prosecution" that is "respectful of the dignity of racial identity and the integrity of racial community." 48 This article joins that call.

43. Lyon, supra note 15 , at 335.

44. Berger v. United States, 295 U.S. 78, 88 (1935). "This exhortation . . . is frequently cited by courts reviewing claims of prosecutorial misconduct, defense counsel raising those claims, and academics commenting on prosecutorial behavior." Bowman, supra note 16, at 312 .

45. Anna Roberts, Asymmetry as Fairness: Reversing a Peremptory Trend, 92 WASH. U. L. REV. 1503, 1529 (2015) (noting that explicit biases include widespread beliefs that "prosecutors are unimpeachable . . . and that the presumption of innocence is a fiction"; implicit biases "tend to disfavor people of color, and thus a disproportionate number of criminal defendants" in ways that "can affect all of the main tasks that jurors are called on to perform").

46. Alfieri, supra note 3 , at 2229.

47. Id. at 2240. While Alfieri was specifically talking about the Central Park Jogger case, his critique is appliable more broadly. Alfieri also notes that both the law and narrative tradition and critical race theory demonstrate the need for rethinking the use of stereotypes, among other longstanding traditions in prosecutorial practices. See id. at 2229-30.

48. Id. at $2241-42$. 


\section{B. How Race Affects Juror Decision-Making}

" $[\mathrm{M}]$ ost participants in the criminal justice system believe that they can make fair and unbiased decisions, but data continue to show results markedly differentiated by race." ${ }^{49}$ The last several decades have produced extensive social science research on how race affects jury decision-making. ${ }^{50}$ This section does not purport to exhaustively summarize that research; instead, it explores findings and themes from this research that provide a helpful context ${ }^{51}$ for understanding how decision-making can be affected by racist prosecutorial rhetoric. ${ }^{52}$

\section{Ingroup versus Outgroup Bias}

One important way that race affects decision-making is through ingroup versus outgroup bias. Ingroup bias "occurs when people make more positive judgments about individuals who belong to the same

49. Praatika Prasad, Implicit Racial Biases in Prosecutorial Summations: Proposing an Integrated Response, 86 FordHAM L. REV. 3091, 3095-96 (2018) (citing Achieving an Impartial Jury (AIJ) Toolbox, Am. BAR Ass'N, https://www.americanbar.org/content/dam/aba/publications/criminaljusti ce/voirdire_toolchest.authcheckdam.pdf [https://perma.cc/LGJ7-BPBV]). While not directly relevant to the topic of this article, there is particularly disturbing research on "shooter bias" and "weapon perception," which shows through a variety of experiments that people are both quicker to shoot and more likely to mis-identify a non-weapon as a weapon for Black rather than white individuals, regardless of whether they display explicit biases. See, e.g., Bilotta et al., supra note 4, at 230-31 (summarizing multiple studies). But see Selmi, supra note 26, at 204-05 (discussing conflicting studies on "shooter bias" and stating that "even if one accepts that there is a shooter bias, there is no clear reason to conclude that the bias is implicit rather than explicit.").

50. This research includes both experimental studies (using mock juries and some divergence from trial practices in order to more precisely test the role of race in decision-making) and review of decisions in actual cases. See Hunt, supra note 18, at 271 (concluding that together, these methods "provide converging evidence that race and ethnicity influence jury decisions and trial outcomes"); Selmi, supra note 26, at 233 (discussing the value of both laboratory studies that attempt to isolate facets of discrimination beyond what is possible in real world activities, and field studies that allow researchers to "test their theories in actual settings" and therefore "provide more compelling evidence of the pervasiveness of discrimination").

51. In other words, most of the social science research discussed below involves studies that do not involve prosecutorial rhetoric in criminal cases. But the results of these studies still provide the backdrop against which prosecutors' racist rhetoric becomes particularly likely to impact jury decision-making.

52. See Hunt, supra note 18, at 277 (discussing that while these different mechanisms can have an explicit component most social scientists believe that "these processes tend to be subtle, if not wholly implicit, making them difficult for jurors to recognize and control."). That means that jurors may genuinely believe that they are basing their judgments on the evidence and complying with jury instructions, while in fact their decisions are being influenced by racial biases in ways they fail to recognize or remedy. 
social category simply because of shared group membership." ${ }^{153}$ Outgroup bias, on the other hand, involves negative judgments against individuals who are not part of the same group. ${ }^{54}$

This dynamic is exemplified in the social science research showing that "jurors tend to make more lenient judgments of same-race defendants and harsher judgments of other-race defendants." 55 One study related to this theory showed that white jurors rated the culpability of Black defendants more strongly than white defendants when the evidence was ambiguous; given the frequency of plea bargains in criminal cases, that study likely mirrors many real-life trials. ${ }^{56}$ It also helps explain the fact that the tendency for jurors to more harshly judge defendants of a different race or ethnicity is particularly pronounced in non-capital cases; ${ }^{57}$ while non-capital cases with strong evidence are often pled, capital cases with similar strength of evidence may go to trial because of the penalty consequences. ${ }^{58}$ That may explain why in capital cases, the race of the victim is more important than the race of the defendant in predicting when the defendant will receive the death penalty. ${ }^{59}$ This finding may also relate to research on Aversive Racism Theory, which shows that people try to avoid bias when they are aware

53. Id. at 275 (citation omitted).

54. See id. at 276; cf. Maureen Johnson, Separate But (Un)equal: Why Institutionalized Anti-Racism is the Answer to the Never-Ending Cycle of Plessy v. Ferguson, 52 U. Rich. L. REV. 327, 378 (2018) (quoting Terry Smith, White Backlash in a Brown Country, 50 VAL. U. L. REv. 89, 98 (2015)) (discussing scholars, including psychologists, who hypothesize that racism goes beyond simple outgroup bias and also includes a component of "addiction" to the privileges of power for those in the dominant cultural group).

55. Hunt, supra note 18, at 274 (citation omitted); see also id. at 271 (discussing dozens of experimental studies and two meta-analyses synthesizing the research confirming this pattern, which "often is referred to as the similarityleniency effect").

56. Elizabeth Ingriselli, Note, Mitigating Jurors Racial Biases: The Effects of Content and Timing of Jury Instructions, 124 YALE L.J. 1690, 1708 (2015) (noting that when the evidence is strong, prosecutors often seek a plea bargain, and when the evidence is weak, defense counsel often seek a plea bargain).

57. Hunt, supra note 18, at 273.

58. See Sherod Thaxton, Leveraging Death, 103 J. CRIM. L. \& CRiminology 475,481 (2013) (discussing how plea bargaining is "theoretically ambiguous" in terms of its effect on the death penalty and how prosecutors may not offer desirable plea deals to defendants who have been charged with capital punishment).

59. Hunt, supra note 18, at 273. Additionally, "racial bias in death sentencing is stronger among White male jurors . . . . Black defendants are $41 \%$ more likely to receive the death penalty when juries include five or more White men." Id. 
of its potential effect. ${ }^{60}$ Research shows that jurors do a better job of guarding against the influence of prejudice when race is treated as salient than when they do not see race as salient. ${ }^{61}$ Thus, when race is not treated as salient, then white jurors' implicit biases often play a role, but biased decision-making is reduced when race is made salient. ${ }^{62}$ In non-capital cases, white jurors may be less likely to see race as significant, so they may be less likely to control their outgroup biases against defendants of color. ${ }^{63}$

Another example of the ingroup versus outgroup bias dynamic involves "attributions, that is, explanations about the causes of behavior." ${ }^{64}$ Research shows that white jurors are more likely to attribute petty crime by white juveniles to "succumbing to peer pressure in the moment," while the same jurors are more likely to attribute the same act by a Black juvenile as being "destructive and defiant." ${ }^{65}$ In the death penalty context, "White jurors, especially men," were more likely to view defendants as "vicious and dangerous individuals who made their victims suffer" while Black male jurors were more likely to view defendants with empathy and "to believe that the defendant is remorseful." ${ }^{66}$ These attribution distinctions are particularly pronoun-

60. Id. at 275; see also Ingriselli, supra note 56, at 1695-96 (noting that aversive racism theory explains behavior of those who are "high in implicit racism, yet low in explicit racism - in other words, they are biased but are unaware of their biases.").

61. Hunt, supra note 18, at 275 (summarizing various studies); see also Samuel R. Sommers \& Phoebe C. Ellsworth, Race in the Courtroom: Perceptions of Guilt and Dispositional Attributions, 26 Personality \& Soc. Psychol. BuLl. 1367, 1371 (2000) (noting that "for a run-of-the-mill case in which the defendant happens to be Black" race isn't perceived by jurors as salient in the same way that they do when racial issues are more obviously central to a case).

62. Ingriselli, supra note 56, at 1696; see also id. at 1698-99 (arguing that traditional definitions of race salience, which require race to be "central" to the trial, are too narrow and that instead subtle references to race can also debias juror responses).

63. See Mikah K. Thompson, Bias on Trial: Toward an Open Discussion of Racial Stereotypes in the Courtroom, 2018 Mich. ST. L. REv. 1243, 1281 (2018) (explaining that in capital offenses the Supreme Court has stated that a "defendant has [a] right to request that prospective jurors be informed of the race of the victim and questioned regarding their potential race biases"); see also id. at 1282-83 (explaining that the Supreme Court later stated that this rule did not apply in a case where "the crime was victimless and nonviolent").

64. Hunt, supra note 18 , at 275.

65. Id. at 276 (citation omitted).

66. Id. at 280 (citation omitted). 
ced "when a criminal act is stereotypically associated with a defendant's racial or ethnic group." ${ }^{67}$

\section{The Power of Stereotypes}

Stereotypes play a powerful role in influencing decision-making. Stereotypes are the well-connected "associations among groups and traits established in children's memories at an early age, before they have the cognitive skills to decide rationally upon the personal acceptability of the stereotypes." 68 These associations come at least in part from cultural forces and images, and they can be reinforced and strengthened in a variety of ways. ${ }^{69}$ The associations affect actions through stereotyping "when judgments are influenced by beliefs about the characteristics of people in a particular category (e.g., racial group)." 70

Stereotypes can involve ostensibly positive beliefs, such as the "Asian as model minority"71 association or the stereotype of Black women as "everyone's favorite aunt or grandmother, . . . ready to

67. Id. at 276 (citation omitted).

68. Thompson, supra note 63, at 1248 (quoting Jody Armour, Stereotypes and Prejudice: Helping Legal Decisionmakers Break the Prejudice Habit, 83 CAL. L. REv. 733, 741 (1995)); see also Armour, supra, at 742 (using the same definition of stereotypes and distinguishing them from prejudice, which means "derogatory personal beliefs"). Armour notes that "some people's stereotypes and personal beliefs overlap; that is, some people not only have knowledge of the cultural stereotypes from years of socialization, but they endorse and accept them as well." Id.

69. See, e.g., Thompson, supra note 63, at 1252 (noting that "racial and ethnic stereotypes are part and parcel of American culture"); Pamela Wilkins, Confronting the Invisible Witness: The Use of Narrative to Neutralize Capital Jurors' Implicit Racial Biases, 115 W. VA. L. REv. 305, 324-25 (2012) (discussing studies showing that media focus, particularly in local news broadcasts, give more airtime to crime committed by Black people and portraying them as more threatening than white criminals, which contributes to political rhetoric, combining to strengthen the association of Black people with crime); Richardson, supra note 22, at 881 (noting that "[f]illing criminal courtrooms with overwhelming numbers of people of color will likely strengthen the already ubiquitous conscious and unconscious association linking people of color with crime" and that even if lawyers and judges "understand on an intellectual level that this disproportionate representation is the predictable result of focusing law enforcement efforts on communities of color").

70. Hunt, supra note 18, at 275. Hunt distinguishes stereotypes from the related but distinct concept of prejudice. "In contrast, prejudice involves negative attitudes or evaluations (e.g., feelings of dislike) toward a social category." Id. Stereotypes can be either positive or negative associations, but prejudices always involve negative characterizations. See id. at 280 .

71. Thompson, supra note 63 , at 1252 . 
soothe everyone's hurt . . ." "72 However, even so-called positive stereotypes can have significant negative impacts on decision-making. ${ }^{73}$

More commonly, however, stereotypes are negative, such as the association of Latinos with illegal immigration or Black people with crime. ${ }^{74}$ Other research shows stereotypes of Black people as dishonest, violent, and less intelligent than whites. ${ }^{75}$ These negative stereotypes are used to rationalize prejudice and justify harsh treatment of others. ${ }^{76}$ For example, during slavery, the association of enslaved peoples with animals was used to justify barnlike housing conditions. ${ }^{77}$

Courts have for decades treated as unlawful intentional discrimination invoking stereotypes to justify decision-making. ${ }^{78}$ Professor Michael Selmi describes an interview study gauging employers' attitudes about race in which many interviewees referred to a perceived lack of work ethic and a "'perceived threatening or criminal demeanor' of Black men." ${ }^{79}$ Selmi noted that these statements attempting to justify behavior based on stereotype would easily establish legal liability for discrimination. ${ }^{80}$ Similarly, the United States Supreme Court recently treated as "overt racial bias" a juror's argument for the defen-

72. Id. at 1251 (quoting Marilyn Yarbrough \& Crystal Bennett, Cassandra and the "Sistahs": The Peculiar Treatment of African American Women in the Myth of Women as Liars, 3 J. Gender, RACE \& Just. 625, 635$36(2000))$.

73. Id. at 1252 .

74. Id. at 1248 .

75. Id. at $1261-62$.

76. Johnson, supra note 54, at 374 (emphasis omitted).

77. Id. at 375 .

78. See Selmi, supra note 26, at 199 (noting that when a police officer associates young Black men with criminal activity or when a school principal treats disciplinary issues differently depending on the race of the child involved, "[t]hese behaviors may be influenced by unconscious attitudes, but the behavior itself is deliberate and intentional and fits easily within standard legal doctrines"); $i d$. at 241-45 (discussing a variety of legal contexts in which courts have explicitly relied on stereotyping to find unlawful discrimination, regardless of whether those stereotypes involved conscious versus unconscious biases).

79. Id. at 240-41 (discussing and quoting Devah Pager \& Diana Karafin, Bayesian Bigot? Statistical Discrimination, Stereotypes, and Employer Decision Making, 621 Annals Am. AcAD. Pol. \& Soc. SCI. 70, 77, 82 (2009)).

80. Id. at 241 (also noting that respondents acknowledged that they knew individuals who did not fit the stereotype, and that the "principal harm of stereotyping [is that] the group judgments are exaggerated and overbroad."). 
dant's guilt in a sexual assault case by explicitly referencing multiple stereotypes of Mexican men mistreating women. ${ }^{81}$

Stereotypes can also affect decision-making in a variety of more subtle ways, including soothing the cognitive dissonance that would otherwise result from significant structural inequities. ${ }^{82}$ The psychological theory of cognitive dissonance says that humans feel great discomfort when trying to maintain two conflicting beliefs, so to alleviate that discomfort, we unknowingly move ourselves into a state of denial about the less-significant of the two beliefs. ${ }^{83}$ Frequently, rather than simply denying information that conflicts with our dominant belief, we make ourselves feel better by "strongly lash[ing] out against the competing belief, convincing ourselves that it is dead wrong and must be soundly defeated." ${ }^{84}$ Cognitive dissonance thus helps explain why police and prosecutors often come up with "outlandish theories" of guilt in response to DNA evidence exonerating someone convicted of a crime; these police and prosecutors have an internalized view of being fighters for justice that makes it very difficult to accept that they could have contributed to a wrongful conviction. ${ }^{85}$ Stereotypes facilitate that process, helping individuals rationalize prejudices and avoid guilt. ${ }^{86}$ And modern research has shown that stereotypes are particularly likely to affect decision-making when an individual is "not motivated to seek individuating information about members of stereotyped groups" and when an individual is "under stress or . . . pressed for time." ${ }^{87}$ In those circumstances, both of which are common in the

81. Pena-Rodriguez v. Colorado, 137 S. Ct. 855, 869 (2017) ("[W]here a juror makes a clear statement that indicates he or she relied on racial stereotypes or animus to convict a criminal defendant, the Sixth Amendment requires that the no-impeachment rule give way in order to permit the trial court to consider the evidence of the juror's statement and any resulting denial of the jury trial guarantee.").

82. Johnson, supra note 54, at 374 .

83. Mark Godsey, Blind Injustice: A Former Prosecutor Exposes the Psychology And Politics of Wrongful Convictions 18 (2017).

84. Id.; see also id. at 18-19 (discussing how this theory helps explain how many ordinary Germans, particularly those closer in the hierarchy to the concentration camps, fully adopted the Nazi position "in order to internally justify their actions and avoid dissonance").

85. Id. at 20 .

86. Johnson, supra note 54, at 374 (emphasis omitted). This process may also help explain the way that people who believe in equality nevertheless rationalize the racial disproportionalities within the criminal justice system.

87. Thompson, supra note 63 , at 1249 . This description of conditions that lead to an increased role for implicit biases echoes the "situation of pressurized decision making by all courtroom actors as systematic triage." Richardson, supra note 22, at 878 (footnote omitted) ("[E]xcessive caseloads impact defense lawyers, prosecutors, and judges alike, creating pressure on each of 
criminal justice system, people rely less on logic and more on mental shortcuts. ${ }^{88}$

Additionally, research shows crucial connections between the nature of the crime and racial stereotypes. Studies show that when news stories on violent crime omit the race of the perpetrator, the majority of white audience members assumes that the perpetrator was Black. ${ }^{89}$ "Jurors are more likely to render guilty verdicts and recommend harsh sentences when defendants are accused of committing crimes that are stereotypically associated with their racial or ethnic group." 90 For example, judgment and sentencing decisions tend to be harsher when white defendants are accused of financial crimes such as embezzlement or fraud, while Black defendants face harsher outcomes than white defendants for theft and violent crimes. ${ }^{91}$ This affect seems to be "especially strong for serious and violent crimes." ${ }^{92}$ Additional research suggests that stereotypes affect information processing and memory. "[I]ndividuals who are impacted by stereotypes do a better job of processing stereotype-consistent information as compared to stereotypeinconsistent information." ${ }^{93}$ Regarding memory, "stereotypes facilitate the way the brain stores and processes information"; when people attempt to recall "hazy" memories, they often fill in those memories with stereotypes. ${ }^{94}$ Consequently, "people often recall stereotypeconsistent information more easily than stereotype-inconsistent information." 95

Stereotypes likely interact with ingroup versus outgroup biases as well. For example, some research shows that jurors tend to be less suspicious of witnesses who share their identity and more skeptical of those who do not. ${ }^{96}$ This effect was particularly pronounced for white

these courtroom actors to engage in triage - the process of allocating scarce resources.").

88. Bilotta et al., supra note 4, at 229.

89. Alford, supra note 39, at 345; see also id. (discussing other studies that reveal the stereotypical association of Black people with violence and hostility, a stereotype that "is associated with fear and loathing" and is "likely to be a strong motivating force" when activated through racist prosecutorial rhetoric in closing argument).

90. Hunt, supra note 18, at 275.

91. $I d$.

92. Id.

93. Thompson, supra note 63 , at 1262.

94. Justin D. Levinson, Forgotten Racial Equality: Implicit Bias, Decisionmaking, and Misremembering, 57 DukE L.J. 345, 376 (2007).

95. Id. at $376-77$.

96. Thompson, supra note 63 , at 1262 . 
jurors being skeptical of the credibility of Black witnesses, including white jurors who reported low levels of prejudice. ${ }^{97}$ Researchers linked this skepticism to stereotypes of Black dishonesty. ${ }^{98}$

\section{Priming for Prejudice}

Additionally, understanding how racist prosecutorial rhetoric works requires understanding the related concepts of prejudice and priming. "[P]rejudice involves negative attitudes or evaluations (e.g., feelings of dislike) toward a social category." ${ }^{99}$ Much of the recent implicit bias research focuses on how these negative attitudes are activated through "priming," which involves presenting information in ways that trigger associations with other ideas. ${ }^{100}$ Our brains interpret new information by fitting it into existing categories, particularly categories that have been recently accessed, and "[p]riming is a way of influencing the categories that are at the forefront of our brains." 101

In experimental research studies using priming, researchers expose participants to stimuli and then measure their responses. ${ }^{102}$ For example, studies show differences in voting patterns depending on the location of the voting place (e.g. higher approval of school bonds when voting in a school rather than another location) and higher reports of conservative social attitudes when questioned about these attitudes in front of a cathedral versus a government building. ${ }^{103}$ In many priming studies, however, participants are unaware of the "primes" because they are flashed on a screen too quickly to be consciously perceived. ${ }^{104}$ Even

97. Id.

98. See id. at 1261-62.

99. Hunt, supra note 18, at 275. Hunt distinguishes between prejudice, which is always negative, and stereotyping, which can be positive or negative, as explained above. Id.

100. Linda L. Berger \& Kathryn M. Stanchi, Legal Persuasion: A Rhetorical Approach to the Science 105 (2018); see also id. at 107 (noting that our brains have so many categories in them but tend to use categories that were recently activated when processing new information).

101. Id.; see also Karenna F. Malavanti, Megan K. Johnson, Wade C. Rowatt \& Charles A. Weaver, III, Subtle Contextual Influences on Racial Bias in the Courtroom, 24 Am. SoC'y Trial Consultants 2, 5 (2012) (defining priming as "the unconscious influence of individuals' environmental cues on their behaviors.").

102. See Justin D. Levinson, Robert J. Smith \& Koichi Hioki, Race and Retribution: An Empirical Study of Implicit Bias and Punishment in America, 53 U.C. Davis L. Rev. 839, 873 (2019).

103. Malavanti et al., supra note 101, at 4.

104. See, e.g., Blasi, supra note 28, at 1248 ("If people are shown an image on a screen for a few milliseconds, followed immediately by a 'masking' image, 
when participants were unaware of the stimuli, those stimuli consistently produced prejudiced results involving both attitudes and decision-making. ${ }^{105}$

For example, social science research shows that priming for race can affect interpretation of ambiguous facts. ${ }^{106}$ In one study, the researcher "presented a set of ambiguous facts to participants after priming them with stereotypes of African Americans," then asked them to judge the person's ambiguous behavior. ${ }^{107}$ "Participants who were primed with more [negative] stereotypes judged the person's ambiguous behavior more harshly than participants who were primed with fewer stereotypes." 108

Similarly, a recent empirical study by Professor Justin Levinson showed that race sometimes affects how jurors remember facts. ${ }^{109}$ In that study, "for some facts, simply altering a legal actor's race caused participants to remember certain facts or generate false memories in racially biased ways." 110 Study participants read a "confrontation" story describing circumstances surrounding a fistfight, were then given a short distracting task, and then were asked questions about their memories of the story. ${ }^{111}$ The facts of the story were identical except for the race of the protagonist: "participants read about either William, a Caucasian man, Tyronne, an African-American man, or Kawika, a Hawaiian man." 112

they will behave in ways that reflect their having seen the first image, but without any conscious awareness of having seen it . . . .").

105. See, e.g., Anders Kaye, Schematic Psychology and Criminal Responsibility, 83 ST. John's L. REV. 565, 577 (2009) (summarizing priming studies); see also Wilkins, supra note 69, at 322 (quoting Justin D. Levinson, Race, Death, and the Complicitous Mind, 58 DePaul L. Rev. 599, 632 (2009)) (brackets in original) (noting that priming one stereotype of a group can activate other stereotypes as well: "For example, a group primed with violent rap music, which primed stereotypes of black males as aggressive and violent, 'were more likely than other participants to judge a Black job applicant as less qualified for a job requiring intelligence' [lower intelligence being another stereotype pertaining to blacks].").

106. Thompson, supra note 63 , at $1267-71$.

107. Id. at $1267-68$.

108. Id.

109. Levinson, supra note 94 , at 350 .

110. Id. at 351 .

111. Id. at 391.

112. Id. at 394. Levinson also used the same methodology with a story involving an employment dispute. Id. "Participants exhibited better memories for the employment scenario than for [t] he [c]onfrontation," perhaps because the confrontation story "contained more racially stereotypical facts." Id. at 402- 
With this one change, Levinson found multiples ways in which "[s]ystematic errors in recall affected participants' memories of [t]he [c]onfrontation in a manner harmful to African Americans, and to a lesser extent, to Hawaiians." 113 For example, participants more successfully recalled "aggressive facts" when they read about Tyronne as compared to William. ${ }^{114}$ The study also showed a "false memory effect" for one fact related to aggression, with more participants who read about people of color falsely remembering a "fact" about the person's aggression. ${ }^{115}$ And while Levinson did not find statistically significant differences in recall of mitigation facts for those reading about William compared to Tyronne, he did find that those who read about Kawika were more likely to falsely remember mitigating facts. ${ }^{116}$

Levinson's research is consistent with earlier studies outside the race context that indicate that rhetorical choices about language can similarly affect memory. Multiple studies of memory demonstrated that people given information about a car accident remembered the car going significantly faster when the accident description used the word "smashed" compared to "contacted" or "hit." 117 And when asked a week later whether the accident scene photos had included broken glass, those who had seen the word "smashed" were more likely to falsely remember the presence of broken glass. ${ }^{118}$

Emotions also play a significant role in priming for retribution. "When a decision-maker feels fear, anger, or both, the need for retribution automatically becomes heightened." ${ }^{119}$ Fear and anger are

03. In other words, the memory effects link back to stereotype consistency discussed in the prior section.

113. Id. at 398 (emphasis omitted).

114. Id. at 398-99.

115. Id. at $400-01$ (while $56 \%$ of participants who read about William falsely remembered a fact showing William as the aggressor, that number rose to $70 \%$ for those reading about Tyronne or Kawika).

116. Id. at 401. These memory biases seem to operate unconsciously; Levinson noted that "participants who manifested more memory bias were not more likely to be explicitly biased." Id. at 404. However, he found one example where that was not true - one instance where participants who read about William and had higher explicit bias and higher memory bias. Id. at 406 n.284. He also found two counterintuitive examples, where participants who read about Tyronne or Kawika were actually more likely to misremember if they had low levels of explicit bias. Id. at 404.

117. Godsey, supra note 83 , at 121 .

118. Id. at 121-22. That was true even if at the time they had not incorrectly inflated the car's speed after seeing that characterization. Id. at 122.

119. Levinson et al., supra note 102, at 854; see also BERGER \& STANCHI, supra note 100, at 110 (noting that "when [someone] experiences anger, . . . the emotion tends to reinforce the desire to blame someone, anyone," 
both intensified by racial stereotypes. ${ }^{120}$ Stereotypes also lessen empathy, particularly when connected to dehumanization. ${ }^{121}$ Dehumanization occurs when people view other people "as less than human and thus not deserving of moral consideration." 122 "As a matter of history, social fact[,] and even neuroscience . . people tend to react to criminals by dehumanizing them." 123 This dehumanization makes people more likely to justify violence. For example, one study showed that when participants were primed with the word "ape," they were more likely to conclude that use of force was justified in a video showing police officers severely and repeatedly striking a Black suspect after the conclusion of a car chase. ${ }^{124}$

Dehumanizing rhetoric can play an important role in priming for emotion, with devastating consequences. For instance, our current mass-incarceration epidemic was shaped in part by "pundits and professors alike warning . . . of a 'new breed' of merciless juvenile 'superpredators' and the horrors of 'crack babies."'125 Levinson argues that this dehumanizing rhetoric played on fear and anger in a racialized way, creating a "moral panic" that has led to hundreds of thousands of Americans imprisoned for decades "based on baseless legislative assumptions." ${ }^{26}$

while sadness tends to make people "attribute the events that occurred to the overall situation rather than to human actions").

120. Levinson et al., supra note 102 , at 868 .

121. Id. at 868-69.

122. Godsey, supra note 83, at 39 (internal quotation omitted). Godsey notes that dehumanizing racial slurs helped slave-owners justify their actions and that both sides in World War II used racial slurs in propaganda. Id. "Racism in any form involves dehumanization." Id.

123. Levinson et al., supra note 102 , at 869 . There is a broader issue with prosecutors' offices having a culture that dehumanizes criminal defendants that prosecutors should take seriously. See, e.g., GODSEY, supra note 83, at 39-52 (describing personal experience as both a prosecutor and as an attorney on an innocence project facing dehumanization of criminal defendants).

124. Levinson et al., supra note 102, at 869-70.

125. Id. at 843 . While that rhetoric is not as explicitly dehumanizing as directly calling someone an ape, words like "breed" and "superpredator" invoke animal imagery. See also BERGER \& STANCHI, supra note 100, at 45 (discussing the "superpredator" metaphor and the briefs in a recent Supreme Court case demonstrating that the superpredator metaphor was also myth).

126. Levinson et al., supra note 102, at 843. This analysis came from an article discussing Levinson's recent study showing that race and retribution have become inextricably linked. "The study found that participants more strongly associated Black faces with the concepts of retribution, payback, and revenge, and White faces with the concepts of rehabilitation, treatment, and redemption." Id. at 844; see also Lee, supra note 33, at 863-66 (summar- 
Regarding criminal trials, one scholar notes that prosecutors "from the time of Cicero until the present" have used the technique of "othering" defendants "as someone outside of the moral community" to "induce a negative emotional response towards the defendant." 127 This technique also plays on jurors' emotions by situating the prosecutor on the same side of the moral line as the jurors, which helps the jury see the prosecutor as trustworthy. ${ }^{128}$ Modern cognitive psychology research thus confirms the insights of early rhetoricians about how othering and stereotyping affects perception. ${ }^{129}$

The role of rhetoric in priming to activate stereotypes is significant, as research on implicit bias indicates that something is needed to trigger the power of a stereotype for people who do not harbor explicit biases. ${ }^{130}$ The "existence of stereotypes or caricatures in the mind of the audience is often not enough to produce the motivating response. Rather, the speaker may need to shape his discourse to call forth these cognitive constructs in the minds of the listeners." 131

But the prosecutor's language doesn't have to directly refer to a stereotype to activate the juror's mental association. For example, a prosecutor could refer to the defendant's actions, rather than the defendant himself, as "animalistic, brutal, and impulsive[,]" which will "bring forth the caricature in the minds of the jurors whose mental models of Black people include this stereotype." 132 Similarly, prosecutors can evoke this stereotype through verbs commonly associated with animals, such as "hunt" or "pounce."133 Other words associated with animals can have a similar effect, such as "prey," or "jungle."134 Additionally, prosecutors can associate defendants with people commonly associated with Black violence, for example invoking O.J. Simpson "since Simpson has become an avatar of the [b]rute caricature

izing research showing a connection between information about race of offenders and support for punitive measures in the criminal justice system).

127. Alford, supra note 39, at 335 (footnote omitted).

128. Id.

129. Id. at 336 .

130. See, e.g., id. at 347 ("[A] stereotype, which lies latent in the mind of its adherent, does not have a force of its own. The appropriate stimulus is often required to elicit the stereotype . . . .").

131. Id. (footnote omitted); see also Prasad, supra note 49, at 3101 ("[J]urors' implicit biases must be triggered before they can adversely affect a defendant's trial.").

132. Alford, supra note 39, at 349 (footnote omitted).

133. Heller, supra note 19 , at 880 .

134. Id. 
in the White community." ${ }^{135}$ References to neighborhoods or physical characteristics like hairstyles can also evoke stereotypes. ${ }^{136}$ Finally, stereotypes can even be activated through what sounds like a disavowal, such as when a prosecutor says "[r] ace has nothing . . . to do with this case" before making an argument that appeals to racial stereotypes. ${ }^{137}$

\section{Framing and Recency Bias}

Racist prosecutorial rhetoric can affect the jury regardless of when it happens at trial; however, the "order and context in which people encounter new information" can play a crucial role in the way that information is understood and remembered. ${ }^{138}$

Much of the scholarship on racist prosecutorial rhetoric focuses on closing arguments, also called summations. ${ }^{139}$ That scholarship emphasizes the important role that closing arguments play, particularly given the greater narrative freedom in these arguments. ${ }^{140}$ Scholars often note the importance of the prosecutor getting the last word ${ }^{141}$ and that courts impose relatively few constraints on closing arguments. ${ }^{142}$ This focus on closing arguments is supported by psychological research on "recency effect," which involves a focus on the most recent information presented. ${ }^{143}$ "Recency effects arise when a fact-finder is

135. Alford, supra note 39 , at 352 .

136. Id. at 353 .

137. See, e.g., id. at 356 (quoting Moore v. Morton, 255 F.3d 95, 99 (3d Cir. 2001)). Alford notes that reviewing courts generally take these arguments at face value, as being a disavowal of the role of race in decision-making, rather than recognizing the use of a rhetorical device to activate racial biases; see also id. at 357-59; Sheri Lynn Johnson, Racial Imagery in Criminal Cases, 67 Tul. L. Rev. 1739, 1752 (1993) (quoting State v. Snowden, 675 P.2d 289, 293 (Ariz. Ct. App. 1983)) (describing a case where the prosecutor said "I don't mean to be racial about this . . . do you think you're going to leave a [B]lack guy out there in a car, or a big car while a robbery is going on?").

138. Mark Spottswood, Ordering Proof: Beyond Adversarial and Inquisitorial Trial Structures, 83 Tenn. L. Rev. 291, 293 (2015).

139. See generally Bowman, supra note 16, at 342-45 (synthesizing various sources on prosecutorial closing arguments).

140. See, e.g., Craig Lee Montz, Why Lawyers Continue to Cross the Line in Closing Argument: An Examination of Federal and State Cases, 28 OHIO N.U. L. REV. 67, 73-74 (2001) (illustrating that closing arguments are cabined only by a prohibition on appealing to the "passion or prejudice" of the jury).

141. See, e.g., John B. Mitchell, Why Should the Prosecutor Get the Last Word?, 27 AM. J. CRIM. L. 139, 146-56 (2000) (discussing various studies about the importance of closing argument in juror decision-making).

142. Alford, supra note 39, at 329.

143. See Spottswood, supra note 138, at 294. 
presented with voluminous, challenging evidence, and they must make an immediate decision following trial." ${ }^{144}$ This research suggests that comments in closing arguments are likely to have outsized significance compared to comments in the middle of the trial. And rebuttal closing arguments may be particularly problematic, given that defense counsel has no opportunity to respond. ${ }^{145}$

In addition to the recency effect, the research on priming demonstrates the importance of comments made early in the trial, such as during opening statements or voir dire. In some contexts, the research demonstrates "primacy effect," which is the tendency for the first piece of information to shape understanding and memory of subsequent information. ${ }^{146}$ "Once people have an impression or belief, they are inclined to pay less attention to subsequent information, particularly information that contradicts the impression." 147 Advocates can shape this impression through framing, which is "a process whereby communicators, consciously or unconsciously, act to construct a point of view that encourages the facts of a given situation to be interpreted by others in a particular manner."148 Advocates use framing techniques when articulating trial themes at the beginning of a case and shape their case presentation and arguments around those themes. Framing and priming are closely related, as they both relate to making "certain information more salient or accessible." 149

Context affects whether primacy or recency is more important to particular decisions ${ }^{150}$ but the details of the conflicting studies are not crucial here. Instead, the key idea is that racist prosecutorial rhetoric in voir dire, opening statements, and closing arguments all can have a significant effect on how jurors understand and evaluate criminal cases, and these effects are generally subconscious rather than conscious.

144. Id.

145. See, e.g., Michael D. Cicchini, Combating Prosecutorial Misconduct in Closing Arguments, 70 OKLA. L. Rev. 887, 909 (2018) (discussing the need for trial courts to step in when improper arguments are made in rebuttal closing).

146. Kathryn M. Stanchi, The Power of Priming in Legal Advocacy: Using the Science of First Impressions to Persuade the Reader, 89 OR. L. REv. 305, 346 (2010).

147. Berger \& StANCHI, supra note 100, at 118.

148. Hyatt Browning Shirkey, Last Attorney to the Jury Box Is A Rotten Egg: Overcoming Psychological Hurdles in the Order of Presentation at Trial, 8 Ohio St. J. CRim. L. 581, 585 (2011).

149. Berger \& Stanchi, supra note 100, at 129.

150. Stanchi, supra note 146 , at 347. 


\section{Neuroscience and Neurorhetoric}

Neuroscience and the emerging discipline of neurorhetoric help provide a biological explanation for the power of stereotypes and coded language. Neuroscience is the study of the organization and functions of the brain. ${ }^{151}$ Neuroscience studies help confirm the results of social psychological studies of race ${ }^{152}$ and explain how brain functions lead to the results observed in psychological studies. ${ }^{153}$ While some have argued that reliance on neuroscience creates a risk of biologizing racism, and thereby removing it from its historical and social contexts, ${ }^{154}$ others emphasize the importance of examining the complexity of the various factors that influence racism. ${ }^{155}$ "[N]euroscience explains that when rhetoric influences us, it does so in an embodied way, triggering electrochemical reactions that traverse our neural pathways, beyond the purview of our conscious thought." ${ }^{156}$ Neurorhetoric thus builds on neuroscience to explain how racist rhetoric physically effects the human brain. ${ }^{157}$

Scholarship on racism and neuroscience often emphasizes the role of the amygdala, a region of the brain associated with fear and the fight-or-flight reaction. ${ }^{158}$ Neuroscientific studies on racial biases show activation of the subject's amygdala when exposed to racialized stimuli, perhaps because the racialized stimuli leads the person to perceive a threat. ${ }^{159}$ Out-group association can also cause activation of the amygdala: "Where a person's identity is of an out-group to our own

151. Anna Spain Bradley, The Disruptive Neuroscience of Judicial Choice, 9 U.C. IRVINE L. REV. 1, 20 (2018).

152. Steven A. Ramirez \& Neil G. Williams, On the Permanence of Racial Injustice and the Possibility of Deracialization, 69 CASE W. RSRV. L. REv. 299, 325 (2018).

153. Bradley, supra note 151 , at 18.

154. Jonathan Kahn, Pills for Prejudice: Implicit Bias and Technical Fix for Racism, 43 Am. J.L. \& MED. 263, 265, 271 (2017).

155. See, e.g., Jerry Kang, Implicit Bias and the Pushback from the Left, 54 ST. Louis U. L.J. 1139, 1147 (2010) (suggesting that to understand racialization, one needs multiple levels of analysis from different perspectives).

156. Jewel, supra note 18 , at 663 .

157. Id. "Whereas cognitive rhetoric might be conceived as the study of how persuasion works in the mind, neurorhetoric looks at how persuasion works in a biological sense, in the brain." Id. at 669 (emphasis omitted).

158. See, e.g., Bradley, supra note 151, at 28 (discussing the high importance of amygdala among neuroscience researchers).

159. See Christian M. Halliburton, Race, Brain Science, and Critical Decision-Making in the Context of Constitutional Criminal Procedure, 47 Gonz. L. Rev. 319, 328 (2011); Ramirez \& Williams, supra note 152, at $325-26$. 
and one that has historically or culturally been associated with negative traits, we process such perceptions and biases in our amygdala, which is where we also process fear." 160 Activation of the amygdala also affects memory, causing heightened attention to some details at the expense of other details. ${ }^{161}$

However, the amygdala is not the only part of the brain relevant to understanding racism. Decision-making involves multiple regions of the brain, sometimes operating sequentially and sometimes operating simultaneously. ${ }^{162}$ These "various regions of our brain, and [the] neural circuitry that connects them, engage in cross-talk when we decide, make a choice, or change our mind."163 Activity in one part of the brain can thus affect another part, such as when emotional rhetoric leads to the release of chemical reactions that dampen the prefrontal cortex that controls higher-order thinking. ${ }^{164}$

This research also helps explain the formation and power of stereotypes. For example, "neuroscience demonstrates that the amygdala activity requires social conditioning from a young age ... [which] suggests that racial responses are learned responses." 165 Relatedly, neuroscience helps explain the development of racially coded associations, as our "[c]ulture can produce unified categories that function as metaphorical 'code' for more implicit concepts." ${ }^{166}$ References to concepts trigger the majoritarian cultural values associated with those concepts. ${ }^{167}$ Repetition, a common rhetorical technique, entrenches these neural pathways, making it smoother and faster "for a conclusory message to reach an individual's consciousness" and creating more certainty in the associated belief. ${ }^{168}$ Thus, repeated cultural references to coded categories "encourage rapid unconscious

160. Bradley, supra note 42 , at 31 .

161. Halliburton, supra note 159 , at 325 .

162. Bradley, supra note 151, at 23. Bradley notes that psychologist Daniel Kahneman popularized these concepts through his explanation of System 1 thought as quick and automatic, with System 2 thought being slower and more complex. $I d$.

163. Id. at $26-27$.

164. Jewel, supra note 18 , at 673 . For a more detailed discussion of the role of emotion in decision-making, see Bradley, supra note 151, at 29-36. Bradley notes that emotion related to what is being decided can be helpful, while unrelated emotion can be a distraction, $i d$. at 34, and that emotion can both help and hinder "normatively correct responses," $i d$. at 36 (quotation omitted).

165. Ramirez \& Williams, supra note 152, at 326-27 (footnote omitted).

166. Jewel, supra note 18 , at 667 .

167. Id.

168. Id. at 664 . 
thinking that has the effect of hardwiring stereotypes into the pathways of the brain." 169

Professor Lucille Jewel's article on neurorhetoric applies these concepts to explain the effectiveness of the Nazi rhetoric dehumanizing Jewish people. ${ }^{170}$ She noted that Nazi propaganda activated and deepened entrenched neural pathways, reinforcing majoritarian cultural values and "a sense of commonality in the face of threat." 171 At the same time, the emotional component of the propaganda hindered activation of higher-order thinking and instead anesthetized Germans to the realities of human suffering. ${ }^{172}$

She also explains how the "welfare queen" stereotype popularized in the United States in the 1980s was coded language that unconsciously activated a variety of negative stereotypes. ${ }^{173}$ The welfare queen image likely "triggered concomitant firings in various neural pathways related to concepts as disparate as women, good and bad mothers, the implicit bias against African Americans, visualized luxury automobiles, and moral verdicts." 174 As a result of the repeated use of the welfare queen metaphor, Americans' view of welfare shifted from a helpful safety net protecting vulnerable children into a "racialized locus of fraud and immorality." 175 These two examples help demonstrate the powerful impact of racially coded language on perception and decision-making. ${ }^{176}$

\section{Group Decision-Making Can Help But Does Not} Cure Individual Biases

Some may expect that group decision-making, like that involved in jury deliberations, would cure at least some types of individual biases. With respect to memory errors, however, Levinson concluded that jury deliberations likely preserve rather than challenge individual memory errors. ${ }^{177}$ Studies on jury deliberations show that jurors try to agree on a common narrative through a combination of "rational persuasion, sheer social pressure, and the psychological mechanism by which

169. Id.

170. Id. at $675-76$.

171. Id.

172. Id.

173. Id. at $677-78$.

174. Id. at 678 .

175. $I d$.

176. Although Jewel's analysis may seem bleak, she concludes her article by offering more hopeful prescriptions about how these toxic neural pathways can be overcome, as discussed infra at notes 356, 360, and accompanying text.

177. Levinson, supra note 94 , at 387-88. 
individual perceptions undergo change when exposed to group discussion." 178 During this process, the most vocal jurors do not always have the most accurate memories, and the likelihood of jurors changing their verdict depends more on their confidence in their memories rather than the accuracy of those memories. ${ }^{179}$ Therefore, the evidence that jury deliberation improves memories is at best weak. ${ }^{180}$ Furthermore, vocal jurors can use improper closing arguments as "ammunition" in the jury room to help persuade other jurors, ${ }^{181}$ so jury deliberations can amplify rather than minimize the effect of individual biases.

Research does suggest, however, that diversity in jury composition can affect jury deliberations in positive ways. ${ }^{182}$ One study suggests that lawyers are less likely to appeal to stereotypes when arguing to a diverse jury. ${ }^{183}$ But even if jury diversity doesn't change attorney behavior, several studies show that increased jury diversity improves decisionmaking. ${ }^{184}$

One study found that compared "with all-White juries, the diverse juries discussed the case longer, considered more of the evidence, and were more accurate in their discussion of that evidence." ${ }^{185}$ That study also indicated that diverse juries were more likely to discuss the potential impact of the defendant's race on the case, with both Black and white participants engaging in that conversation: ${ }^{186}$

Perhaps the most important insight from the study was that the more intense deliberation was not the result of African American jurors contributing different perspectives, but it was the result of White jurors who acted differently, more conscious, in the

178. Lisa Kern Griffin, Narrative, Truth, and Trial, 101 GEO. L.J. 281, 327 (2013) (quoting Harry Kalven, Jr. \& Hans Zeisel, The American Jury 489 (1966)).

179. Levinson, supra note 94, at 389 (discussing Mary E. Pritchard \& Janice M. Keenan, Does Jury Deliberation Really Improve Jurors' Memories?, 16 Applied Cognitive Psych. 589, 600 (2002)).

180. Id.

181. Cicchini, supra note 145 , at 892.

182. Hunt, supra note 18, at 274 ("[B]iases in jury decision making often occur in response to the interaction of races among trial parties, not the race of a single party."). Much scholarly work is being done on the Batson issue. See, e.g., sources cited supra note 33. However, the Batson issue is generally beyond the scope of this article.

183. Bilotta et al., supra note 4 , at 236.

184. Id. (summarizing studies).

185. Hunt, supra note 18, at 279.

186. Id. 
presence of other diverse jurors, presumably because they did not want to appear biased. ${ }^{187}$

That research connects to the Aversive Racism Theory mentioned above, which indicates that jurors do a better job of guarding against the influence of prejudice when they see race as salient. ${ }^{188}$ The presence of jurors of color may implicitly make race salient for white jurors, "reminding them of their egalitarianism and thereby decreasing their biases." 189 This research shows that diverse juries are one tool that can help minimize the impact of biases; other tools are discussed in more detail below in Part III $(\mathrm{C})$.

\section{Courts' Current Approaches Are Ineffective at Dealing with Racist Prosecutorial Rhetoric at Trial}

Current law fails to prevent racist prosecutorial rhetoric or adequately deal with it when it occurs. Section A shows that prosecutors are using racist prosecutorial rhetoric. Section B shows that courts deny that even explicitly racist language has racialized meaning, while Section C describes the procedural devices that appellate courts use to uphold convictions.

\section{A. Prosecutors Use Racist Prosecutorial Rhetoric}

The sections above introduced the backdrop of how race can affect criminal trials generally and how racist rhetoric can exacerbate these underlying issues of racialized decision-making. This section illustrates how recent cases demonstrate that prosecutors use these racist themes and images in seeking convictions. ${ }^{190}$ The cases discussed below show a wide variety of ways that prosecutors' racist rhetoric invoke stereotypes or otherwise prime the jury to decide based on racial prejudices.

While most of the cases below contain more subtle references, some relatively recent cases involve explicitly racist language and argu-

187. Selmi, supra note 26 , at 229.

188. See supra notes 57-62 and accompanying text.

189. Ingriselli, supra note 56, at 1701; see also Liana Peter-Hagene, Jurors' Cognitive Depletion and Performance During Jury Deliberation as a Function of Jury Diversity and Defendant Race, 43 L. \& Hum. Behav. 232, 234 (2019) ("Specifically, people might become [cognitively] depleted when they engage in interracial interactions, but these interactions might also provide the very impetus needed for people to become aware of, and motivated to avoid, racial bias.").

190. This section focuses on the prosecutor's arguments in cases within the last twenty-five years, without regard to what the reviewing courts thought of them, a topic discussed in Sections B and C below. 
ments. ${ }^{191}$ For example, the Supreme Court of Alabama in 1996 analyzed a case in which the prosecutor used the n-word repeatedly in discussing the motive for the crime. ${ }^{192}$ The Alabama Supreme Court concluded that the motive argument would have been fine without the "emotionally charged racial slur." 193 A more recent Seventh Circuit case upheld a defendant's conviction for shooting three police officers when the prosecutor asked several witnesses about whether defendant's beliefs "as a [B]lack Muslim" provided a motive to shoot the officers that would overcome his insanity defense. ${ }^{194}$

More commonly, appellate cases involve animal imagery. ${ }^{195}$ For example, prosecutors in California often compare criminal defendants to a "Bengal Tiger," an analogy built on the idea that Bengal tigers seem docile in captivity but indiscriminately kill in the wild. ${ }^{196}$ "In California, the use of this story is not limited to one or two counties, or one or two prosecutors. It has been used all over the state." ${ }^{197}$ Additionally, a 2016 case from the Fourth Circuit discussed a death penalty sentencing hearing in which the prosecutor argued that giving the defendant a life sentence rather than the death penalty would allow for him to "come back out. Meeting him again will be like meeting King

191. For a summary of older cases on this topic, see S. Johnson, supra note 137, at $1754 \&$ nn.57-59. Of course, reasonable people can disagree on where to draw the line between "blatant" racist arguments and more subtle ones. Id. at $1760-61$.

192. Ivery v. State, 686 So.2d 495, 504-05 (Ala. 1996). The prosecutor also used a variant of the n-word, " $\mathrm{n} * * * * *$ itious," to refer to hatred of Black people. The prosecutor and the Alabama Supreme Court opinion spelled both words out rather than using the asterisks. While the prosecutor used these words in prosecuting what appears to be a hate crime against a person of color by a white person, rather than using it against a Black defendant, prosecutors' use of this language raise a variety of concerns. See infra Section III(B) for more on why prosecutors should be held to a higher standard than defense counsel.

193. Id. at 505. Jeff Sessions was the Alabama Attorney General at the time Alabama defended this conviction. Id. at 498.

194. Aliwoli v. Carter, 225 F.3d 826, 830 (7th Cir. 2000). The court concluded that these were proper questions even though every witness asked denied this possible motive and "characterized black Muslims as peaceful and lawabiding citizens." Id. at 831 .

195. For examples of older cases using animal imagery see Johnson, supra note 137 , at $1753-54$.

196. Heller, supra note 19 , at $870-71$.

197. Id. at 877, 883 (quoting People v. Duncan, 810 P.2d 131, 143 (1991)) (noting that it has been used since the mid-1990s in capital cases in at least six counties and that the California Supreme Court has "unequivocally" upheld the practice, concluding that it "does not [necessarily] invoke racial overtones"). 
Kong on a bad day." 198 The prosecutor also labeled the defendant as a "monster," a "big old tiger," and "the beast of burden." 199 Prosecutors use a variety of other animal images as well, such as calling a group of defendants "a pack of wolves" or individual defendants "a punk thug dog" or "a snake [who] slithers on his underbelly."

Prosecutors also find a variety of other ways to invoke racialized stereotypes. For example, an Idaho case in 2014 involved a prosecutor singing a few lines of "the Dixie song[,] Right? Oh, I wish I was in the land of cotton. Good times not forgotten." ${ }^{201}$ Another case involved repeated references to "the white lady" and comments about the Black defendant's vulgar sexual comments to her, even though the case involved justifiable homicide in a later altercation far removed from the "white lady." 202 Another prosecutor repeatedly said "po-leese" instead of "police" to call attention to the defendant's race in connection with an argument about an alleged Black anti-snitching code and stated that "black folk don't testify against black folk." ${ }^{203}$ In another case, the prosecutor twice referred to defendants as "bad people." 204 After the trial court overruled an objection, the prosecutor escalated the argument: "There are bad people in the world, ladies and gentlemen. We are lucky where we live not to come into contact with as many as there may be in other parts of the country. But there are still some around here." ${ }^{205}$ Prosecutors sometimes invoke these stereotypes while simultaneously denying that they are doing so, such as by saying: "Well, we know what that's a code word for. He's a big, strong, [B]lack man, but he's a rough character. Members of the [j] ury, this is not about race." 206

198. Bennett v. Stirling, 842 F.3d 319, 324 (4th Cir. 2016).

199. Id.

200. Heller, supra note 19, at 878-80 nn.53-70 and accompanying text (including these and other animal images).

201. State v. Kirk, 339 P.3d 1213, 1215 (Idaho Ct. App. 2014).

202. Wallace v. State, 768 So.2d 1247, 1249-50 (Fla. 2000). Although, the actions toward the white woman led to the altercation, the court indicated that race should not be considered in making the determination of culpability at the time of the shooting.

203. State v. Monday, 257 P.3d 551, 553-54, 557 (Wash. 2011).

204. United States v. Cannon, 88 F.3d 1495, 1502 (8th Cir. 1996).

205. $I d$.

206. State v. Cabrera, 700 N.W.2d 469, 474 (Minn. 2005) (underscoring that the prosecutor's argument in that case was particularly appalling because he was suggesting that defense counsel was making a racial argument when that was not the case); see also State v. Shabazz, 48 P.3d 605, 620 (Haw. Ct. App. 2002) (prosecutor stated "[r]ace has nothing to do with this case. In fact, as [the victim] said, her son is half black; her boyfriend was black."); Cole v. State, 399 P.3d 618, 620 (Wyo. 2017) (prosecutor argued in rebuttal closing that "an African-American man in Wyoming is still not allowed to 
Sexual assault cases provide a particularly common setting for racist rhetoric, especially language that suggests that the crime is worse because of the race of the perpetrator. ${ }^{207}$ Prosecutors sometimes bring in references to skin color in these cases, with weak pretexts as to why skin color is relevant. ${ }^{208}$ The prosecutor in one case made repeated references to the victim being a local Hawaiian girl who began to be afraid when "she sees that there are six African-American males in the room." ${ }^{209}$ Another prosecutor stated that it is "every mother's nightmare" to find "some black, military guy on top of your daughter." ${ }^{10}$ By calling attention to race in these cases, the prosecutors subtly - or not so subtly-invoked the emotion surrounding the stereotype of Black men being sexually predatory towards white women. ${ }^{211}$

\section{B. Appellate Courts Often Refuse to Recognize Improper Language}

Although prosecutors use racist prosecutorial rhetoric, appellate courts often fail to recognize much of that rhetoric as racist, or even more generically improper. ${ }^{212}$ In doing so, courts' reasoning is strained

steal a car and take the police on a high-speed chase. It doesn't matter what race he is. A white person is not allowed to do that either."). In repeating the references to race, the prosecutor called attention to race while formally arguing that it was irrelevant. See Alford, supra note 39, at 357-59 (regarding why that approach invokes stereotypes).

207. For example, the case in which the prosecutor sang the lines of the "Dixie song" referring to cotton involved sexual assault of a minor. State v. Kirk, 339 P.3d 1213, 1215 (Idaho Ct. App. 2014). "We agree that the racial reference here was indirect and perhaps innocently made." Id. at 1217. However, the court emphasized that the effect on the jury was more important than prosecutorial intent. $I d$.

208. People v. Robinson, 454 P.3d 229, 231 (Colo. 2019), cert. denied, 2020 WL 5882233 (U.S. Oct. 5, 2020) (No. 19-1218) (prosecutor made graphic comments about rape victim's pasty white skin color and seeing a black penis).

209. State v. Shabazz, 48 P.3d 605, 610 (Haw. Ct. App. 2002) (emphasis omitted). The victim's fear might have come from being outnumbered, but the race of the men outnumbering her should not have sparked that fear, as the prosecutor suggested. See id.

210. State v. Rogan, 984 P.2d 1231, 1237 (Haw. 1999).

211. For a discussion of stereotypes related to sexuality, see CoRnEL WEST, RACE MATTERS 86-87 (1993).

212. Of course, appellate courts do sometimes appropriately recognize and reject racist prosecutorial rhetoric. See, e.g., Kirk, 339 P.3d at 1216 ("'Dixie' was an anthem of the Confederacy, an ode to the Old South, which references with praise a time and place of the most pernicious racism. The prosecutor's mention of the title, 'Dixie,' as well as the specific lyrics recited by the prosecutor, referring to 'the land of cotton,' expressly evoke that setting with all its racial overtones."). In United States v. Cruz-Padilla, 227 F.3d 1064 (8th Cir. 2000), the court noted that the prosecutor repeatedly argued that the defendant was lying because he "is here under fraudulent and illegal 
in a variety of ways, from affirmatively endorsing arguments as proper to minimizing their impropriety.

Courts sometimes affirmatively justify even explicitly racist rhetoric. For example, the California Supreme Court found "no impropriety in the argument" based on the Bengal tiger analogy described above. ${ }^{213}$ The prosecutor in one California case described going to the San Diego Zoo and seeing "a Bengal tiger in captivity, behind bars, and is being fed so much meat every day" and "looking like [a] kitten[]."214 The prosecutor then contrasted the Bengal tiger in captivity with one "in its natural habitat" behind a palm frond in India or Pakistan, then immediately shifted to talking about the defendant: "If you were there that night, you wouldn't see the defendant in his suit, the way you have seen him in this trial. You would see him with a butcher knife, out to get money. You would be seeing him in a very natural habitat." 215 The California Supreme Court justified this argument in two different ways. First, the court concluded that the "prosecutor was attempting to focus the jury's attention on the vicious nature of the crime" and was entitled to argue "that modest behavior in the courtroom was not inconsistent with violent conduct under other less structured and controlled circumstances." ${ }^{216}$ The court also rejected the defendant's argument that the Bengal tiger analogy was racist: "Likening a vicious murderer to a wild animal does not invoke racial overtones. Indeed, the circumstances of the murder might have justified even more opprobrious epithets." ${ }^{217}$ That case is not an outlier; California courts use that reasoning repeatedly, including a nearly identical version in a more recent California Supreme Court opinion. ${ }^{218}$

circumstances, and as such, he is basically from day to day living a lie" which made "lying and deceiving to Mr. Cruz-Padilla not something that is hard to do or out of the ordinary." Cruz-Padilla, 227 F.3d at 1068. The court concluded that the prosecutor crossed the line by emphasizing emotion rather than evidence and that the "government's repeated references to Cruz-Padilla's [immigration] status reinforced to the jury his foreign origin and contributed nothing of a legitimate evidentiary value." Id. at 1069.

213. People v. Duncan, 810 P.2d 131, 142 (Cal. 1991); see also Heller, supra note 19 , at 883 .

214. Duncan, 810 P.2d at 142 .

215. Id. The prosecutor's next sentence was about the overwhelming evidence of the defendant's guilt. Id.

216. Id. at $142-43$.

217. Id. at 143 .

218. People v. Brady, 236 P.3d 312, 342 (2010) (adding "necessarily" to the idea that wild animal comparisons are not racial and concluding that prosecutors are entitled to argue that docile behavior in the courtroom is not inconsistent with murdering someone). The courts' reasoning in these cases fails to 
Similarly, state courts in South Carolina concluded that comparing a defendant to King Kong was an appropriate reference to the defendant's size and strength. ${ }^{219}$ The court similarly concluded that calling the defendant, Bennett, a "caveman" was "merely descriptive" of testimony that Bennett had pulled someone by the hair twice. ${ }^{220}$ The court acknowledged that the King Kong reference "could have racial connotations" but still "was not an appeal to the passions or prejudices of the jury." ${ }^{221}$ The Fourth Circuit's analysis in Bennett's habeas proceeding explained the flaws in this reasoning, noting that throughout history, Black people "have been appallingly disparaged as primates or members of a subhuman species in some lesser state of evolution." 222 The Fourth Circuit concluded that the prosecutor thus encouraged the jury to view Bennett as less human because of his race. ${ }^{223}$ The Fourth Circuit's analysis reflects the social science research described above, but it came in an opinion issued sixteen years after the hearing in which the prosecutor made these arguments. ${ }^{224}$ In another case, the Supreme Court of Georgia, a federal district court, and the Eleventh Circuit all failed to acknowledge the racial significance of the prosecutor calling the defendant "a mad dog" even though that "characterization implicated all three of the key definitions of the brute [stereotype]: a mad dog is an animal that is also brutally violent, incapable of thought, and acts completely on impulse." 225

account for the longstanding stereotype associating Black people with animals. See supra note 77 and accompanying text.

219. State v. Bennett, 632 S.E.2d 281, 288 (S.C. 2006). The Fourth Circuit, in upholding the granting of Bennett's habeas petition, correctly noted that "[t]he prosecutor easily could have highlighted Bennett's physical attributes in a race-neutral manner." Bennett v. Stirling, 842 F.3d 319, 325 (4th Cir. 2016) (including pointing out that the same prosecutor had done so in an earlier hearing and giving examples of how the prosecutor could have done so again).

220. Bennett, 632 S.E.2d at 289.

221. Id. at 288 .

222. Stirling, 842 F.3d at $324-25$.

223. Id. at 324. That court also noted the reference's cross-racial implications, as King Kong swings "the frail, white, blonde Fay Wray at the top of the Empire State Building." The court also quoted a journal article calling the movie "a racist cautionary tale about interracial romance." Id. at 325 (quoting the appellee's brief, which quoted Phillip Atiba Goff, Jennifer L. Eberhardt, Matthew Christian Jackson \& Melissa J. Williams, Not Yet Human: Implicit Knowledge, Historical Dehumanization, and Contemporary Consequences, 94 J. Personality \& Soc. Psych. 292, 293 (2008)).

224. Id. at 319,321 .

225. Alford, supra note 39, at 350 (describing Johnson v. Zandt, 295 S.E.2d 63, 69 (Ga. 1982)). 
Additionally, courts fail to acknowledge explicitly racial language by suggesting that jurors may attribute non-racial meanings to the words used. For example, the Seventh Circuit concluded that "it is not even certain ... that the reference to the witness's 'shucking and jiving' was racial in character" because although the "phrase is Negro dialect . . . numerous other words and phrases of that dialect . . . have become absorbed into standard English and are now applied to members of all racial and ethnic groups." ${ }^{226}$ That court also concluded that calling the defendant "super-fly" was unmistakably racial because it was a reference to a movie series, but reasoned that because those movies were marketed to Black audiences, it was unclear whether the white jury would have understood the reference. ${ }^{227}$

Courts sometimes deflect the racist overtones of prosecutorial rhetoric by focusing on the prosecutor's intent. The Supreme Court, outside the context of racial arguments, said that courts "should not lightly infer that a prosecutor intends an ambiguous remark to have its most damaging meaning." ${ }^{228}$ The Seventh Circuit includes this idea in its formulation of the rule on racial arguments: "a racial remark is improper if it is 'intentionally injected into volatile proceedings where the prosecutor had targeted the defendant's ethnic origin for emphasis in an attempt to appeal to the jury's prejudices.'" 229 That court applied this rule to justify questions to several witnesses about the defendant's "membership in the [B]lack Muslim faith" because these questions "were only meant to show" motive and were "clearly intended to rebut" the defendant's proffered insanity defense. ${ }^{230}$ Similarly, an author extensively discusses an Oklahoma capital case in which the court justified the prosecutor's introduction of an image of a black ape and, while showing the image to the jury, said "that's [the defendant] in a nutshell." ${ }^{231}$ The trial court overruled defense counsel's objection, and the court of appeals explicitly concluded that the prosecutor did not

226. Smith v. Farley, 59 F.3d 659, 664 (7th Cir. 1995).

227. $I d$.

228. Donnelly v. DeChristoforo, 416 U.S. 637, 647 (1974) (cautioning the courts against assuming that the jury will "draw [the most damaging] meaning from the plethora of less damaging interpretations").

229. See, e.g., Aliwoli v. Carter, 225 F.3d 826, 831 (7th Cir. 2000) (quoting United States v. Hernandez, 865 F.2d 925, 928 (7th Cir. 1989)).

230. Id. at 830-31. The concurrence noted the problem with that reasoning: "to ascribe to a defendant a motive to kill simply because he is a Black Muslim and because other African-Americans, or other Muslims, have expressed distrust (or worse) of different races and religions, is to engage in wholly inappropriate stereotyping." Id. at 832 (Rovner, J., concurring in part and dissenting in part).

231. Alford, supra note 39, at 342 (discussing Allen v. State, 871 P.2d 79, 97 (Okla. Crim. App. 1994)) (emphasis omitted). 
intend the statement to be interpreted as arguing that the defendant was an ape. ${ }^{232}$ As explained above, however, whether a statement activates a stereotype has nothing to do with whether the person making the statement intended for it to do so. Courts should be focusing on the potential impact of the statement on the jury, not on the prosecutor's intent. ${ }^{233}$

Relatedly, courts sometimes avoid confronting the racist dimension of prosecutorial rhetoric by using more generic labels like "inflammatory" or "name-calling." 234 For example, in the Oklahoma capital case, only one court out of many levels of review even came close to acknowledging the racist dimension of the prosecutor's use of the "black ape" image with the statement that the image was the defendant in a nutshell. ${ }^{235}$ The Tenth Circuit labeled the image and language "improper name calling" without acknowledging the inherent racism; the court used that weaker label in an unpublished opinion denying the defendant's habeas petition. ${ }^{236}$ In another case, the United States Supreme Court failed to explicitly note the racial connotations of the prosecution's reference to the defendant as an animal and statement that the defendant "shouldn't be out of his cell unless he has a leash on him and a prison guard at the other end of that leash." 237

Finally, courts fail to clarify the appropriate line between proper and improper rhetoric by blurring the analytically distinct issues of whether the language was improper and whether the defendant was

232. Id. Prosecutors in other cases discussed in the prior subsection argued that they did not intend their comments to be racist, although the courts rejected those arguments. See, e.g., State v. Shabazz, 48 P.3d 605, 621 (Haw. Ct. App. 2002) (prosecutor argued that he didn't intend to be racist and that he referred to defendants as Afro-American because he didn't want to use the victim's words of "black dude").

233. Prasad, supra note 49, at 3118 (noting that prosecutorial intent can sometimes be difficult to discern, and that if motives do matter, courts should consider more than explicit bias because "[t]he fact that some courts find subtle racial arguments plausible suggests that the jurors might find them persuasive").

234. Scholars often use the "inflammatory" or "name-calling" labels for racist prosecutorial rhetoric. See, e.g., Alford, supra note 39, at 329-30, 364. Those categories, however, also include non-racial arguments, such as appeal to patriotism or class. See, e.g., Charles L. Cantrell, Prosecutorial Misconduct: Recognizing Errors in Closing Argument, 26 Am. J. Trial Advoc. 535, $561-62(2003)$.

235. Alford, supra note 39, at 342-43 (discussing Allen, 871 P.2d at 97).

236. Id. at 342. Ms. Allen was ultimately executed. Id. at 340.

237. Darden v. Wainwright, 477 U.S. 168, 180 n.12 (1986). 
prejudiced by the prosecutor's rhetoric. ${ }^{238}$ For example, in a 2020 North Carolina case involving the prosecution of a white defendant for killing a young Black man, the prosecutor's rebuttal closing argued that race had been an undercurrent of the whole case and a focus of defense counsel's closing. ${ }^{239}$ After the defense's objection was overruled, the prosecutor said: "Let's talk about the elephant in the room. If they want to go there, consider it." ${ }^{240}$ The prosecutor then rhetorically asked if the victim and others with him "were a bunch of young, white males walking around wearing N.C. State hats, is he laying dead bleeding in that yard?"241 The North Carolina Supreme Court assumed without deciding that these remarks were improper, focusing instead on whether the argument was prejudicial; the court upheld the conviction because there was no reasonable probability that the defendant would have been acquitted if the trial court had sustained the objection. ${ }^{242}$ The concurrence wrote separately to explain that the prosecutor's argument was proper because it was not based on racial animosity and because the case had involved a risk that jurors could be swayed by race, starting from jury selection onward. ${ }^{243}$ The concurrence was right in this analysis, but the majority's approach in assuming that the comments were improper may make future prosecutors afraid to address the racial motive for a hate crime. ${ }^{244}$

\section{Appellate Procedural Doctrines Prevent Meaningful Remedies}

Even when courts label racist prosecutorial rhetoric as improper, they often fail to provide any meaningful remedy because of the appellate doctrines of harmless error and plain error. ${ }^{245}$ The combined effect

238. The courts often do so when analyzing plain error in the absence of an objection. See infra Section II(C). But they sometimes do so even when the defendant objects. See State v. Copley, 839 S.E.2d 726, 728 (N.C. 2020).

239. Copley, 839 S.E.2d at 728.

240. Id.

241. Id.

242. Id. at 731 .

243. Id. at 732 .

244. For a discussion of the specific challenges of prosecuting white defendants for committing crimes against people of color, see infra note 307.

245. See, e.g., V.A. Richelle, Racism as a Strategic Tool at Trial: Appealing RaceBased Prosecutorial Misconduct, 67 TuL. L. REv. 2357, 2358 (1993) ("However, procedural and substantive doctrines such as harmless-error analysis and limited standards of review may tie the hands of appellate courts. The courts' limited ability to review actions of the trial court and the small number of remedies available to them may preclude the reversal of verdicts colored by racial prejudice."). 
of these doctrines means that "prosecutors know they are likely to get away with this form of misbehavior." 246

The harmless-error doctrine allows an appellate court to uphold a conviction even after finding that the prosecutor's conduct was improper when the appellate court concludes that the case against the defendant was so strong that the improper conduct likely did not change the outcome. ${ }^{247}$ Several scholars have critiqued courts' harmless error analysis as overestimating the strength of the government's case or relying too much on simply counting the number of improper references. ${ }^{248}$ This approach is inconsistent with the research described above about how racial stereotyping can taint both memories and evaluation of evidence of guilt. ${ }^{249}$

Scholars have also noted the perverse incentives created by harmless error analysis, which encourages prosecutors to "weigh the commission of evidentiary or procedural violations not against a legal or ethical standard of appropriate conduct, but rather, against an increasingly accurate prediction that the appellate courts will ignore the misconduct when sufficient evidence exists to prove the defendant's guilt." ${ }^{250}$ Yet when cases are close, prosecutors still have an incentive to

246. Cicchini, supra note 145 , at 893,922 .

247. See, e.g., Bowman, supra note 16, at 315. In some circumstances, defense counsel must prove that the error affected the outcome, while in other circumstances, the prosecutor must prove beyond a reasonable doubt that the error was harmless. See, e.g., Richelle, supra note 245, at 2369-70. Some have argued that neither of those standards is adequate, and instead that courts should treat race-based prosecutorial misconduct as a structural error that requires immediate reversal without consideration of whether the misconduct was harmless. See, e.g., id. at 2368.

248. See, e.g., Lyon, supra note 15, at 327 (noting that courts often count the references without engaging in deeper analysis of their effect); Demetria D. Frank, The Proof is in the Prejudice: Implicit Racial Bias, Uncharged Act Evidence 83 the Colorblind Courtroom, 32 HARv. J. RACIAL \& ETHNIC JusT. 1, 24-25 nn.139, 142 (2016) (noting that courts often rely on the weight of the evidence against the defendant); Bowman, supra note 16, at 347-52 (discussing several problems with courts' harmless error analysis in cases of improper prosecutorial rhetoric without focusing specifically on racist prosecutorial rhetoric - but much of the same logic applies in this specific context).

249. See supra Part I(B). It also arguably shifts the burden of fairness to the defendant. Earle, supra note 34, at 1229.

250. Bennett L. Gershman, The New Prosecutors, 53 U. PitT. L. Rev. 393, 425 (1992); see also Angela J. Davis, Arbitrary Justice: The Power of the American Prosecutor 127 (Oxford Univ. Press 2007) ("[The harmless error rule] permits, perhaps even unintentionally encourages, prosecutors to engage in misconduct during trial with the assurance that so long as the evidence of the defendant's guilt is clear, the conviction will be affirmed."). 
use improper rhetoric to tip the scales. ${ }^{251}$ Thus, the harmless-error doctrine fails to provide any disincentive to avoid racist prosecutorial rhetoric..$^{252}$

When appellate courts label conduct as improper but refuse to impose any meaningful remedy, the appellate courts' warnings about impropriety are easily seen as empty threats. ${ }^{253}$ For example, one author discusses a Florida case in which defense counsel on appeal noted that seven previous cases warned prosecutors that the same argument was prosecutorial misconduct; in the eighth case, the appellate court merely declared that appellate courts would be forced to start ordering reversals if this line of improper argument continued in future cases. ${ }^{254}$ He also discussed a similar California case in which the appellate court threatened that future reversals might be necessary but still affirmed a conviction even though the court found it "disheartening" that the prosecutor "took pride in" previous admonitions about improper conduct. ${ }^{255}$ These empty threats of future reversals without present consequences functionally tell prosecutors that they can continue doing what they have been doing. When courts routinely hold that conduct is improper but harmless, that "creates a culture in which ... defendants are virtually guaranteed to have their constitutional rights violated." 256

The situation is even worse when defense counsel fails to object and appellate courts invoke the plain-error doctrine. Although appellate courts generally refuse to review issues that were not presented to the

251. Alford, supra note 39, at 334 (analogizing closing arguments to a basketball game in the final minute; the closer the score, the more the prosecution has an incentive to use racist prosecutorial rhetoric).

252. See Bowman, supra note 16, at 316-17 (arguing that beyond the incentives created, courts' current approaches to these issues may exacerbate prosecutors' own cognitive biases).

253. Cicchini, supra note 145 , at 893-94.

254. Id. at 893 (discussing Briggs v. State, 455 So. 2d 519, 521-22 (Fla. Dist. Ct. App. 1984)).

255. Id. at 894 (discussing People v. Congious, No. B0202709 (Cal. Ct. App. Dec. 4, 1987)). Although these cases involved other types of prosecutorial misconduct in argument, rather than racist prosecutorial rhetoric, the same "empty threat" dynamic is at play when courts refuse to reverse.

256. State v. Jackson, No. 97681-3, 2020 WL 4006802, at*7 (Wash. July 16, 2020). The state had conceded at oral argument that trial courts were refusing to hold individualized hearings required by precedent, which led to the Washington Supreme Court's reasoning quoted above about a system in which defendants were virtually guaranteed to have their rights violated. Id. Although Jackson involved mandatory shackling rather than racist prosecutorial rhetoric, the court's reasoning applies in this context as well, particularly if trial courts are overruling objections or otherwise justifying racist prosecutorial rhetoric. 
trial court through formal objections, the plain-error doctrine allows for that review when failure to do so would undermine the trial's fundamental fairness. ${ }^{257}$ Courts often use this doctrine to review claims of racist prosecutorial rhetoric. ${ }^{258}$ However, this standard is nearly impossible to meet, as it often requires a defendant to prove both that the remarks were so improper as to have denied him a fair trial and that the result of the trial would have been different without the remarks. ${ }^{259}$

The plain-error doctrine therefore inappropriately puts the burden on defense counsel to object rather than on the prosecutor to avoid racist rhetoric. ${ }^{260}$ Yet defense counsel may have valid reasons for not objecting, such as being afraid that they, rather than the prosecutor, may be seen as the one "playing the "race card."'261 The phrase "playing the race card" is pejorative, suggesting "a dirty trick" to "exploit our sympathies to racial injustice in order to secure some political or material advantage." ${ }^{262}$ Defense counsel therefore rightly fear jury backlash if the trial court overrules the objection. ${ }^{263}$

Furthermore, if well-intentioned prosecutors may not recognize the racist dimension of their rhetoric, defense counsel may be even less

257. Richelle, supra note 245, at 2359 (citing United States v. Young, 470 U.S. $1,16(1985))$.

258. Id. at 2359-60.

259. Cicchini, supra note 145, at 922 (citing United States v. Anderson, 303 F.3d 847, 854 (7th Cir. 2002)); see also Richelle, supra note 245, at 236162 (discussing various standards and approaches that courts use in plain error review).

260. See Montz, supra note 140, at 76, 78 (discussing the "plain error" doctrine and how it significantly limits appellate review of prosecutorial misconduct when defense counsel fails to object).

261. See, e.g., Prasad, supra note 49, at 3112 . This concern by defense counsel is bolstered by case law in which prosecutors attack defense counsel for playing the race card. See, e.g., State v. Cabrera, 700 N.W.2d 469, 474 (Minn. 2005) (alleging that defense counsel was "just throwing mud on young black men" and then arguing that references to gang membership involved "wild and, I submit, racist speculation on the part of counsel here"); United States v. Richardson, 161 F.3d 728, 735 (D.C. Cir. 1998) (addressing argument by Black prosecutor that defense's theory that Defendant had been mis-identified as the one to commit a robbery was based on defense counsel arguing that "we all look alike" without ever addressing the substance of the misidentification risk in the case).

262. Christopher A. Bracey, The Color of Our Future: The Pitfalls and Possibilities of the Race Card in American Culture, 5 StAn. J. C.R. \& C.L. 89, 93-94 (2009).

263. Alford, supra note 39, at 337. 
likely to pick up on the problem with that rhetoric. ${ }^{264}$ But "subtle" references to stereotypes may be even more dangerous than explicit racist appeals given that they may activate biases without jurors recognizing what is happening and guarding against them. ${ }^{265}$ And even when defense counsel recognize the problem, "the misconduct typically happens too quickly to mount a thoughtful and effective response." 266

Additionally, the plain-error doctrine sometimes leads to a lack of clarity about whether prosecutorial remarks are improper. ${ }^{267}$ That approach makes it harder for prosecutors' offices to use appellate opinions in training prosecutors about the boundaries between proper and improper arguments. ${ }^{268}$ Appellate courts' opinions can serve a pedagogic function, but only when they draw reasonably clear lines between proper and improper conduct. ${ }^{269}$

While these doctrines do not always stand in the way of reversal, ${ }^{270}$ courts often affirm convictions even in the face of fairly egregious misconduct. ${ }^{271}$ For example, the Colorado Supreme Court recently relied on the plain-error doctrine in upholding the sexual assault conviction of a defendant whose trial involved the prosecutor making

264. Prasad, supra note 49, at 3112 (noting that even if the plain-error doctrine makes sense for explicitly racist appeals, it prevents defense counsel and trial courts from providing meaningful intervention for arguments based on implicit biases).

265. Armour, supra note 68 , at 767.

266. Cicchini, supra note 145 , at 893.

267. See supra Part II(C).

268. See Bruce A. Green, Regulating Prosecutors' Courtroom Misconduct, 50 LoY. U. CHI. L.J. 797, 808-09 (2019).

269. See $i d$. at 808 .

270. See, e.g., United States v. Cannon, 88 F.3d 1495, 1503 (8th Cir. 1996) (finding reversible error because "[w]e believe that by twice calling the AfricanAmerican Defendants 'bad people' and by calling attention to the fact that [they] were not locals, the prosecutor gave the jury an improper and convenient hook on which to hang their verdict"). In an unusual case, the Minnesota Supreme Court reversed a conviction even though it concluded that "it would be difficult for us not to conclude that the prosecutor's comments were harmless beyond a reasonable doubt." State v. Cabrera, 700 N.W.2d 469, 475 (Minn. 2005). The court concluded that although there was strong evidence of the defendant's guilt, reversal was required when the prosecutor's argument and the trial court's overruling of defense's objection "may have led the jury to conclude that defense counsel himself was racist - an implication wholly unsupported by the record." Id. at 474-75.

271. For example, in Darden v. Wainright, the prosecutor said that the defendant was an animal and should not be out of a cell without a leash. The Court concluded that the comments did not "so [infect] the trial with unfairness" as to require reversal. 477 U.S. 168, 181 (1986) (quoting Donnelly v. DeChristoforo, 416 U.S. 637, 643 (1974)). 
explicit and repeated references to the race and skin tone of the defendant and victim. ${ }^{272}$ The court of appeals had reversed the conviction, reasoning among other things that "errors involving racial discrimination must be treated with added precaution" and that "comments that appeal to racial prejudice fundamentally undermine the principle of equal justice and therefore demand that an appellate court set appropriate standards to deter such conduct." ${ }^{273}$ The court agreed that the comments were improper, rejecting several arguments by the government justifying the prosecutor's remarks. ${ }^{274}$ However, the court ultimately affirmed the conviction based on the plain-error doctrine, reasoning that "we cannot say that the error so undermined the fundamental fairness of [the defendant's] trial so as to cast serious doubt on the reliability of his judgment of conviction." ${ }^{275}$

In another case, the court relied on the plain-error doctrine in upholding a conviction even when the prosecutor's opening statement contained sixteen references to "black males," "larger black male[s]," and "smaller black male[s]." ${ }^{276}$ The court's reasoning seemed to blur the question of whether the comments were improper and whether they were prejudicial. ${ }^{277}$ The court stated that it did "not condone the gratuitous use of race, as the prosecutors did in this case," but the court also emphasized that the remarks "were descriptive, not pejorative." 278

272. People v. Robinson, 454 P.3d 229, 231 (Colo. 2019) ("You're going to hear that [A.M.] is white. And she's actually pretty pasty. She's pasty white. And you obviously have seen Mr. Robinson is dark. He is an African American of dark complexion. [E.G.] looks over and she can see a dark penis going into a white body. That's how graphic she could see [sic].").

273. Id. at 232 .

274. Id. at 234 .

275. Id. at 235. The court relied on the general instruction the trial court gave advising jurors to not "allow bias or prejudice... to influence their decisions," as well as the fact that the jury acquitted the defendant on some counts. Id. The court's analysis of the comments' impropriety suggested confusion over why the prosecutor would have thought the comments were relevant and how to balance the probative value against prejudicial effect. See id. at 234. If the Colorado Supreme Court had some difficulty with that analysis given ample time for reflection, that suggests it is unreasonable to expect defense counsel to do this calculation effectively in deciding whether to object in the moment.

276. State v. Mitchell, 783 A.2d 1249, 1253 (Conn. App. Ct. 2001).

277. Id. at $1254-55$.

278. Id. The court did not discuss why sixteen separate mentions of "black" was necessary or useful for identification, or why the prosecutor could not have just talked about the larger and smaller male without reference to race, at least after the first time. The court also noted that the comments were only made in opening statements, which the prosecutor structured as a "mystery" 
While some descriptive reference to race is proper, the court failed to analyze the repetitive nature of the sixteen separate references. ${ }^{279}$ The court also emphasized that the "alleged misconduct was not central to any critical issue in the case, " ${ }^{280}$ which is commonly part of harmlesserror analysis. The court also relied on the strength of the state's case and ultimately concluded that the defendant was not deprived of a fair trial. ${ }^{281}$ The dissent, by contrast, noted that racial arguments need to be more carefully scrutinized, and stated that "I cannot conceive of any valid reason for those racial references." 282

These decisions, and many more like them, show the courts' naïveté about the severity and impact of racist prosecutorial rhetoric. Even if these decisions can be justified in individual cases, collectively they create a system that tolerates and even encourages prosecutors to use racist prosecutorial rhetoric. The next section lays a foundation for potential solutions to this current state of structural racism.

\section{Focus on Trial Courts for Solutions About Controlling Biases}

The clear theme of the research described above in Part I(B) is that decision-making improves when actors are aware of the ways in which race affects decision-making. Therefore, this section focuses on raceconscious rather than colorblind solutions ${ }^{283}$ to the problem of racist prosecutorial rhetoric. These solutions relate to court actions, as "courts provide the primary restraint on prosecutorial misconduct" at trial. ${ }^{284}$

about what happened, and that in closing arguments the prosecutor referred to them by name rather than description. See $i d$.

279. For the importance of repetition, see supra notes 165-169 and accompanying text.

280. Mitchell, 783 A.2d at 1254. Although the court said that, the court also noted elsewhere in the opinion that the victims could not positively identify the defendant, so identification did seem to be a critical issue. See $i d$. at 1253.

281. Id. at 1255 .

282. Id. at 1259 (Spear, J., dissenting). The dissent also used a race-switching argument that if the robbery victims had been Black and the defendants were white, the prosecutor would not have made sixteen references to the perpetrators being white. $I d$.

283. See, e.g., Atiba R. Ellis, Normalizing Domination, 20 CUNY L. REv. 493, 504 (2017) ("[T]here ought to be a reinvigoration of what race consciousness means, even if that meaning forces us to stand contrary to the majoritarian view that we live in a post-racial society.").

284. Lyon, supra note 15, at 335-36; see also Alford, supra note 39, at 333 ("If it is likely that White jurors possess negative stereotypes about Black defendants, this creates a clear incentive for prosecutors to cater to jurors' prejudices with racist argumentation, either overt or subtle. Given these 
Section A below argues that trial courts rather than appellate courts are best positioned to provide that restraint. Section B argues why trial courts should focus on prosecutors rather than treating prosecutors and defense counsel equally. Section C summarizes the social science research about controlling bias, also called debiasing strategies, which provides the foundation for the specific strategies discussed below in Part IV.

\section{A. Trial Courts are Better Positioned than Appellate Courts to Spur Change}

While changes to appellate review ${ }^{285}$ and professional discipline rules $^{286}$ may also be useful in confronting racist prosecutorial rhetoric, trial courts are in the best position to make an immediate and lasting impact. ${ }^{287}$

First, trial courts are better positioned than appellate courts to evaluate the context of challenged prosecutorial rhetoric and to see

incentives, it is the courts' willingness to address covert racism that is crucial to the creation of an effective deterrent."); Green, supra note 268, at 812-13 (discussing the organizational reasons why prosecutors' offices tend to support rather than serve to check prosecutorial misconduct); Randall Grometstein \& Jennifer M. Balboni, Backing out of a Constitutional Ditch: Constitutional Remedies for Gross Prosecutorial Misconduct Post Thompson, 75 ALB. L. REV. 1243, 1281 (2011) (noting that the courts providing a check on prosecutorial behavior is part of the constitutional system of checks and balances between the three branches of government).

285. Appellate court analysis needs to be reshaped as well to deal with the problems identified above. This article is the first of three dealing with the various facets of racist prosecutorial misconduct. A future article will discuss changes to harmless error and plain error analysis in these cases.

286. Professional discipline has generally not been a common or effective method of checking prosecutorial behavior. See Grometstein \& Balboni, supra note 284, at 1269 (discussing a study by the Center for Public Integrity of 11,000 allegations of prosecutorial misconduct and noting that only thirty-four of them led to professional discipline hearings). Some scholars have nevertheless focused on use of the professional discipline system enforcing the ethics rules as the best route to deal with prosecutorial misconduct. See, e.g., Chris Cialeo, [In]equality Under the Law: Remedying Unequal Antidiscrimination Ethics Rules for Federal Prosecutors, 28 Geo. J. Legal Ethics 435, 43739 (2015); Green, supra note 268, at 810-14. A brief review of that scholarship indicates that current ethics rules need to be strengthened, which is something I also plan to explore in another follow-up article.

287. See, e.g., Albert W. Alschuler, Courtroom Misconduct by Prosecutors and Trial Judges, 50 TEx. L. REv. 629, 675-76 (1972) (arguing for trial courts to take a more active role in dealing with prosecutorial misconduct and noting that " $[\mathrm{i}] \mathrm{t}$ is perhaps unfortunate that the legal profession has come to look to the appellate courts as the principal or almost exclusive source of innovation in criminal procedure"). 
juror reactions. ${ }^{288}$ The "cold record" of an appellate transcript often fails to include details, such as the prosecutor's tone of voice or facial expressions, that trial judges can observe and evaluate. ${ }^{289}$ While the court reporter in one case noted that the prosecutor repeatedly said "po-leese" rather than "police," ${ }^{290}$ that kind of detail in the transcript seems to be relatively rare and could easily have been invisible on appeal or only made visible only through defense counsel's argument.

Trial courts are also best positioned to confront prosecutors about their use of stereotypes. Research supports the idea that explicitly confronting individuals with their reliance on stereotypes can effectively decrease their reliance on those stereotypes, at least temporarily. ${ }^{291}$ Researchers found that when study participants were made aware of the role of stereotype in their responses, "participant responses displayed significantly fewer stereotypes (compared to responses given before the confrontation)." ${ }^{292}$ Appellate court review does not provide this kind of immediate confrontation, while trial judges can take a variety of immediate actions during trial to provide this confrontation, as explained below.

Additionally, trial courts possess broad powers to take action. ${ }^{293}$ While sources of trial court authority may vary by jurisdiction, judges can generally rely on statutory authority, codes of ethics, and court rules when controlling attorney courtroom behavior. ${ }^{294}$ Additionally, "[t]he doctrine of inherent judicial power permits the judicial branch to take necessary actions to fulfill its constitutional functions, even when those actions are not expressly authorized by constitution or statute." ${ }^{295}$ This inherent power allows courts to control the conduct of judicial proceedings. ${ }^{296}$ In exercising these various powers, judges have broad

288. Earle, supra note 34, at 1229.

289. Lyon, supra note 15 , at 327.

290. State v. Monday, 257 P.3d 551, 553-54 (Wash. 2011).

291. Levinson, supra note 94, at 413.

292. Id. at $413-14$.

293. See, e.g., Mary Sue Backus, The Adversary System is Dead; Long Live the Adversary System: The Trial Judge as the Great Equalizer in Criminal Trials, 2008 Mich. St. L. ReV. 945, 972 (2008).

294. Ty Tasker, Sticks and Stones: Judicial Handling of Invective in Advocacy, 42 Judges' J. 17, 18 (2003).

295. Backus, supra note 293, at 972.

296. Sheppard v. Maxwell, 384 U.S. 333, 363 (1966) ("[W]e must remember that reversals are but palliatives; the cure lies in those remedial measures that will prevent the prejudice at its inception."). 
discretion, ${ }^{297}$ including the power to impose contempt sanctions. ${ }^{298}$ Contempt sanctions can be imposed against prosecutors as well as against defense counsel, although courts generally impose these sanctions much more frequently against defense counsel. ${ }^{299}$ Trial courts may even have an ethical obligation to act: "The trial judge has the responsibility for safeguarding both the rights of the accused and the interests of the public in the administration of criminal justice." ${ }^{300}$ As explained above, racist prosecutorial rhetoric implicates both the rights of individual defendants and the broader public interest in the fair and impartial administration of justice. These various sources of authority support actions by individual trial judges, and judges can also "suggest, and express support of, new legislation, rulemaking, and ethics guidelines where needed." 301

On the other hand, when trial courts fail to confront racist prosecutorial rhetoric, that failure encourages it to continue and even to worsen. ${ }^{302}$ Several commentators have raised concerns about "ethical

297. Backus, supra note 293, at 972 . In fact, these powers are generally so broad that valid concerns have been raised about the potential for "idiosyncratic" and "erratic rules." Louis S. Raveson, Advocacy and Contempt: Constitutional Limitations on the Judicial Contempt Power Part One: The Conflict Between Advocacy and Contempt, 65 WAsH. L. REv. 477, 483 (1990). My point here is not to delineate the outer limits of these powers, but to demonstrate that trial courts have ample authority to take meaningful action to deal with racist prosecutorial rhetoric.

298. D. Alana Leaphart, Authority of the Trial Judge, 77 Geo. L.J. 1009, 1023 (1989).

299. See, e.g., Alschuler, supra note 287, at 673-74; see also Raveson, supra note 297, at 582-83 (noting that defense counsel are cited for contempt far more than prosecutors, and discussing various factors that may account for this disparity, which does not seem to reflect more misconduct by defense counsel than prosecutors).

300. Backus, supra note 293, at 962 (quoting Am. BAR Ass'N, ABA StANDARds for Criminal Justice Special Functions of the Trial Judge 6-1.1 (3d ed. 2000)). While the ABA Standards are not mandatory in any jurisdiction, courts nevertheless "giv[e] them considerable weight." Id. at n.83.

301. Tasker, supra note 294, at 21. As discussed in Part IV, some specific steps should be taken by individual trial judges, but many of the solutions would benefit from rulemaking in the form of court rules or model jury instructions.

302. Green, supra note 268, at 812 (arguing that courts should not ignore "minor, but visible, prosecutorial infractions" because "[c]ontemporary social science teachings offer reasons to worry that this strategy fosters not only recurring low-level misconduct but more serious wrongdoing."); see also Tasker, supra note 294, at 21 (quoting People v. Travis, 276 P.2d 193, 199 (Cal. Dist. Ct. App. 1954)) (noting that courts should express "disapproval rather than . . . tacit approval" to minimize incentives for attorneys to engage in inappropriate behavior). 
slippage" or "slippery slope" regarding courts failing to discipline prosecutors. ${ }^{303}$ When prosecutors get away with "overreaching in little visible ways," they may become more willing to commit more serious misconduct. ${ }^{304}$ Again, trial courts are better positioned than appellate courts to provide the kind of corrective interventions needed, and research shows that their failure to do so may have significant consequences for the overall pattern of prosecutorial behavior, regardless of what appellate courts decide later. ${ }^{305}$

\section{B. Trial Courts Should Focus on Prosecutors}

The solutions described below focus on prosecutors; they should not be applied as written to defense counsel. ${ }^{306}$ While defense counsel might certainly use racist rhetoric, several reasons support treating prosecutors differently. ${ }^{307}$

303. See, e.g., Green, supra note 268, at 813 (discussing "ethical slippage"); Earle, supra note 34, at 1214 (noting that courts allowing racism to go unaddressed perpetuates injustice and "erodes the safeguard of a fair trial").

304. Green, supra note 268, at 813 . In those situations, the failure of courts and other entities to provide any check for misconduct may blind them to the fact that their behavior is inappropriate. See infra note 409 and accompanying text.

305. Green, supra note 268 , at 810,812 .

306. Application of these concepts to civil cases is beyond the scope of this article.

307. In focusing on prosecutors, I do not want to minimize the dangers from defense counsel using racist rhetoric, particularly when representing white defendants being prosecuted for crimes against Black victims, and some scholars have used that lens to argue for rules about racial references in criminal trials that would apply to both prosecutors and defense counsel. See, e.g., Jonathan Markovitz, "A Spectacle of Slavery Unwilling to Die": Curbing Reliance on Racial Stereotyping in Self-Defense Cases, 5 UC IRvINE L. REv. 873, 931 (2015) ("Several scholars have suggested prohibiting any discussion of race at trial, or developing 'race shield' laws, modeled after rape shield laws, that would prohibit reliance on racial imagery, with several exceptions."). I certainly do not intend for this article to make it harder to prosecute cases of racial violence against victims of color, and I have tried to craft solutions below that allow prosecutors to demonstrate to courts the need for racially conscious language and theories. See, e.g., Alfieri, supra note 3 , at 2242 ("Race-conscious, community-oriented duties to investigate and prosecute cases of racially motivated violence correspond with the public purposes of criminal justice."). But even in these cases, prosecutors should avoid narratives that reinforce "hierarchies of white dominance and black subordination." Id. at 2243. In other words, prosecutors should be careful to avoid racist rhetoric, even when they might think they are using that rhetoric for a just cause. Instead, I argue that prosecutors should avoid in all cases rhetoric that would be racist when used against a Black defendant, even if that rhetoric is arguably non-racist in a particular case. See infra note 409. Finally, although the role of defense counsel in countering racist prosecutorial rhetoric is beyond the scope of this article, others have produced good scholarship on this topic. See generally, e.g., Wilkins, supra note 69. And I 
As Professor Anna Roberts points out, "an examination of some of the core structures of the criminal justice system reveals that asymmetry is a central component of the system's design and of its attempts to achieve fairness." 308 The Constitution provides criminal defendants with several rights that are not provided to the prosecution, such as the right to confront adverse witnesses and the right not to be compelled to self-incriminate. ${ }^{309}$ Courts interpreting these rights have reinforced asymmetry, for example in placing the burden on the prosecution beyond a reasonable doubt to secure a criminal conviction. ${ }^{310}$

Additionally, prosecutors and defense counsel play different roles within the system. As noted above, prosecutors have an ethical duty to "seek justice" rather than to win convictions at any cost, while defense counsel must represent their clients and seek acquittals or other clientcentered responses without an eye towards broader issues of justice. ${ }^{311}$

Prosecutors are also representatives of the government, and government representatives have a particularly important role to both literally enforce anti-discrimination laws and act within the spirit of those laws when performing other tasks. ${ }^{312}$ In using racist rhetoric, "a prosecutor would, at the very least, be acting contrary to the spirit of . . . antidiscrimination laws as a means of enforcing other laws."313 And when judges fail to impose consequences on prosecutors for using racist rhetoric, that failure "effectively results in two branches of government sanctioning such discriminatory conduct." "314

Jurors' views of prosecutors and defense counsel also matter. Jurors and other members of the public generally do not understand why

agree with the Critical Race Theory scholarship that emphasizes the importance of ensuring that defense counsel can tell their client' stories when representing people of color. See, e.g., Delgado \& Stefancic, supra note 42, at 43-56 (discussing legal storytelling and narrative analysis within Critical Race Theory, including how these techniques help reveal "ignored or alternative realities" and how counter-storytelling helps provide a "cure for silencing"). So while it may be appropriate to limit the rhetoric available to defense counsel, at least in some circumstances, the nuances of that issue are beyond the scope of this article, and courts can and should focus at this point on prosecutorial rhetoric.

308. Roberts, supra note 45, at 1539.

309. Id.

310. Id.

311. Id. at 1540 .

312. See Cialeo, supra note 286, at 441.

313. $I d$.

314. Id.; see also Johnson, supra note 54, at 333-34 (noting the danger in the government validating "the basic premise of Plessy - that people of color can be permissibly othered and degraded"). 
defense counsel must extend their zealous advocacy even to guilty clients. ${ }^{315}$ Research also shows that jurors' explicit and implicit biases both favor the prosecution. ${ }^{316}$ "Because of her unique position, juries invest the prosecutor with authority beyond that of an advocate, and the prosecutor must be accountable for that authority." ${ }^{317}$ The combination of these factors suggest that racist prosecutorial rhetoric poses asymmetrical danger to the integrity of the fairness of the criminal justice system, and they support the idea that asymmetrical treatment of prosecutors better ensures the goal of fairness.

\section{Overview of Debiasing Strategies from Social Science Research}

While the research described above presents a somewhat daunting picture of how many different ways race can affect decision-making in the criminal justice system, that research also provides a much more hopeful picture regarding several effective debiasing strategies. ${ }^{318}$ This section summarizes five strategies that collectively provide the foundation for the specific solutions discussed in Part IV. These strategies are (1) considering the effect of biases and stereotypes on decision-making; (2) making race salient in a way that empowers controlling the effect of biases; (3) priming egalitarianism; (4) reducing cognitive load; and (5) making space for counter-narratives.

An important first step is recognizing the existence of implicit bias, dispelling the illusion that our decision-making is color-blind. ${ }^{319}$ For example, studies show that simply raising awareness of potential implicit bias in decision-making was shown to lead to enrolling a more diverse medical school class and a reduction in basketball referees calling fouls in a racially disparate way, without any changes to the processes used in making these decisions. ${ }^{320}$ This increased awareness

315. Roberts, supra note 45, at 1549.

316. Id. at 1529 ("The explicit biases include widespread assumptions that police and prosecutors are unimpeachable, that the guilt of the accused is likely, and that the presumption of innocence is a fiction.") (footnotes omitted). Roberts also notes that jurors' implicit biases "tend to disfavor people of color, and thus a disproportionate number of criminal defendants. These implicit biases can affect all of the main tasks that jurors are called upon to perform: evaluation of evidence, evaluation of behavior, recall of facts, and judgment of guilt." Id. at 1529-30 (footnotes omitted).

317. Lyon, supra note 15 , at 335.

318. "[S]tudies consistently show that implicit bias can be controlled and regulated, and that its operation is not inevitable." Selmi, supra note 26 , at 232. This research does not mean that prejudice has an easy fix, but it does suggest that people with egalitarian values can control the effect of stereotypes on their decisions. See $i d$.

319. Lee, supra note 33 , at 866 .

320. Selmi, supra note 26 , at 231. 
helps people exercise more care in decision-making, particularly for those who are internally motivated to self-correct. ${ }^{321}$

That insight relates to the second key strategy — making race salient in a way that empowers individuals to control biases. Race salience means making decision-makers "aware of racial issues that can bias their decision-making, like the operation of racial stereotypes." 322 This increased awareness through race salience encourages decision-makers with egalitarian values "to consciously suppress stereotype-congruent responses that would otherwise be automatic." ${ }^{323}$ Race salience can also help reduce bias in high-prejudice individuals who may try to appear egalitarian, in compliance with broader societal norms toward egalitarianism. ${ }^{324}$ For both egalitarian and high-prejudiced individuals, making race salient provides motivation for them to avoid allowing stereotypes to affect their judgments. ${ }^{325}$

Several studies demonstrate that making race salient can even the scales for Black and white defendants, while failure to do so leads to disparate treatment. ${ }^{326}$ For example, one study showed that white mock jurors were more likely to convict Black defendants than white defendants and to recommend longer sentences when race was not mentioned, but when race was explicitly mentioned, that disparity disappeared. ${ }^{327}$ Another study found that white jurors were more likely to perceive white defendants as more honest and moral, and Black defendants as more violent, when race was not salient. ${ }^{328}$

321. Richardson, supra note 22, at 887-88; see also Selmi, supra note 26 , at 230 ("Increasing awareness is likely to have the strongest effect on those who are receptive to the notion that implicit bias is a real issue, and that discrimination remains a pervasive societal force.").

322. Lee, supra note 23 , at 1586 .

323. Id.; see also Selmi, supra note 26, at 230 (noting that those most likely to be able to control biases are those who have egalitarian ideals but are likely to underreport their own explicit biases).

324. Lee, supra note 23, at 1608; see also Selmi, supra note 26, at 229-30 (discussing studies showing "that people are likely to act in a less biased fashion when they know their actions are subject to review or judgment"; these studies included one on the effect of televising baseball games to a national audience on umpires' strike zones and bias and another on biased cardiac care to Black patients).

325. See Blasi, supra note 28 , at 1258 .

326. Lee, supra note 23, at 1588-89 ("Making race salient does not give the Black defendant an advantage over the similarly situated White defendant. Failing to make race salient, however, seems to lead to unequal treatment of similarly situated defendants, with the Black defendant receiving the short end of the stick.").

327. See Thompson, supra note 63, at 1295.

328. Id. at $1295-96$. 
Race can be made salient in a criminal trial in a variety of ways, but simply having a victim and defendant of different races is not enough. ${ }^{329}$ Similarly, race is not made salient just by making decisionmakers aware of the race of the defendant or victim. ${ }^{330}$ Instead, research shows that jurors are better at guarding against the influence of prejudice in cases involving allegations of discrimination or that are otherwise more obviously racially charged. ${ }^{331}$ For example, one experiment involved a fight between two teammates on a high school basketball team. ${ }^{332}$ In both scenarios, one player was Black and the other was white; the only difference between the two scenarios was the addition of a single sentence that the defendant had been subjected to racial remarks and unfair criticisms of teammates in the other racial group earlier in the season. ${ }^{333}$ In the version of the scenario without that sentence, mock jurors voted to convict the Black defendant $90 \%$ of the time and the white defendant only $70 \%$ of the time. ${ }^{334}$ In the scenario with the one additional sentence making race salient, however, both defendants were convicted at the same rate. ${ }^{335}$

Several scholars have argued that courts should make race salient by raising the issue of bias or stereotyping in "routine" cases involving defendants of color that do not involve facts that more obviously make race relevant. For example, Professor Cynthia Lee argues that defense counsel should use voir dire to question jurors about potential racial bias $^{336}$ and should use opening statements to educate jurors on the potential role of bias in decision-making and frame the story in a way that makes the jury more able to see the relevance of race. ${ }^{337}$ Other authors stress the role of jury instructions in making jurors aware of

329. Lee, supra note 23 , at 1563 .

330. Id. at 1586 .

331. See Hunt, supra note 18, at 275 (citing studies). "In other words, the very notion of 'playing the race card' is misleading. By virtue of . . . automatic and connectionist processes . . . 'race cards' are always present and having an effect, even when they are face down or still in the deck." Blasi, supra note 28 , at 1274 .

332. Id. at 1247 .

333. Id.

334. Id.

335. Id. See infra Section IV(A) regarding using voir dire and jury instructions to effectively make race salient.

336. Lee, supra note 23, at 1590-91; see also Hunt, supra note 18, at 283 (suggesting that jurors could be asked to reflect on their own racial biases during voir dire).

337. Lee, supra note 23, at 1593-94; see also Lee, supra note 33, at 862-63. 
the potential impact of implicit bias on decision-making and urging jurors to guard against relying on stereotypes in decision-making. ${ }^{338}$

In raising the idea of biased decision-making, however, approach matters. As noted above, the term "implicit bias" is more effective than "unconscious racism" in suggesting that these biases are controllable. ${ }^{339}$ Furthermore, terms like "unconscious racism" or "aversive racism" suggest individual immorality. ${ }^{340}$ Strategies that come across as moralizing are more likely to be counter-productive rather than helpful, as "the seemingly universal drive to maintain our self-image plays a role in generating stereotypes and prejudice." ${ }^{341}$ On the other hand, "deviation from rational decisionmaking is not simply a cognitive glitch, but a meaningful cultural statement that reflects the way people unknowingly carry society's weaknesses with them at all times." 342 So the framing of these issues for jurors should generally include reference back to the underlying research into biased decision-making ${ }^{343}$ and should emphasize the ability to counteract implicit biases and stereotypes through a focus on non-prejudiced beliefs. ${ }^{344}$

That leads to the third debiasing strategy, priming for egalitarian beliefs. Race consciousness is not by itself enough to undo structural racism, as "[o]ne may have a subordinationist race consciousness or an

338. See, e.g., Mark W. Bennett, Unraveling the Gordian Knot of Implicit Bias in Jury Selection: The Problems of Judge-Dominated Voir Dire, the Failed Promise of Batson, and Proposed Solutions, 4 HARV. L. \& POL'Y REV. 149, 169 (2010); Thompson, supra note 63, at 1301-06.

339. See supra notes 28-30 and accompanying text.

340. Blasi, supra note 28 , at 1276 . While this insight is arguably inconsistent with my use of "racist" throughout this article, the term here refers to the rhetoric rather than the person using it. See supra note 41 and accompanying text. Additionally, this article is intended to appeal to people (particularly prosecutors and judges) with egalitarian values and low prejudice, to help them change their approaches to this issue by giving them a broader framework for understanding the racism inherent in certain rhetorical choices. See also Blasi, supra note 28, at 1281 (noting that another scholar's explanation of "institutional racism" is helpful because "despite the emotive implications of the term, it is at bottom an account of how very ordinary and unremarkable are the methods by which we maintain structures of inequality. ... [T]his account ... [is] less likely to encounter the resistance generated by more moralizing and accusatory stances."). Thus, the term "racist prosecutorial rhetoric" should be seen as conveying urgency rather than moral judgment.

341. Id. at 1271 .

342. Levinson, supra note 94, at 420.

343. Blasi, supra note 28 , at 1276.

344. See Armour, supra note 68, at 744 (discussing "the possibility of inhibiting and replacing stereotype-congruent responses with nonprejudiced responses derived from nonprejudiced personal beliefs"). 
egalitarian race consciousness." ${ }^{345}$ Making race salient is important, but it should be done in a way that furthers an egalitarian approach to race consciousness. While racist rhetoric can activate stereotypes and prime for prejudice, antidiscrimination norms can also be primed and activated. ${ }^{346}$ For example, jurors can be instructed that they should not allow their verdicts to be influenced by bias or prejudice. A recent study concluded that an instruction with language about avoiding bias or prejudice, even without mentioning race, was helpful in priming for egalitarianism. ${ }^{347}$ That study's author concluded that "explicit race salience and egalitarianism may be additive, such that their combination is more powerful at reducing biases than either alone." 348 Similarly, attorneys can use voir dire or closing arguments to remind jurors to guard against biases, reinforcing egalitarianism without specifically referring to race. ${ }^{349}$

A fourth strategy involves reducing cognitive loads. ${ }^{350}$ "Studies have shown that cognitive load interferes with the ability to process information in a controlled manner, making people more vulnerable to stereotyping and other mental shortcuts." ${ }^{351}$ This occurs because people draw on the same mental resources for directing their attention, holding things in working memory, reasoning, and controlling expressions of bias. ${ }^{352}$ In such situations, relying on stereotypes provides a mental shortcut, but that heightens the risk of biased behavior. ${ }^{353}$ Reducing cognitive load, by contrast, minimizes the need for reliance on mental

345. Ellis, supra note 283, at 500 (footnotes omitted); see also id. at 504 ("Race consciousness can be constructive or destructive, and it is our choice as to whether to be complicit with an erasure of race consciousness that facilitates a new racial domination, or by our consciousness to work to articulate a racial awareness that bolsters our democratic values.").

346. See Blasi, supra note 28 , at 1276 .

347. Ingriselli, supra note 56 , at $1730-31$.

348. Id.

349. See Blasi, supra note 28 , at 1276 .

350. Jamillah Bowman Williams, Accountability as a Debiasing Strategy: Testing the Effect of Racial Diversity in Employment Committees, 103 IowA L. REV. 1593, 1601 (2018); see also Hunt, supra note 18, at 275 ("[L]owering the cognitive demands on jurors may help them to avoid the influence of prejudice.").

351. Avani Mehta Sood, Attempted Justice: Misunderstanding and Bias in Psychological Constructions of Criminal Attempt, 71 Stan. L. Rev. 593, 648 (2019); see also Thompson, supra note 63, at 1249 (noting that high cognitive load makes individuals under stress or pressed for time more likely to rely on stereotypes).

352. Jillian K. Swencionis \& Phillip Atiba Goff, The Psychological Science of Racial Bias and Policing, 23 PSYch. PuB. POL'y \& L. 398, 402 (2017).

353. See $i d$. 
shortcuts like stereotypes and encourages more thoughtful decisionmaking. ${ }^{354}$

Finally, courts should provide opportunities for counter-narratives. Counter-narratives are a useful tool for replacing toxic prior mental associations with new, more positive associations. ${ }^{355}$ Professor Jewel's article on neurorhetoric stresses the importance of counternarratives: "To the extent that rhetoric produces collective neural pathways that reinforce racial oppression and subordination, the identification and deployment of alternative discourses have the potential to carve out healing pathways that can reshape brains, both individually and collectively." ${ }^{356}$ Many scholars have written about the importance of defense counsel offering counter-narratives to humanize their clients. ${ }^{357}$ But there is also an important systemic component to counternarratives as a debiasing strategy. ${ }^{358}$ As discussed above, stereotypes come in part from culture, and repeated references to those stereotypes more firmly entrenches them in our individual and collective understandings. ${ }^{359}$ Law's emphasis on repetition of rules and standardized language "creates collective neural pathways that become collectively entrenched." ${ }^{600}$ Thus, in making race salient and priming egalitarianism, courts can foster counter-narratives within the criminal justice system. The next Part below offers concrete strategies for doing so.

\section{Specific Proposed Solutions}

This section offers specific actions trial courts can use to implement the general debiasing strategies discussed above. Section A describes creating an effective foundation to guard against juror biases through voir dire and pretrial jury instructions. Section B proposes using a

354. See Williams, supra note 350, at 1601 n.45.

355. Walter I. Gonçalves, Jr., Narrative, Culture, and Individuation: A Criminal Defense Lawyer's Race-Conscious Approach to Reduce Implicit Bias for Latinxs, 18 Seattle J. Soc. Just. 333, 374 (2020).

356. Jewel, supra note 18 , at 665.

357. See, e.g., Gonçalves, Jr., supra note 355, at 338 (emphasizing the value of client-centered strategies such as "presenting important life experiences of the client" to humanize the client and "present [them] as a unique person"); Blasi, supra note 28, at 1270 (discussing the "bind" of defense counsel in deciding whether to present stereotype-inconsistent information about a client, which both helps the client by encouraging the jury to view the client as exceptional and also reinforces the broader stereotype).

358. See, e.g., Levinson, supra note 94, at 407 (discussing the value of "exposure to "counterstereotypes" and arguing that cultural solutions must be pursued).

359. See supra Parts $\mathrm{I}(\mathrm{B})(2)$ and $\mathrm{I}(\mathrm{B})(5)$.

360. Jewel, supra note 18 , at 681 . 
checklist of racist prosecutorial rhetoric and requiring prosecutors to bring a motion in limine when they believe that race is relevant to the case. That section should prevent much racist prosecutorial rhetoric, but not all, so Section C offers strategies for dealing with problems that occur during trial. Section D suggests a method for tracking violations across trials and offices to better facilitate dealing with repeat offenders. These solutions would work best in combination with one another, but even implementing some of these approaches would be a marked improvement over the current situation.

\section{A. Create an Effective Foundation}

The two strategies discussed in this section build on the race salience research described above to create a foundation for minimizing the effect of any racist prosecutorial rhetoric that might occur at trial. These solutions are specifically targeted at making the jury aware of implicit biases and on guard against relying on stereotypes or biases. ${ }^{361}$ While these strategies focus on the jury, they should also help make race salient to prosecutors, defense counsel, and judges, which creates a foundation for the solutions discussed in subsequent sections that are focused on those actors.

\section{Use Voir Dire to Make Race Salient}

Courts can use voir dire to make race salient. ${ }^{362}$ While courts are only required to use voir dire to deal with racial bias in a limited set of cases, they have broad discretion to do so in any case. ${ }^{363}$ Some judges have been hesitant to use this authority, fearing that calling attention

361. This approach is consistent with the theory in some of the sources on racist prosecutorial rhetoric that frame the issue as violating the Sixth Amendment's right to an impartial jury. See, e.g., State v. Monday, 257 P.3d 551, 557-58 (Wash. 2011); Calhoun v. United States, 568 U.S. 1206, 1208 (2013) (statement of Sotomoyor, J., respecting the denial of certiorari); see also Earle, supra note 34, at 1217-18 (arguing that the Sixth Amendment guarantee of an impartial jury requires a pragmatic focus on outcomes, while Equal Protection analysis bogs down over questions of a prosecutor's intent and whether actions were harmless). It should also help prevent the kind of racist rhetoric used by a juror during deliberations in Pena-Rodriguez v. Colorado, in which two jurors reported that a third juror, an ex-law enforcement officer, explicitly referenced that experience to argue that Mexican men "believe they could do whatever they wanted with women" and that "nine times out of ten Mexican men were guilty of being aggressive toward women and young girls." 137 S. Ct. 855, 862 (2017). And even if it does not prevent such rhetoric, it should give the other jurors ammunition to explain why that approach should not be used in deliberations. See Cicchini, supra note 145, at 892.

362. Lee, supra note 23 , at 1590 . Voir dire is the process of questioning jurors in advance of the jury selection process. See $i d$.

363. Id. at 1592; Thompson, supra note 63, at 1281 n.303. 
to race will only exacerbate implicit bias. ${ }^{364}$ But the research on race salience described above demonstrates that instinct is incorrect; there is a far greater danger of implicit bias affecting decision-making when courts take a color-blind approach rather than making race salient. ${ }^{365}$

If courts agree to use voir dire to address racial biases, they should allow attorneys for the parties to do the questioning on this topic, rather than doing it themselves. ${ }^{366}$ Research shows that jurors are more likely to answer attorneys more candidly but are more likely to give judges the answer that they think the judge wants to hear. ${ }^{367}$ Therefore, judicially conducted voir dire may actually obscure rather than reveal some biases. ${ }^{368}$

Whoever does the questioning, though, should be careful about how questions are phrased. Closed questions that ask jurors if they can be fair are unlikely to be helpful. ${ }^{369}$ Instead, questions should be openended to educate jurors on implicit bias and ask them to reflect on it and guard against its impact. ${ }^{370}$

2. Give Jury Instruction(s), including a Debiasing Instruction, Before Opening Statements

Another common suggestion for making race salient is through the use of jury instructions. ${ }^{371}$ Many authors have offered a variety of different instructions that could be used for this purpose; ${ }^{372}$ these

364. Bennett, supra note 338, at 169.

365. See supra notes $283,322-338$ and accompanying text.

366. Bennett, supra note 338 , at 160 . For attorneys who would prefer to have the court conduct this voir dire, see infra note 370 and accompanying text.

367. Bennett, supra note 338 , at 160 .

368. Id. If judges choose to conduct voir dire on this topic, attorneys can still request permission to give potential jurors a questionnaire with race-relevant questions. Lee, supra note 23, at 1591.

369. See, e.g., Bennett, supra note 338, at 160 (suggesting that typical closed questions about fairness only reach explicit bias and do not do anything to help detect or prevent implicit biases); Lee, supra note 33, at 868 .

370. See, e.g., Gonçalves, Jr., supra note 355, at 354 (stressing that defense counsel should use voir dire to educate jurors about implicit bias); Lee, supra note 33, at 846-47 (stressing that jurors should reflect on how implicit bias could impact decision-making); Bilotta et al., supra note 4, at 236 (discussing social science research supporting the idea of asking jurors to reflect on racial biases during voir dire).

371. See supra notes 338, 347-349 and accompanying text regarding effectively using jury instructions to make salient both race and egalitarianism.

372. See, e.g., Thompson, supra note 63, at 1301-06 (including an instruction on life experiences that does not mention race, as well as instructions on general racial stereotypes and specific stereotypes that have been invoked in a particular case); Ingriselli, supra note 56, at 1718-19, 1730-33 (describing an 
different models may be more or less appropriate in different cases. ${ }^{373}$ Judges may want to have a standard instruction educating jurors on implicit bias and urging them to avoid relying on stereotypes or biases in their decision-making. ${ }^{374}$ This instruction should avoid language that inadvertently suggests that bias is inevitable or difficult to control, as well as any language with a moralizing tone. ${ }^{375}$ Prosecutors and defense counsel could argue for the appropriateness of additional instructions in specific cases.

The best approach, however, would be to have committees on model jury instructions in each jurisdiction evaluate their current instructions and look for opportunities to refine their model instructions. ${ }^{376}$ A rules committee would be well-suited to focus on the clarity of the instruction, as clarity matters. Several studies demonstrate that

experiment testing the effectiveness of a variety of different instructions, concluding that egalitarian and race-salience instructions were most effective when combined and rejecting the effectiveness of "self-affirming" or "procedural justice" instructions); Bennett, supra note 338, at 169 n.85 (quoting the instruction that Judge Bennett gives routinely). Some of these instructions give detail about the ways in which implicit biases can affect judgments. See, e.g., Thompson, supra note 63, at 1302 (including specific language about biases affecting memory, judgments about believability, and decision-making).

373. For example, Thompson's instruction on life experiences would be useful in courts that routinely give a similar instruction or in cases in which the prosecutor argued that jurors should rely on their life experiences in making credibility determinations between people of different races. See Thompson, supra note 63, at 1301.

374. See, e.g., Bennett, supra note 338, at 169 n.85 (containing Judge Bennett's standard instruction, which among other things asks jurors "to recognize that all of us may be affected by implicit biases in the decisions that we make. Because you are making very important decisions in this case, I strongly encourage you to critically evaluate the evidence and resist any urge to reach a verdict influenced by stereotypes, generalizations, or implicit biases."). Judge Bennett's standard instruction is fairly similar in approach, although with slightly different language, to the egalitarian instruction that Ingriselli found to reduce bias. See supra notes 347-348 and accompanying text.

375. For example, both Judge Bennett's instruction and Ingriselli's egalitarian instruction refers to "unconscious bias," but "implicit bias" would be better language to use, and courts should avoid language about biases being difficult to control. See supra notes 29-30 and accompanying text.

376. Thompson, supra note 63 , at 1290 . Thompson has an extended discussion of pattern jury instructions in various jurisdictions; that approach seems beneficial because these instructions are produced through a deliberative process. $I d$. at 1290-93. Additionally, trial courts would clearly be authorized to give these instructions, while they are sometimes reluctant to do so in the absence of a model instruction. See, e.g., State v. Plain, 898 N.W.2d 801, 817 (Iowa 2017) (noting that the trial court erred in refusing to give a requested implicit bias instruction because the trial court wrongly concluded that it did not have the authority to do so). 
legal standard instructions can be hard for jurors to understand. ${ }^{377}$ When jurors have difficulty understanding the instructions, those instructions are less effective. ${ }^{378}$

Beyond the language used, courts should also focus on timing. The research indicates that it is more effective to give jury instructions generally, and debiasing instructions in particular, before the jury hears evidence. ${ }^{379}$ When jurors are given instructions before they hear evidence, those instructions provide a framework for evaluating the evidence and help them focus on and remember relevant evidence rather than improper considerations such as race. ${ }^{380}$ Relatedly, pre-evidence instructions "prime jurors to organize the evidence according to legal principles rather than personal biases." 381

An empirical study supported these conclusions, showing a greater debiasing effect when debiasing instructions were given before the evidence as compared to when those instructions were given after the evidence. ${ }^{382}$ The study's author also found that "explicit race salience only mattered when there were egalitarian instructions presented preevidence"; in other words, explicit race salience was not enough without also priming egalitarianism before the jurors heard the evidence. ${ }^{383}$ Another study indicates that providing jury instructions

377. Ingriselli, supra note 56 , at 1716.

378. Id. at $1716-17$.

379. See id. at 1730-31; Leonard B. Sand \& Steven Alan Reiss, A Report on Seven Experiments Conducted by District Court Judges in the Second Circuit, 60 N.Y.U. L. Rev. 423, 439-40 (1985) (describing experiments in real trials, explaining that judges and counsel in the majority of cases overall and all the criminal cases found preinstruction to be helpful). While some participants in these experiments expressed ambivalence, the study's author concluded "that most, if not all, of the ambivalence toward preinstruction stems from unfamiliarity with the procedure and the increased burden it may place on the court and counsel. Not a single respondent pointed to any negative effect of preinstruction on the jury." Id. at 442.

380. Ingriselli, supra note 56, at 1715 ; see also Sand \& Reiss, supra note 379 , at 438 (footnote omitted) ("[B] ecause attention and memory processes are more acute when a perceiver has an understanding of what he or she is looking for, preinstruction may enhance the jurors' ability to remember the information presented at trial.").

381. Ingriselli, supra note 56, at 1715.

382. Id. at 1729. Ingriselli also found that timing intersects with clarity: "Timing should have less of an effect if jurors do not understand the instructions, as they cannot form a framework within which to evaluate evidence regardless of when the instructions are presented." Id. at 1716.

383. Id. at 1731. That finding conflicts at least to some extent with earlier research on race salience; Ingriselli suggests that prior studies of race salience used interracial crimes, while her hypothetical did not. Id. She concludes that because she "excluded the victim's race in order to avoid this confounding factor, the data suggests that perhaps the results from past 
before opening statements can also help focus counsel on the issues presented in the case, similar to the effect of a pretrial conference. ${ }^{384}$ The Supreme Court recently noted with approval the process of instructing the jury "at the outset of the case" as one of several things that can help reduce racial bias in jury deliberations. ${ }^{385}$ Thus, courts should give some debiasing instruction prior to opening statements in cases where the social science research indicates that race could affect juror decision-making without their awareness. ${ }^{386}$

\section{B. Prevent Racist Prosecutorial Rhetoric}

This section focuses on strategies for preventing the use of racist prosecutorial rhetoric during trials. It aims to give prosecutors and judges the necessary tools to recognize rhetoric that is racist and the incentives to use those tools effectively. ${ }^{387}$ Specifically, this section proposes that judges adopt a checklist that clearly identifies racist prosecutorial rhetoric and flatly prohibits the use of most of this rhetoric at trial, while also providing a mechanism for prosecutors to argue race-sensitive issues in individual cases when appropriate. The checklist would help well-intentioned prosecutors avoid inadvertent use of racist rhetoric, and it would make it easier for judges to provide remedies when prosecutors do use that rhetoric. Additionally, the checklist would put prosecutors on notice that they need to file a motion in limine seeking permission to raise racial issues and to clarify the boundaries of appropriate argument, so that individual cases can be treated appropriately while still generally preventing improper argument.

1. Use a Checklist to Clarify What Language is Potentially Racist

Checklists have long been recognized as a valuable tool for avoiding biased decision-making. Legal decision-makers have relied on studies in the medical context about how use of checklists can improve decision-

studies have been driven in part by an interaction between the defendant's race and the victim's race rather than by explicit race salience alone." Id.

384. Sand \& Reiss, supra note 379 , at 441.

385. Pena-Rodriguez v. Colorado, 137 S. Ct. 855, 871 (2017).

386. The debiasing instruction should be given in conjunction with other foundational instructions, such as the reasonable doubt standard, rather than by itself. See Ingriselli, supra note 56, at 1730. That was the design in Ingriselli's study, although she does not discuss it separately. However, it is logical that a debiasing instruction would be connected to other instructions about how jurors should decide, rather than talking only about race or bias.

387. See Markovitz, supra note 307, at 933 ("[P]art of the effort to curtail the influence of racist stereotyping in self-defense determinations must involve providing judges and prosecutors with resources and incentives to take an active role in identifying the problem"). 
making by supporting good performance rather than threatening punishment for poor performance. ${ }^{388}$ "Checklists can help reduce biased judgments because having predetermined criteria to guide decisionmaking can hinder people's unintentional tendency to change the criteria upon which their decisions are based in order to fit their preferred course of action." 389

A checklist in this context would provide some clarity around rhetoric that is inherently racist, although of course line-drawing would be challenging. It is fairly easy to say that some references, such as the explicit use of racial slurs, should be prohibited, but "subtle racist appeals that could be interpreted as having nonracist meanings" are more difficult to deal with. ${ }^{390}$ Various scholars have suggested ways to categorize racist rhetoric; these approaches all have their own strengths and weaknesses. ${ }^{391}$ Courts adopting their own checklists may want to consider these other approaches, but this article proposes a structure based on whether or not the prosecutor explicitly refers to race or a racial stereotype, whether the prosecutor uses coded language to do so, and whether the racial reference has more probative value than prejudicial effect. Each of these categories is explained in more detail below, with examples drawn from reported cases to illustrate how the categories would work; it is impossible to be comprehensive, however, so readers should not conclude that potential examples not included below would be appropriate. ${ }^{392}$ Appendix A provides a sample checklist using these categories that courts could adopt or modify.

388. See, e.g., Stephanos Bibas, Jennifer Blasser, Keith A. Findley, Ronald F. Wright, Jennifer E. Laurin \& Cookie Ridolfi, New Perspectives on Brady and Other Disclosure Obligations: Report of the Working Groups on Best Practices, 31 Cardozo L. Rev. 1961, 1974-75 (2010) (explaining an ABA report relying on Continuous Quality Improvement studies in medicine); Lauryn P. Gouldin, When Deference Is Dangerous: The Judicial Role in Material-Witness Detentions, 49 Am. Crim. L. REv. 1333, 1380-81 (2012) (discussing use of checklists to improve decision-making, including a project in the Manhattan District Attorney's Office to create conviction integrity programs using similar principles); Richardson, supra note 22, at 891 (discussing the San Francisco Public Defender's Office use of checklists to help attorneys guard against implicit bias in their handling of cases).

389. L. Song Richardson \& Phillip Atiba Goff, Implicit Racial Bias in Public Defender Triage, 122 YALE L.J. 2626, 2645 (2013).

390. Markovitz, supra note 307 , at 932.

391. See, e.g., Armour, supra note 68, at 767-68 (summarizing some of the earlier approaches, including tests that focus on symbolism and cultural meaning); Earle, supra note 34, at 1233-40 (discussing different strategies for handling explicit references to race versus indirect references to race).

392. Thompson, supra note 63 , at 1303. 


\section{a. $\quad$ Prohibit Use of Racial Slurs and Explicit References to Stereotypes}

First, and hopefully uncontroversially, courts should absolutely prohibit prosecutors from using racial slurs. "Racial slurs universally are considered prejudicial and therefore impermissible." ${ }^{393}$ For example, the prosecutor's use of a variant of the n-word to mean hatred of Black people would fall under this absolute prohibition. ${ }^{394}$ There is no place for prosecutors to use racial slurs in their arguments. Even when the slur comes from the defendant's language or that of a witness, the prosecutor can refer to "the slur" rather than repeating the language. ${ }^{395}$

Additionally, courts should absolutely prohibit prosecutors from explicitly appealing to stereotypes. For example, the use of animal imagery should be prohibited. ${ }^{396}$ As discussed above, courts sometimes justify a prosecutor's comparison of the defendant to a Bengal tiger, a rabid $\mathrm{dog}$, or a snake, to give just a few examples. ${ }^{397}$ Prosecutors sometimes use movie references to similar effect, such as referring to King Kong or calling the defendant a monster. ${ }^{398}$ While "[v]ivid expression and exaggeration for effect are many an attorney's stock-intrade," 399 use of this imagery activates the most pernicious stereotypes and appeals to emotions in ways that are likely to anesthetize the jury from resisting dehumanization. ${ }^{400}$ Dehumanization is particularly likely to invoke stereotypes and influence the jury when used against defendants of color, and this dehumanizing rhetoric is never necessary for prosecutors to argue their cases. Courts should require prosecutors to look for ways to frame their arguments that focus on the specific

393. Developments in the Law: Race and the Criminal Process: VI. Racial Bias and Prosecutorial Conduct at Trial, 101 HARv. L. REv. 1588, 1590 (1988).

394. See Ivery v. State, 686 So. 2d 495, 504 (Ala. Crim. App. 1996). I am not suggesting that the prosecutor could not elicit witness testimony about a defendant's use of racial slurs.

395. That was apparently the situation in Ivery; the prosecutor apparently intended to argue that Black victims deserve justice. In cases involving testimony about a defendant's or witness's use of racial slurs, that issue should be analyzed under Evidence Rule 403, but the prosecutor can emphasize the slur in argument without repeating it.

396. See Heller, supra note 19.

397. See supra notes $213-225$ and accompanying text.

398. See, e.g., Bennett v. Stirling, 842 F.3d 319, 321 (4th Cir. 2016) (involving both King Kong and monster references); Lyon, supra note 15, at 330 (discussing a case where the prosecutor referred to the movie "Gorillas in the Mist" to invoke the "black ape" stereotype).

399. Bennett, 842 F.3d at 322.

400. See supra notes 170-172 and accompanying text (discussing Jewel's explanation for the effectiveness of dehumanizing rhetoric in Nazi Germany). 
evidence. ${ }^{401}$ For example, prosecutors can argue the viciousness of the crime without using an animal or monster image for the perpetrator. ${ }^{402}$

Similarly, courts should prohibit other language that directly invokes racial stereotypes. For example, Professor Sherri Lynn Johnson described several cases with explicit invocation of racial stereotypes, such as referring to Native Americans committing crimes because they are unable to handle liquor. ${ }^{403}$ Similarly, the prosecutor who sang a Dixie song referencing "the land of cotton" invoked slavery and the range of stereotypes associated with it. ${ }^{404}$ And several cases discussed above played on stereotypes of sexually inappropriate behavior towards white women, while some cases involved inflammatory language about immigration status and dishonesty. ${ }^{405}$ Prosecutors should stick to the facts of the cases at hand rather than contextualizing them within broader narratives founded on these stereotypes.

Courts should also prohibit explicit references to race that, in context, suggest that the crime is worse because of the race of the participants involved. As discussed above, this line of argument often comes up in sexual assault cases, where the prosecutors link the victim's fear to the race of the perpetrator. ${ }^{406}$ Prosecutors also sometimes argue that the reaction of others to the victim's sexual assault will be worse because of race. ${ }^{407}$ For example, one prosecutor argued, "I want you to

401. In doing so, prosecutors should not explicitly reference race or invoke the stereotype of Black men as particularly violent, as the United States Supreme Court has recently confirmed that such an approach is improper. Buck v. Davis, 137 S. Ct. 759, 775 (2017) (reasoning that it was ineffective assistance of counsel for defense counsel in a capital case to put on testimony of an expert witness who relied on the defendant's race as an aggravating factor suggesting future dangerousness, and noting that "[i]t would be patently unconstitutional for a state to argue that a defendant is liable to be a future danger because of his race"). The Court noted that the witness's "testimony appealed to a powerful racial stereotype - that of black men as "violence prone" and called that argument "a particularly noxious strain of racial prejudice." Id. at 776 .

402. See, e.g., Bennett, 842 F.3d at 325 (giving several examples of how the improper arguments in that case could have been rephrased in race-neutral ways that avoided appealing to stereotypes).

403. Johnson, supra note 137 , at 1752-53.

404. See State v. Kirk, 339 P.3d 1214, 1216 (Idaho Ct. App. 2014).

405. See supra notes 202, 207-211.

406. See, e.g., State v. Shabazz, 48 P.3d 605, 610 (Haw. Ct. App. 2002) (involving repeated references to the victim as a "local woman" and then linking her fear of the defendants to their race).

407. See, e.g., State v. Rogan, 984 P.2d 1231, 1238, 1242 (Haw. 1999) (reversing the defendant's conviction based on the prosecutor's argument that it is "every mother's nightmare . . . [to find] some black, military guy on top of your daughter"); Lyon, supra note 15, at 328-29 (quoting State v. Richmond, 904 P.2d. 974, 983 (Kan. 1995)) (describing cases where prosecutors argued, 
think about how embarrassing it is for an 18-year-old white girl from Crestview to admit she was raped by a black man. It is humiliating." ${ }^{408}$ In these cases, the references to the perpetrator's race are not made to help identify the perpetrator or for any other legitimate purpose, but instead to suggest that the victim's shame or trauma would be worse based on the race of the perpetrator and that those around her would react accordingly. The court's checklist should prohibit these arguments linking race to the severity of the crime.

\section{b. $\quad$ Coded Language to Invoke Race or Stereotypes}

Courts should also prohibit coded language that more subtly invokes stereotypes. Again, the line between explicit appeals and more subtle use of coded language may be difficult to draw, but my focus here is on language that prosecutors might argue is not a reference to race or stereotypes at all. ${ }^{409}$ This section does not try to cover every type of coded appeal, but instead should help courts recognize coded appeals generally.

One foundational category of coded appeals involves use of us/them rhetoric. As explained above, ingroup/outgroup bias is a foundational concept for understanding how race affects decision-making; people tend to make more positive judgments about others within one's ingroup and make more negative judgments against those not part of that group. ${ }^{410} \mathrm{Us} /$ them arguments sometimes emphasize the ingroup status of the victim, such as in the case in Hawaii where the prosecutor repeatedly referred to the victim as a "local woman." ${ }^{411}$ More com-

for example, to "[t]hink about having to divulge to your husband that you were raped by a black male. Think about having to divulge that information to law enforcement.").

408. Lyon, supra note 15, at 330 (discussing State v. Reynolds, 580 So. 2d 254, 256 (Fla. Dist. Ct. App. 1991)).

409. Well-intentioned prosecutors may not recognize the racial dimensions of the arguments discussed in this section, but courts should focus on impact rather than intent; the rhetoric discussed in this section is likely to activate juror stereotypes. This section should therefore also help educate wellintentioned prosecutors, who can therefore choose to avoid this racist rhetoric.

410. See supra Part I(B)(1); see also Earle, supra note 34, at 1234 (footnotes omitted) (quoting In re Murchison, 349 U.S. 133, 136 (1955)) ("By creating a 'we' and a 'they,' the prosecutor can induce jurors to decide the case based upon stereotyped beliefs about other racial groups. Because 'our system of law has always endeavored to prevent even the probability of unfairness,' this kind of reference merits serious scrutiny.").

411. See, e.g., Shabazz, 48 P.3d at 622 (referring to prosecutor's statement describing the victim as a "local woman" to appeal to the jurors' ingroup biases while referring to the defendants as "African-Americans"). In a few cases, the prosecutors used ingroup/outgroup biases against defense counsel, such as when the Black prosecutor argued that defense counsel's argument 
monly, the prosecutor's language stresses the defendant as a member of an outgroup; for example, a prosecutor argued that the relevant standard was "what would a reasonable person do under the circumstances, not the culture that these people live in." $" 112$ References to "anti-snitching codes" can also be argued in a racially coded way. ${ }^{413}$ Similarly, one court noted a prosecutor's statements that repeatedly focused on the defendant's immigration status to suggest he was lying "went far beyond arguing that [the defendant] should not be trusted because he uses a false identity. The government's repeated references to [his] status reinforced to the jury his foreign origin." 414

Relatedly, courts should beware of language that appeals to jurors as a group in a way that positions the defendant on the other side of the ingroup/outgroup line. For example, the prosecutor in one case emphasized that the defendant was from the South Side of Chicago while the victim of the case lived on the North Side of Chicago, where the case was tried. ${ }^{415}$ The prosecutor stated that there was "no reason for him to be there except to cause trouble, to look for some victim" and concluded with the statement, "you decide whether to protect your streets, your community from [the defendant]."

that the defendant had been misidentified was based on the idea that "we all look alike" and contrasted "Mr. Boss's [(defense counsel's)] world" with the witness's "world." United States v. Richardson, 161 F.3d 728, 735-36 (D.C. Cir. 1998).

412. State v. Graves, 442 P.3d 1228, 1233 (Utah Ct. App. 2019) (referring to the prosecutor's statement, "that's the way these people talk"); see also United States v. Cannon, 88 F.3d 1495, 1502 (8th Cir. 1996) (referring to the prosecutor's statements describing the defendants as "bad people" and then arguing that there are many bad people in the world, and "[w]e are lucky where we live not to come in contact with as many as there may be in other parts of the country. But there are still some around here."); Prasad, supra note 49, at 3107-08 (giving examples of other cases with "these people" language).

413. Compare State v. Monday, 257 P.3d 551, 557 (Wash. 2011) (concluding that the prosecutor inappropriately linked "this code to 'black folk' only" when "[c]ommentators suggest the 'no snitching' movement is very broad"), with United States v. Weekes, 224 F. App'x 200, 207 (3d Cir. 2007) (alterations in original) (concluding that prosecutor reasonably inferred that there was a "street code that says you don't talk. You don't become an eyewitness" because the defendant had testified "nobody [is] going to talk about that in [my neighborhood]").

414. United States v. Cruz-Padilla, 227 F.3d 1064, 1069 (8th Cir. 2000) (citations omitted).

415. Lyon, supra note 15, at 328.

416. Id. (alteration in original) (quoting People v. Johnson, 581 N.E.2d 118, 126 (Ill. App. Ct. 1991)). The court rejected the defendant's arguments that these were appeals to racial prejudice, holding that it was "not improper for the State to comment unfavorably upon the defendant or to urge the fearless administration of the law." Id. (quoting Johnson, 581 N.E.2d at 127). This 
have been treated as improper, because arguments "that identify the defendant as a threat to the community . . . serve to motivate jurors to punish the defendant (and to protect the community) by returning a guilty verdict." 117

Prosecutors are also likely activating outgroup biases when they use coded language that calls unnecessary attention to the defendant's race. For example, one author noted that "[p]rosecutors have called attention to the Blackness of the defendant by making extraneous references to African American hairstyles . . . [or] the fact that a defendant lives in a segregated Black neighborhood." ${ }^{118}$ The Washington Supreme Court concluded that use of "po-leese" rather than "police" was a coded racial appeal. ${ }^{419}$ The Seventh Circuit should have reached (but did not) the same conclusion about the prosecutor's references to "shucking and jiving" about a Black witness and "Superfly" about a Black defendant ${ }^{420}$ Prosecutors also make inappropriate racially coded references by referring to the "inner city" or calling the defendant a "thug" or "hoodlum." "These references, while not as explicitly racist as the comments discussed in subsection (a) above, still have the power to activate stereotypes and affect decision-making.

c. Balancing the Probative Value Against the Prejudicial Effect of Racial Language

Although courts should prohibit racist prosecutorial rhetoric to the greatest possible extent, some references to race are inevitable; this

analysis, however, fails to recognize the power of ingroup/outgroup biases; the court should have held that these comments were improper.

417. Alford, supra note 39, at 333. While we/they language may not always have racist overtones, prosecutors should nevertheless avoid this rhetorical approach in all cases, for the reasons explained in note 409 above. Prosecutors should focus on the evidence of the individual defendant's guilt, without invoking group membership to motivate the jury.

418. Id. at 353 (first citing United States ex rel. Haynes v. McKendrick, 481 F.2d 152, 160 (2d Cir. 1973); and then citing People v. Brown, 229 N.E.2d 922, 926 (Ill. App. Ct. 1967)).

419. State v. Monday, 257 P.3d 551, 557 (Wash. 2011) ("[T]he only reason to use the word 'poleese' was to subtly, and likely deliberately, call to the jury's attention that the witness was African American and to emphasize the prosecutor's contention that 'black folk don't testify against black folk.' ... This conduct was highly improper.").

420. Lyon, supra note 15, at 327 (discussing Smith v. Farley, 59 F.3d 659, 663 (7th Cir. 1995)).

421. Prasad, supra note 49, at 3098 (footnotes omitted) (noting that "inner-city," "welfare queens," and "thugs" all allude to race without being explicit); Cicchini, supra note 145 at 900 (footnotes omitted) (noting that "dope pusher" and "hoodlum' . . . could very well be considered inflammatory, improper, and even reversible error"). 
subsection should help courts and prosecutors recognize the line between proper and improper references to race. Fundamentally, courts should prohibit references to race that appeal "to passion and prejudice" while allowing references to race that refer to "facts and law." words, courts should be looking at whether a prosecutor's reference to race appeals to bias. ${ }^{423}$

In determining whether a prosecutor's racial language appeals to bias, courts should think about the probative value of the prosecutor's reference as compared to the likely prejudicial effect. ${ }^{424}$ This approach is similar to the balancing courts do under Evidence Rule 403, although courts should be careful not to overestimate relevance or discount the potential prejudice from such evidence. ${ }^{425}$ One author convincingly argues that the probative value should have to substantially outweigh the prejudicial effect, although that is the reverse of the typical approach under Rule 403, which normally requires the prejudicial effect to substantially outweigh the probative value in order to justify exclusion. ${ }^{426}$

When focusing on relevance, courts should analyze the evidentiary support for the reference to race. For example, if a case involves an issue about the validity of cross-racial identification, there will need to be more discussion of race than in a case that does not involve such an issue. ${ }^{427}$ And a limited reference to race for purpose of identity would often make sense. However, if identity is not disputed in a particular case, then even a single reference to race would not be justified based

422. Earle, supra note 34, at 1222. As Earle correctly points out, however, "the problem for courts lies not in recognizing this distinction, but in determining into which category a racial reference falls." Id.

423. See Armour, supra note 68, at 768 ("Group references that exploit, exacerbate, or play on the prevailing stereotypes that factfinders carry with them into the jury box subvert the rationality of the fact-finding process. But references that challenge the factfinders to reexamine and resist their discriminatory responses enhance the rationality of the fact-finding process."); Cialeo, supra note 286, at 447 (arguing that except in cases with a racially-motivated crime, attorneys should not be able to ask leading questions that "exhibit or are intended to appeal to or engender bias" in cross-examining witnesses or when dealing with hostile witnesses on direct exam). While Cialeo is focused on questioning witnesses, the same framework is helpful when thinking more broadly about racist prosecutorial rhetoric.

424. See Earle, supra note 34, at 1234-36 (analogizing to Rule 403 analysis of balancing probative value and prejudicial effect in trying to create a bright line between neutral and non-neutral references to race).

425. See id. at 1230-31.

426. See id. at 1234-35 (discussing both Rule 403 and her proposed approach without noting the reversal of the balancing test in her argument).

427. United States v. Richardson, 161 F.3d 728, 735 (D.C. Cir. 1998). 
on showing identity. ${ }^{428}$ Additionally, race will be relevant in cases where there is evidence to suggest that the defendant's motive for the crime was racial. ${ }^{429}$ But in all these circumstances, courts should make sure that the relevance of race is based on actual evidence, rather than speculation. ${ }^{430}$

Additionally, courts should focus on the ways in which the prosecutor handles these issues when analyzing prejudicial effect. As noted above, repetition is a key rhetorical tool for affecting decisionmaking, ${ }^{431}$ so courts should be particularly skeptical of unnecessary repetition of racial references. For example, the court in State $v$. Mitchell should have seen the sixteen references to Black males of various sizes in opening argument as prejudicial, even if a single reference would have been justified as being relevant to the identity issue in the case. ${ }^{432}$ Similarly, even if a single reference to a defendant being Black is relevant for identity purposes, that does not excuse the highly prejudicial effect of repeatedly emphasizing that the victim or the arresting officer in a case is white. ${ }^{433}$

When considering prejudice, courts should also focus on the specific language used. As discussed above, coded language can invoke stereotypes, so prosecutors should be using race-neutral rather than

428. See State v. Rogan, 984 P.2d 1231, 1240 (Haw. 1999) (noting that identity was not an issue, so the lower courts' reliance on identity to justify racial reference was improper).

429. See, e.g., Cialeo, supra note 286, at 447 (talking about how crimes involving racial motives will need to be treated differently); see also supra note 307 and accompanying text (discussing cases in which the defendant claims selfdefense based on racial fear; the prosecution in those cases needs to be able to argue the ways in which race does not justify the defendant's fear).

430. Therefore, the Seventh Circuit wrongly decided Aliwoli v. Carter, 225 F.3d 826 (7th Cir. 2000). The Seventh Circuit justified the prosecutor's repeated questions about racial motive for shooting police officers, and then stated that the questions were harmless because the witnesses all denied the racial motivation. Aliwoli, 225 F.3d at 831. The court failed to recognize that the prosecutor never had any evidentiary basis on which to ask the questions. See also Developments in the Law, supra note 393, at 1591-92. There, the authors discuss an earlier case in which a federal district court held that the prosecutor's theory of the case violated due process. The prosecutor argued that the two Black defendants killed the white victim because of racial revenge for a murder of a white victim earlier the same day in the same city, without any evidence linking the two cases-just resting on the assumption of motive based on the race of the defendants and victims.

431. See supra note 168 and accompanying text.

432. See State v. Mitchell, 783 A.2d 1249, 1258 (Conn. Ct. App. 2001); see also Earle, supra note 34, at 1235 (arguing that "gratuitous" references to race, "which by definition adds nothing to the trial, would be inadmissible under Rule 402").

433. Developments in the Law, supra note 393, at 1590. 
inflammatory language as much as possible. For example, a prosecutor can focus on the evidence of brutality of the crime without analogizing the defendant to an animal in doing so. ${ }^{434}$ Additionally, a prosecutor can argue that people refused to come forward because of anti-snitching norms without attributing that "code" to people of a particular race. ${ }^{435}$ Prosecutors should also focus on the individual defendant(s) without making broader references to "these people." ${ }^{\prime 36}$ And prosecutors should be careful in sexual assault cases that their limited references to identity does not suggest that the racial identity of the defendant or victim somehow makes the crime worse. Courts should also remember that denying something is about race is a rhetorical device that can invoke prejudicial responses. ${ }^{437}$

2. Require a Motion in Limine by Prosecutors for Proposed References to Race on a Case-by-Case Basis

While courts could in some instances evaluate these line-drawing issues during the flow of trial, the better practice is to require prosecutors to bring a motion in limine in advance to justify their planned use of race. Some commentators urge defense counsel to file a motion in limine prohibiting references to race, ${ }^{438}$ but the better practice would be to have prosecutors bring that motion seeking permission to reference race either explicitly or implicitly.

Judge Furman of the Colorado Court of Appeals recently advocated for this approach: "Parties should give notice of their intent to introduce evidence or argument related to race and should have to overcome a presumption that such evidence is irrelevant." ${ }^{339}$ This approach would help both parties articulate their arguments, which can help prosecutors focus on drawing appropriate lines and can make it easier for defense counsel to respond. It would also help trial courts by

434. Bennett v. Stirling, 842 F.3d 319, 326 (4th Cir. 2016) ("The prosecutor easily could have highlighted Bennett's physical attributes in a race-neutral manner. There was no impediment to the prosecutor's ability to note 'repeated examples of [Bennett's] proclivity to viciously and savagely attack others defenseless to someone of his size.' Indeed, the prosecutor did so in a raceneutral manner before the earlier mixed-race jury.") (citations omitted).

435. State v. Monday, 257 P.3d 551, 557 (Wash. 2011).

436. See, e.g., State v. Graves, 442 P.3d 1228, 1233 (Utah Ct. App. 2019) ("[T]hat's the way these people talk.").

437. See supra note 137 and accompanying text.

438. See, e.g., Heller, supra note 19 , at 893.

439. People v. Robinson, 459 P.3d 605, 615 (Colo. App. 2017) (Furman, J., concurring), rev'd and remanded, 454 P.3d 229 (Colo. 2019). Unfortunately, the Colorado Supreme Court declined to adopt this approach and overruled the court of appeals' decision to reverse the defendant's conviction, holding that any error was harmless. Robinson, 454 P.3d. at 236. 
providing briefing on the issue and giving judges more time to decide the issue than the court would have in ruling on an objection during trial. ${ }^{440}$ Trial courts could then provide clearer directions about what "is relevant and appropriate and help ensure that evidence or argument related to race is only used for a proper and limited purpose." ${ }^{441}$ This approach would also provide a clearer record for appellate review. ${ }^{42}$

For example, a motion in limine would be particularly helpful in cases where the prosecutor's theory involves race as a motive. Courts could require prosecutors to make an offer of proof about the evidentiary support for that theory to ensure that prosecutors were not simply relying on speculation. For example, in Aliwoli v. Carter, the Seventh Circuit approved of the prosecutor's questions about whether the defendant's beliefs as a Black Muslim gave him reason to shoot police officers; the prosecutor argued that these questions were proper to rebut the defendant's insanity defense. ${ }^{443}$ If the court had required the prosecution to provide an offer of proof demonstrating the evidentiary basis for that theory, the court should have realized the prosecutor was relying on speculation and prohibited the prosecution from asking questions on this topic of several witnesses, all of whom denied that the defendant's race and "religion played any role in the crime . . . and characterized black Muslims as peaceful and law-abiding citizens." ${ }^{444}$

A motion in limine would also help clarify the appropriate boundaries for arguments referring to places that could be seen as invoking racial stereotypes. For example, in State $v$. Graves, the prosecutor in Utah mentioned the defendant's Puerto Rican heritage fifty-seven times in a two-day trial, including forty-eight times during the second day. ${ }^{445}$ The court concluded that some of these references were justified because they referred to the defendant's own alleged statement at the time of the shooting that "[t]his is how we do it in Puerto Rico," which the prosecution contended showed that the defendant fired the gun deliberately rather than accidentally. ${ }^{446} \mathrm{~A}$ pretrial motion could have helped resolve a dispute over the validity of that argument as well as a factual question of whether the defendant

440. Jennifer M. Miller, To Argue Is Human, to Exclude, Divine: The Role of Motions in Limine and the Importance of Preserving the Record on Appeal, 32 Am. J. Trial Advoc. 541, 541 (2009).

441. Robinson, 459 P.3d at 615 (Furman, J., concurring).

442. Id.

443. Aliwoli v. Carter, 225 F.3d 826, 831 (7th Cir. 2000).

444. Id.; see also supra notes 193, 429-430 and accompanying text (regarding the evidentiary basis for motive arguments).

445. State v. Graves, 442 P.3d 1228, 1234 (Utah 2019).

446. Id. at 1232,1234 . 
had ever made that statement. ${ }^{447} \mathrm{~A}$ motion in limine could also have helped clarify which references were more probative than prejudicial, whether any of the specific contexts of the references were particularly prejudicial, and whether the cumulative effect was likely to be problematic such that the prosecutor should have found other ways to discuss the issues.

A motion in limine can also be particularly helpful in addressing the appropriate boundaries of prosecutor arguments that respond to defense counsel's theories. Many courts justify even fairly extreme prosecutorial comments as appropriate responses to defense counsel's arguments. ${ }^{448}$ For example, State v. Cabrera involved issues about gang membership of the defendants and various witnesses, and the prosecutor and defense attorneys had different theories about the probative value and prejudicial effect of that evidence. ${ }^{49}$ The prosecutor argued that some of its witnesses had been in gangs but were now trying to get on with their lives, and the prosecutor accused defense counsel of engaging in "wild, and I submit, racist speculation" about their current gang involvement. ${ }^{450}$ The prosecutor characterized defense counsel's argument as follows: "He's a big, strong black man, but he's a rough character. Members of the Jury, this is not about race." "451 The appellate court held that this language and the trial judge's decision to overrule the defense's objection "may have led the jury to conclude that defense counsel himself was racist - an implication wholly unsupported by the record." ${ }^{452}$ A motion in limine could have helped both sides determine the appropriate boundaries of how to talk about gang membership and its potential connections to race, and it could also have helped the trial court recognize the prosecution's escalation of the

447. See id. at 1235 (noting that Graves denied having ever made the statement and witnesses were inconsistent in their recollection of it). Even if the court had allowed the prosecutor to ask about the statement, the court could have cautioned the prosecutor about how to handle the conflicting evidence about the statement rather than simply asserting that defendant had said it. And a motion in limine combined with the checklist proposed in this article might have either deterred the prosecutor from making references to "these people" or put defense counsel and the trial court on notice about the need to step in.

448. See, e.g., Darden v. Wainright, 477 U.S. 168, 179-82 (1986) (justifying prosecutor's comment, that defendant was an animal who should not leave his cell unless he was on a leash, on the grounds that it was "responsive to the opening summation of the defense," who argued that some other person committed the crime and that perpetrator was an animal).

449. State v. Cabrera, 700 N.W.2d 469, 472-74 (Minn. 2005).

450. Id. at 474 .

451. Id.

452. Id. at 475 . 
argument about the evidence into a rhetorical device invoking racial stereotypes and blaming the other side for it. Similarly, a motion in limine could help ensure that the prosecutor responds to the substance of defense counsel's argument rather than simply invoking a stereotype. ${ }^{453}$

\section{Responses When Problems Arise at Trial}

If courts adopt the checklist and motion in limine requirements discussed above, that should prevent many instances of racist prosecutorial rhetoric, but some issues will still come up at trial. ${ }^{454}$ This section is designed to help courts think through how to respond to those issues.

\section{Act Sua Sponte When a Problem Occurs Rather Than} Requiring an Objection

Historically, trial courts have very rarely sua sponte reprimanded prosecutors for racist rhetoric. ${ }^{455}$ But given the realities described above, courts should be more willing to step in rather than waiting for defense counsel to object. As discussed above, defense counsel may have a variety of reasons for not objecting, including fear of the trial court validating that rhetoric by overruling the objection and fear of being seen as the one playing the race card. ${ }^{456}$ The North Carolina Supreme Court acknowledged defense counsel's challenges and concluded that it is therefore "incumbent on the trial court to monitor vigilantly the

453. See United States v. Richardson, 161 F.3d 728, 735 (D.C. Cir. 1998) (defense's theory was that the defendant had been mis-identified, and the prosecutor responded by arguing essentially that defense counsel thought all Black people look alike). A motion in limine regarding the prosecution's proper response to the mis-identification theory should have helped both the prosecutor and the court ensure that the prosecutor's response focused on the evidence showing that the identification was correct rather than merely arguing that defense counsel was being racist. People v. Dizon, 697 N.E.2d 780, 787 (Ill. App. Ct. 1998) (treating prosecutor's references to south Asian cultures and Latinos, which occurred during a discussion of gangs, as invited by the defense's misidentification theory). A motion in limine could have helped the parties focus more clearly on the identification issues and helped the prosecutor and the court avoid mixing up the different Asian groups discussed.

454. See, e.g., People v. Robinson, 459 P.3d 605, 615 (Colo. App. 2017) (Furman, J., concurring), rev'd 454 P.3d 229 (Colo. 2019) (acknowledging that a witness might unexpectedly introduce racial evidence at trial). Prosecutors may also make racial references at trial, deliberately or inadvertently, notwithstanding the procedures discussed above.

455. See Alford, supra note 39 , at 337.

456. See supra notes 260-263 and accompanying text. 
course of such arguments [and] to intervene as warranted." ${ }^{457}$ The court further stated that "it becomes the duty of the trial judge to intervene to stop improper argument and to instruct the jury not to consider it" when, among other things, the prosecutor "become[s] abusive." "458

The checklist described above should help courts recognize when to intervene, particularly when prosecutors use racial slurs or animal imagery, or when prosecutors repeatedly reference the race of the participants beyond what is strictly necessary. In such circumstances, defense counsel may object, but trial courts should be willing to step in even in the absence of an objection.

2. Admonish the Prosecutor in Front of the Jury for Appealing to Bias and Give a Specific Curative Instruction

Regardless of whether defense counsel objects or the trial court intervenes sua sponte, trial courts should actively confront racist language head-on rather than reinforcing colorblind narratives. "Attempts at being colorblind can exacerbate the power of implicit racial biases because ignoring race can cause automatic engagement of stereotype-congruent responses." ${ }^{59}$ Therefore, jurors are less likely to be influenced by racist prosecutorial rhetoric when courts flag the racial dimension, rather than simply sustaining an objection or using a more generic label like "inflammatory." 460 This labeling is particularly important for "more subtle expressions of prejudice." ${ }^{461}$ Therefore, courts should make clear to the jury that the language used might trigger reactions based on bias or stereotype. ${ }^{462}$

457. State v. Jones, 558 S.E.2d 97, 105 (N.C. 2002). The court also talked about entertaining and responding to objections. $I d$. But the issue in the case was whether the trial court had erred by failing to intervene ex mero motu, i.e. sua sponte, and the state supreme court agreed with defendant that the trial court should have done so. See id. at 103.

458. Id. at 105 .

459. Prasad, supra note 49, at 3100 (noting that people can suppress stereotyped responses when made aware of those issues); see also Blasi, supra note 28 , at 1252 ("In order to inhibit judgments and behavior based on stereotypes, we must be aware of the specific stereotype at the time it is activated.").

460. See Earle, supra note 34, at 1215 (arguing that courts should "give serious and consistent credence to charges of racism and recognize the many instances in a trial in which subtle arguments may prey on unconscious fears and resentments of the jury" rather than just deeming comments "regrettable" or "improper"). While Earle's focus was on appellate rather than trial courts, the same logic applies to trial courts, particularly if they are going to take a major role in dealing with racist prosecutorial rhetoric as argued in this article.

461. Blasi, supra note 28 , at 1254 .

462. Courts do not need to use the word "racist" in labeling the conduct; it is probably more effective to talk about invoking a stereotype or triggering bias. Consistent with the approach throughout the article, the focus should 
Furthermore, a reprimand in front of the jury may create more personal risk for the prosecutor than the current approaches, which externalize the costs of prosecutorial misconduct. ${ }^{463}$ If racist prosecutorial rhetoric contributes to the conviction, then the defendant bears that cost, while the prosecutor's office is the one that primarily bears the cost of reversal on appeal. ${ }^{464}$ But when a trial court expressly labels a prosecutor's rhetoric as being an inappropriate invocation of bias or stereotypes, the prosecutor will likely feel some shame. ${ }^{465}$ The trial court should not set out to humiliate the prosecutor, but "psychologists have long deemed shame a healthy tonic in appropriate doses because it reminds the recipient of the societal norms that should guide and circumscribe her thoughts and actions." " 466 Therefore, labelling the prosecutorial rhetoric as an inappropriate invocation of bias or stereotype can help encourage prosecutors to avoid that behavior going forward and help the jury guard against being influenced by that rhetoric. ${ }^{467}$

After the court labels the improper remark as potentially triggering bias, the trial court should give a specific rather than general curative instruction. Reviewing courts sometimes rely on the fact that trial courts gave general instructions not to rely on bias, ${ }^{468}$ but that approach is flawed. If a trial court overrules an objection, or if the conduct is

be on the conduct rather than the person and to avoid moralizing language when possible.

463. Green, supra note 268 , at 812 .

464. Id. at $812-13$ (explaining why the prosecutor's office bears the primary burden of reversal but is still likely to back the individual prosecutor, concluding that "even if the trial prosecutor's behavior was clearly wrongful, the office may excuse it on the theory that a suitably aggressive prosecutor cannot help but get carried away occasionally").

465. See Lara Bazelon, For Shame: The Public Humiliation of Prosecutors by Judges to Correct Wrongful Convictions, 29 GEO. J. LEGAL ETHICS 305, 312 (2016) (quoting Deni Smith Garcia, Three Worlds Collide: A Novel Approach to the Law, Literature, and Psychology of Shame, 6 Tex. Wesleyan L. Rev. 105, 121 (1999)) ("Shame 'falls along a continuum of emotions ranging from embarrassment on one end to mortification on the other."').

466. $I d$.

467. See id. There may be some risk that this approach will lead jurors to sympathize with the prosecutor, but the court in doing this labeling should reinforce egalitarian norms of avoiding biased decision-making, rather than specifically using the word "racist" or focusing on the prosecutor's intent.

468. For example, in Darden v. Wainright, 477 U.S. 168 (1986), the case involving the comment about the defendant being an animal who should not be let of his cell except on a leash, the United States Supreme Court upheld the conviction in part because "the trial court instructed the jurors several times that their decision was to be made on the basis of the evidence alone, and that the arguments of counsel were not evidence." Darden, 477 U.S. at 182. 
never flagged as improper, then jurors could reasonably conclude that the general instruction to avoid bias does not apply to the specific comment at issue. ${ }^{469}$ The level of detail needed for curative instructions will vary depending on the circumstances, but trial courts should provide any specific direction needed to ensure that the jury properly recognizes the situation and to encourage prosecutors to avoid similar missteps in the future. ${ }^{470}$

3. Grant a Mistrial for Particularly Serious or Repeated Violations During the Same Trial

When an isolated remark is quickly corrected before the jury, that should be a sufficient remedy. But in other circumstances, the court should consider granting a mistrial. The foundational case on prosecutorial misconduct in argumentation emphasizes mistrial as a remedy. ${ }^{471}$ Mistrial is an appropriate remedy for many cases involving racist prosecutorial rhetoric because of the difficulties in measuring potential prejudice from that rhetoric. ${ }^{472}$ Mistrial is also appropriate in many of these cases because of the significant harm caused by these remarks. ${ }^{473}$

When considering whether to grant a mistrial, courts should provide both parties an opportunity to be heard outside the presence of the jury. ${ }^{474}$ The prosecutor should have to argue why the comments

469. See, e.g., State v. Diehl, 528 S.E.2d 613, 617 (N.C. Ct. App. 2000), rev'd 545 S.E.2d 185 (N.C. 2001). The court of appeals correctly highlighted the inadequacy of the trial court's response to defense counsel's objection, which was "Well, let's just - We're not going to have that thing going on." Id. at 615,617 . The appellate court correctly reasoned that this "overly brief and vague comment did not admonish the jury to disregard the objectionable remarks. We hold that direct and decisive action by the trial court was required in the form of an instruction directed to the jurors notifying them that the prosecutor's appeal to race was improper and that they should disregard it." Id. at 617. Unfortunately, however, the North Carolina Supreme Court reversed this decision and incorrectly concluded that the trial court did not abuse its discretion. Diehl, 545 S.E.2d at 188.

470. See Prasad, supra note 49, at 3125 (noting that judges should "be prepared to describe what implicit associations and stereotypes the improper argument may draw"). Prasad relies on both the idea of providing clarification for the jury and informal discipline/incentives for better behavior for the prosecutor. See id.

471. Berger v. United States, 295 U.S. 78, 85 (1935) ("The trial judge, it is true, sustained objections to some of the questions, insinuations and misstatements, and instructed the jury to disregard them. But the situation was one which called for stern rebuke and repressive measures and, perhaps, if these were not successful, for the granting of a mistrial.").

472. Lyon, supra note 15 , at 334 .

473. See, e.g., State v. Thompson, 233 So. 3d 529, 563 (La. 2017).

474. See Lyon, supra note 15, at 333 (arguing that the court should hold an immediate hearing without the jury present to determine whether a prosecu- 
were not likely to be prejudicial, and could also argue any probative value to justify the remarks. ${ }^{475}$ Defense counsel should have the opportunity to respond to these arguments and could potentially provide wider context for the remarks, such as how they relate to comments made in voir dire. ${ }^{476}$ This hearing would help the trial court consider its decision with a fuller picture of how the comments fit into the overall trial, and would allow the court to make explicit findings that would help the reviewing court on appeal if a mistrial is denied. ${ }^{477}$

The precise standard for granting a mistrial could vary according to typical court practice, but courts should consider both the prejudicial effect of the comments and any potential probative value they have. For example, in Louisiana, a mistrial is mandatory after defense motion when "during the trial or in argument, [the prosecutor] refers directly or indirectly to ... [r]ace, religion, color, or national origin, if the remark or comment is not material and relevant and might create prejudice against the defendant in the mind of the jury." ${ }^{\prime 78}$ This approach requires the court to find both a lack of probative value and a potential for prejudice. Courts could instead use the stronger balancing approach described above in the motion in limine section, requiring the court to conclude that the probative value substantially outweighs any potential for prejudice. ${ }^{479}$

Regardless of the precise standard used, a mistrial would generally be appropriate for very serious racial references, such as slurs, animal imagery, or other statements that directly invoke a negative stereotype. Similarly, a mistrial would be appropriate if the prosecutor had brought

tor's racist rhetoric was prejudicial). While defense counsel should generally move for a mistrial, courts could ask to confer with the parties about this remedy after intervening sua sponte, as discussed above. But defense counsel should be allowed to weigh in on the appropriate remedy. Cf. Armour, supra note 68, at 768 (suggesting that defense counsel should actually have the ability to choose the remedy). While I think Armour's suggestion goes too far, I agree that defense counsel's perspective should be an important consid-eration.

475. See Lyon, supra note 15, at 333-34 (discussing a similar approach to a hearing).

476. See, e.g., Thompson, 233 So. 3d at 529, 534 (discussing the connection between the prosecutor's comment in questioning a witness to an earlier exploration of race in voir dire and both parties' opening statements).

477. See Lyon, supra note 15, at 334 (noting the often inadequate record for reviewing courts and the value of holding a hearing in providing a better foundation for appellate review).

478. La. Code Crim. Proc. Ann. art. 770. The "Official Revision Comment" for the statute notes that "[t]his article purports to carry out, with some variation, the jurisprudential rules with reference to remarks and comments which normally are not cured and cannot be cured by an admonition." Id.

479. See supra Section IV(B)(1)(c). 
a motion in limine and then made remarks that violated the court's decision on the motion. Mistrial would also be appropriate for cumulative violations, as suggested by the Supreme Court in Berger v. United States. ${ }^{400}$ Ultimately, trial courts should be more willing to grant a mistrial in order to guard against racist prosecutorial rhetoric prejudicing the defendant and to ensure that prosecutors bear the burden of avoiding this rhetoric. ${ }^{481}$

\section{D. $\quad$ Track Repeat Violators Across Trials}

Finally, I recommend that courts provide greater transparency and tracking of these rebukes across cases. ${ }^{482}$ That approach can take a variety of different forms, such as a searchable database that records key information about incidents of racist prosecutorial misconduct or a compilation of transcripts of these instances. ${ }^{483}$ Regardless of the exact mechanism used to implement this idea, these "rebuke banks" could be helpful in several ways. ${ }^{484}$

On an individual level, these rebuke banks may help incentivize prosecutors to ensure that their rhetoric does not cross the line. This applies both to new prosecutors wanting to avoid rebukes and longtime prosecutors who may need to shift their behavior after recognizing the ways that their previous rhetoric may have been problematic. ${ }^{485}$ After all, the key goal of this article and these strategies is to prevent racist prosecutorial rhetoric.

Additionally, this approach would help courts and disciplinary authorities identify repeat offenders. For trial courts, that information could be helpful as they play an increased role in being vigilant about

480. Berger v. United States, 295 U.S. 78, 85 (1935); see supra note 471 and accompanying text.

481. Lyon, supra note 15 , at 334-35.

482. This specific proposal relies heavily on Bruce Green's recommendation. See Green, supra note 268 , at $815-18$. But it is also conceptually similar to creating a "prosecutorial misconduct project" tracking appellate court reversals for prosecutorial misconduct. See Adam M. Gershowitz, Prosecutorial Shaming: Naming Attorneys to Reduce Prosecutorial Misconduct, 42 U.C. DAVIS L. REV. 1059, 1064 (2009). Both Green and Gershowitz argue that making this kind of information available would help identify repeat offenders and put pressure on prosecutors' offices to improve their cultures and practices. See id. at 1065; Green, supra note 268, at 815-16.

483. See Green, supra note 268, at 815 (arguing for a searchable database of trial transcripts). The exact mechanism may vary across courts based on logistics, and chief judges or court administrators should explore the most workable version of this approach for their particular jurisdiction.

484. See id. at $815-18$.

485. See id. at 816 ; see also $i d$. at 813 (discussing the potential for "unethical amnesia" when individual rebukes do not also include more structural remedies as well). 
listening for racist prosecutorial rhetoric and acting sua sponte. Knowing who has been rebuked before and why may help judges recognize more subtle racial appeals in future cases. It may also be helpful in encouraging judges to refer these repeat offenders for disciplinary action and for disciplinary authorities to have more complete information upon which to act. ${ }^{486}$

Finally, and crucially, rebuke banks would help decision-makers identify patterns within prosecutor offices, which in turn can lead to more structural reforms. ${ }^{487}$ This increased transparency can support efforts by supervisors to strengthen a "culture of compliance" within offices that could improve "internal culture and controls." 488 Additionally, this device could help encourage office-wide trainings as needed, and could even help with efforts to hold senior administrators accountable for office-wide problems. ${ }^{489}$ These more structural incentives should help counterbalance the structural pressures on prosecutor offices to focus more on convictions than on their important role in ensuring justice. ${ }^{490}$ Ultimately, these changes are crucial for dealing with the structural problems of racial bias within the criminal justice system.

\section{CONCLUSion}

Racist prosecutorial rhetoric is a serious problem that poses a threat to the integrity of the criminal justice system. This article has attemp-

486. Green correctly notes that disciplinary authorities have generally been unwilling to discipline prosecutors in these cases. Id. at 811; see also Prasad, supra note 49, at 3119-22 (discussing prosecutor discipline and arguing that courts have so far overestimated that technique for handling racist prosecutorial rhetoric). It may be that disciplinary rule changes are also needed, something I plan to explore in a future article.

487. See Green, supra note 268, at 816-17.

488. Id. at 816 .

489. See Bruce Green \& Ellen Yaroshefsky, Prosecutorial Accountability 2.0, 92 Notre Dame L. Rev. 51, 70 (2016) ("[C]ritics increasingly push blame up the ladder in the prosecutors' office, perceiving low-level prosecutorial wrongdoing as symptomatic of bad culture, bad leadership, bad compliance systems, or other systemic inadequacies for which supervisors and chief prosecutors should be held responsible.").

490. See, e.g., Bowman, supra note 16, at 330 (discussing the structural pressures on prosecutors and their offices); GODSEY, supra note 83, at 34 (describing "administrative evil," the way that actors in a bureaucracy are structurally conditioned to focus on what's good for the organization in a way that can functionally silence individuals' own moral compasses); Richardson, supra note 22, at 871 (describing an ethnographic study of criminal courts in Cook County, Illinois, in which several prosecutors expressed personal misgivings about the criminal justice system but "learned to rationalize their racialized behaviors by separating their perspectives from their practices" and treating their practice of law as a duty that did not need to reflect their personal beliefs). 
ted to educate judges and prosecutors on how to rethink rhetorical choices within criminal cases. Doing so is an important part of the overall reckoning about the role of racism within the criminal justice system and is necessary for ensuring that criminal trials are conducted fairly and impartially.

Trial courts should take the lead in recognizing racist prosecutorial rhetoric and in taking steps to prevent prosecutors from using that rhetoric. Trial judges are also in the best position to act when prosecutors do use this rhetoric and to evaluate appropriate remedial measures. The line-drawing questions presented by prosecutorial rhetoric can be challenging, but this article has proposed an approach that can help courts draw these lines more clearly, allowing for prosecutors to argue the appropriateness of race-related language and arguments in individual cases while prohibiting a much wider swath of both coded and explicitly racist language than courts typically label as inappropriate. This article also includes a method for tracking racist prosecutorial misconduct across cases that would facilitate better systemic information about the scope of the problem, which will help provide more systemic responses. 


\section{Appendix A: Possible Checklist for Courts to Use in Prohibiting Racist Prosecutorial Rhetoric:}

Prosecutors should keep their arguments focused on the specific evidence regarding the defendant in a particular case, rather than using broader language that invokes stereotypes or group-based biases. Courts should enforce this approach and should prohibit the following types of arguments or language as being inherently biased, regardless of the prosecutor's intent:

- Racial slurs

- Animal references/analogies (including actual animals, use of other words that convey animal imagery like "hunt" or "habitat," movie references like "Gorillas in the Mist," references to monsters or other non-human imagery, etc.)

- Language invoking stereotypes (e.g. Dixie/cotton reference, generalizations about groups based on race/ethnicity, coded language to invoke race)

- Us/them references (e.g. "these people," "protect your community") - do not try to divide the jury from the defendant based on generalized appeals

- Unnecessary emphasis on locations with racial connotations or the race of the defendant or the victim beyond what is necessary in the case

- Arguments suggesting that the severity of the crime or trauma from it is worse because of the race of the people involved 
Despite these general prohibitions, some cases require a discussion of race. In such cases, courts should require a motion in limine by the prosecution to justify the probative value of racial references and to ensure that it substantially outweighs the prejudicial effect. Courts and prosecutors should consider the following general guidelines in connection with this motion:

\begin{tabular}{|l|l|}
\hline $\begin{array}{l}\text { Likely Appropriate (substantially } \\
\text { more probative than prejudicial) }\end{array}$ & $\begin{array}{l}\text { Likely Inappropriate (more preju- } \\
\text { dicial than probative) }\end{array}$ \\
\hline $\begin{array}{l}\text { Limited reference to race for } \\
\text { identification purposes only } \\
\text { when identity is an issue }\end{array}$ & $\begin{array}{l}\text { Repeated references to race to } \\
\text { show identity, or a single refer- } \\
\text { ence to race to show identity } \\
\text { when identity is not disputed }\end{array}$ \\
\hline $\begin{array}{l}\text { Discussion of race in connec- } \\
\text { tion with the validity of cross- } \\
\text { racial identification }\end{array}$ & $\begin{array}{l}\text { Accusations that identification } \\
\text { argument is based on stereo- } \\
\text { type that all people of a race or } \\
\text { ethnicity look alike }\end{array}$ \\
\hline $\begin{array}{l}\text { Arguments related to racial } \\
\text { motive only when there is evi- } \\
\text { dence supporting that theory }\end{array}$ & $\begin{array}{l}\text { Arguments related to race as } \\
\text { motive that are based on } \\
\text { speculation or generalizations } \\
\text { rather than concrete evidence }\end{array}$ \\
\hline
\end{tabular}

Note that a motion in limine should never be used to justify racial slurs or animal imagery, which are never probative and are always highly prejudicial.

Similarly, a motion in limine should not justify invocation of a stereotype; the prosecutor should focus instead on the evidence in the case without making broader group references to invoke stereotypes.

Additionally, courts should not over-rely on the idea of the prosecutor's remarks being an invited response to defense counsel's argument. The prosecutor's response should focus on the substance of the argument (e.g. mis-identification, self-defense) without either explicitly or implicitly invoking stereotypes or bias.

Finally, references to race, even when relevant, should be kept to a minimum to the extent possible under the circumstances of the individual case. Repeated references are more likely to be prejudicial, and the probative value can generally be established through limited references. 